Ann. Biol. anim. Bioch. Biophys., I96r, 1 (3), 323-383

\title{
LA POLYSPERMIE CHEZ LES ANIMAUX
}

\section{PIKÓ}

Station de Physiologie animale, Centre national de Recherches zootechniques, Jouy-en-Josas (S. et O.) (1).

\section{PLAN DU MÉMOIRE}

\section{INTRODUCTION}

\section{CHAPITRE I}

\section{LA POLYSPERMIE CHEZ LES INVERTÉBRÉS E'T CHEZ LES POIKILOTHERMES}

A. - Polyspermie physiologique

a) Bryozoaires

b) Insectes (Arthropodes)

c) Aranéides (Arachnides; Arthropodes)

d) Sélaciens (Elasmobranches ; Poissons)

e) Urodèles (Amphibiens)

f) Reptiles

Discussion et Conclusions

B. - Polyspermie pathologique

Polyspermie pathologique accidentelle

a) Oursin (Echinides)

b) Ascaris megalocephala (Nématodes)

c) Esturgeon (Acipenséridés, Chondrostéens)

d) Anoures (Amphibiens)

Polyspermie expérimentale

a) polyspermie par action d'agents chimiques

b) polyspermie par modifications physiologiques de l'ovocyte

I. - Fécondation de l'œuf double ou polynucléé

2. - Androgenèse di-et polyspermique

3. - Hybridation

4. - Fécondation del'œuf immature ou surmature. Surinsémination

c) polyspermie par « refécondation » de l'œuf fécondé

Causes de la monospermie

Discussion et Conclusions

Références bibliographiques

\section{ChAPITRE II}

I,A POI,YSPERMIE CHEZ LES OISEAUX ET LES MONOTRÈMES

a) Oiseaux

I. - Observations cytologiques

2. - Observations indirectes sur l'effet des spermatozoïdes surnuméraires (mosaïque, bipaternité)

(1) Adresse actuelle : Division of Bio'ogy, California Institute of Techuology, Pasadena, California, 
b) Monotrèmes

Discussion et Conclusions

Références bibliographiques

\section{Chapitre III}

LA POLYSPERMIE CHEZ LES MAMMIFÈRES

a) Polyspermie naturelle.
I. Rat
2. Souris
3. Campagnol
4. Hamster doré
5. Lapin
6. Cobaye
7. Furet
8. Chat
9. Truie
Io. Vache
I I. Brebis

b) Mécanisme d'inhibition de la polyspermie. "Refécondation ". Spermatozoïdes supplémentaires.

I. Nombre des spermatozoïdes sur les lieux de la fécondation.

2. Réaction de la zona pellucida

3. Réaction vitelline

4. La « refécondation » d'œufs fécondés

5. La destinée des spermatozoīdes supplémentaires

c) Effets de différents facteurs et des conditions expérimentales sur la fréquence de la polyspermie.

I. Fécondation retardée

Rat. - Souris. - Hamster doré. - Lapin. - Truie.

2. Choc thermique. Hypo- et hyperthermie

3. Age de la femelle

4. Souche

5. Milieu

6. Doubles accouplements successifs

7. Insémination artificielle

8. Irradiation artificielle

9, Autres traitements

d) Morphologie et développement des œufs polyspermiques.

I. Cytologie de la fécondation et du début de segmentation

2. La destinée des embryons polyspermiques

Discussion et Conclusions

Références bibliographiques

RÉSUMÉ ANGLAIS

\section{INTRODUCTION}

Les observations de O. HeRTWIG (I875) sur l'œuf d'Oursin et celles de VAN BENEDEN sur l'œuf de Lapine (I875) et de l'Ascaris (I888), ont jeté les bases de la conception actuelle sur la nature de la fécondation : la fécondation normale suppose l'union de deux gamètes haploïdes, l'un mâle et l'autre femelle.

On peut différencier deux types d'œufs. Dans l'un, un seul spermatozoïde pénètre normalement dans 1'œuf. La polyspermie, c'est-à-dire la pénétration dans le cytoplasme de 1'œuf de deux ou plusieurs spermatozoïdes, est anormale et aboutit presque toujours à un développement pathologique, d'où le nom de " polyspermie pathologique ». Nous trouvons ce type d'œuf dans la plupart des groupes du règne animal. 
Dans le deuxième type d'œuf, la pénétration de plusieurs spermatozoïdes à l'intérieur de l'œuf est un phénomène régulier; mais un seul spermatozoïde s'unit au noyau femelle, tandis que les spermatozoïdes "surnuméraires" sont éliminés du processus de la fécondation. C'est le cas de la "polyspermie physiologique ", décrite pour la première fois par RückERT (I89r). Ce type de fécondation s'observe chez les Insectes, les Poissons élasmobranches, les Amphibiens urodèles, les Reptiles, les Oiseaux.

Dans le présent article nous avons cherché à donner une vue d'ensemble des deux types de polyspermie dans le règne animal en insistant particulièrement sur la cytologie de la fécondation et sur le développement.

Nos connaissances sur la fécondation polyspermique, et sur ses conséquences au cours du développement embryonnaire, découlent des études approfondies faites à la fin du siècle dernier et au début du présent. Des résultats récents, comme la découverte d'un type de " polyspermie pathologique " chez les Mammifères, et les observations génétiques originales concernant le rôle possible des "spermatozoïdes surnuméraires " chez les Insectes et chez les Oiseaux, nous ont amené à compléter et, en partie, à reviser l'image précédemment admise.

Nous avons adopté le plan suivant : Dans un premier chapitre sont discutées d'une façon sommaire les observations faites chez les Invertébrés et les Vertébrés poikilothermes, en séparant les deux types distincts de la polyspermie. Dans le deuxième chapitre, sont passées en revue les données concernant les Oiseaux et les Monotrèmes. Enfin, le troisième chapitre traite de la polyspermie chez le reste des Mammifères.

Mentionnons encore ici les ouvrages antérieurs, traitant de la polyspermie d'une façon plus ou moins détaillée et qui nous ont fourni les éléments de base : GoDLEWSKX (I9I3) et WILSON (I928) donnent des revues générales de la polyspermie. Les problèmes de la polyspermie physiologique sont discutés par RüCKERT (I899, Igro) et pat FANKHAUSER (I948). BRACHE'T (I93I), GRASSÉ (I94I), donnent une analyse approfondie de la fécondation, surtout chez les Invertébrés, avec beaucoup de détails sur la polyspermie. Le livre de RothschiLD (I956) traite des problèmes actuels de la fécondation et consacre un chapitre à la polyspermie, surtout en ce qui concerne le mécanisme d'inhibition de la polyspermie. Chez les Mammifères, Austrn et BRADEN (I953b) donnent une revue critique des observations antérieures sur la "polyspermie ". AUstin et Bishop (I957a) résument les données sur les conditions préliminaires de la fécondation, y compris le mécanisme d'inhibition de la polyspermie; ces mêmes auteurs (AUSTIN et BISHOP, I957b) publient par ailleurs une revue générale de la fécondation chez les Mammifères, contenant un excellent résumé de la fécondation polyspermique. 
CHAPITRE, I

\section{LA POLYSPERMIE CHEZ LES INVERTÉBRÉS ET CHEZ LES POIKILOTHERMES}

\section{A. - Polyspermie physiologique}

\section{a) Bryozoaires}

D'après BonNevie (Igo7) chez Membranipora pilosa L. la polyspermie serait non seulement constante mais indispensable pour le développement de 1'œuf fécondé. Un seul spermatozoïde se transformerait en pronucleus mâle et les spermatozoïdes surnuméraires (d'un nombre très élevé) apporteraient la " chromatine somatique " nécessaire au métabolisme de la cellule, rétablissant ainsi la relation nucléoplasmique normale.

\section{b) Insectes (Arthropodes)}

Chez les Insectes, la fécondation polyspermique semble être presque universelle (WIGGLEWORTH, I947).

HENKING. (I892) est le premier à avoir observé avec quelque détail la polyspermie physiologique chez plusieurs groupes d'Insectes : Hémiptères (Pirrhocoris), Coléoptères (Agelastica, etc.), Hyménoptères (Lasia), Lépidoptères. Bien qu'en général plusieurs spermatozoïdes (jusqu'à 7) pénètrent dans l'œuf, la majorité dégénère d'emblée dans le plasma périphérique. Très fréquemment (dans environ 50 p. Ioo des cas) 2 ou 3 spermatozoïdes arrivent jusqu'à l'intérieur du vitellus où ils subissent les mêmes changements et se développent en pronucléi mâles. Mais un seul pronucleus mâle s'unit au pronucleus femelle, tandis que les pronucléi surnuméraires dégénèrent probablement sans subir de division (HENkING, I892).

La destinée des spermatozoïdes surnuméraires dans l'œuf du Bombyx du mûrier a été le sujet d'études approfondies, surtout grâce aux travaux de BATarıLon et 'Tchou-su (I928, I930, I933) et plus récemment de 'TCHou-su et Chang-ko (I949, I95I). Les résultats de ces travaux ont été résumés par ElLEANGorn et Riabinina (I953) et Tchou-su lui-même (I953).

Chez Bombyx mori, ainsi que chez Sphinx colligata (Tchou-su et Chang-Ko, I95I), la polyspermie est la règle : de 2 à 5 ou 6 spermatozoïdes pénètrent dans l'œuf. Leurs têtes se gonflent et autour de chacune d'elles s'isole un îlot plasmatique, assez volumineux : il en résulte autant de pronuclei mâles, tous semblables, et caractérisés par une relation nucléo-plasmique $\left(\frac{\mathrm{N}}{\mathrm{P}}\right)$ faible.

Un seul noyau mâle, le plus voisin du pronucleus femelle s'unit à lui : le noyau amphimixique commence à se diviser assez régulièrement d'heure en heure (sans formation astérienne). 
A leur tour, les noyaux surnuméraires se préparent aussi à la division (indépendamment de celle du syncaryon), mais leur cinèse ne dépasse jamais la métaphase. L.es deux centres se détachent du fuseau, entrainant le cytoplasme, puis s'en éloignent, s'irradient et peuvent se diviser plusieurs fois. Les figures mitotiques figées et dénudées du plasma, sont condamnées à la dégénérescence pycnotique, mais leurs restes peuvent être retrouvés, pendant 24 heures ou plus (TCHOU-SU, I953).

Le comportement des noyaux surnuméraires chez le Bombyx est indépendant du syncaryon : dans l'œuf non activé ils subissent essentiellement la même régression (BATAILLON et TCHOU-SU, I933).

TChou-Su et Chang-ko (I949, I95I) supposent que la désintégration des îlots haploïdes serait due à leur faible relation $\left(\frac{\mathrm{N}}{\mathrm{P}}\right)$ et serait provoquée par une insuffisance d'oxygène, tandis que l'îlot embryonnaire diplö̈de, à relation $\left(\frac{N}{\mathrm{P}}\right)$ en équilibre, peut se développer normalement; mais la suppression des oxydations par une solution faible de $\mathrm{KCN}$, provoque chez ce dernier des changements analogues à ceux des noyaux surnuméraires.

En effet, les nuclei surnuméraires semblent pouvoir échapper à la dégénérescence et commencer à se diviser normalement si, par exemple par la fusion de deux noyaux, la diploïdie est rétablie (mérogonie dispermique). Dans ce cas, une part de l'embryon se développera à partir du noyau de l'œuf fécondé et l'autre part à partir du noyau dispermique donnant naissance à une mosaïque ou à un gynandromorphe (TANAKA, I953).

TCHOU-SU (I953) rend compte également d'observations intéressantes sur l'effet de 1'insémination "hétérospermique " chez Bombyx avec du sperme mixte de deux ou trois races différentes. La vitalité et la résistance aux températures élevées de la descendance ont surpassé celles des croisements simples. Les caractères morphologiques des larves et des cocons issus de la fécondation " hétérospermique » ont montré, dans quelques cas, des changements compliqués et tout à fait inattendus, qui ne peuvent être expliqués, d'après Tchou-su, que par la participation des spermatozoïdes surnuméraires à la détermination de ces caractères.

Chez Drosophila, dans les cas typiques, de cinq à huit spermatozoïdes pénètrent dans 1'œuf (SONNENBLICK, I950). Ce nombre peut augmenter considérablement et aller jusqu'à quelques centaines. Les conséquences de la polyspermie excessive ont été examinées en détail par HUETTNER (I927). Le développement est presque toujours anormal. La formation du globule polaire peut être désorganisée. Les spermatozoïdes surnuméraires peuvent former des fuseaux de forme et de polarité extrêmement variables (avec ou sans division du centrosome). Il peut s'en suivre le développement de fuseaux pluripolaires, avec des mitoses irrégulières. Cependant, dans quelques cas, les mitoses pluripolaires se régularisent (par exemple par élimination de centrosomes) et, la bipolarité rétablie, il s'en suit une division normale avec le nombre polyploïde des chromosomes. (Notons que la variabilité des figures mitotiques et des changements d'un type de mitose à l'autre ont été également observés par FANKHAUSER et MOORE (I94Ib) chez les noyaux spermatiques se développant dans les fragments androgénétiques de l'œuf de Triturus palmatus).

Dans quelques rares cas, les spermatozoïdes surnuméraires peuvent se développer indépendamment (par exemple après la conjugaison de deux noyaux, à la suite de 
dimegalie, ou après duplication des chromosomes d'un seul spermatozoïde) et, selon toute apparence, sans effet nuisible pour le développement de l'œuf. L'origine de certaines mosaïques et gynandromorphes pourrait être ainsi expliquée (HUETTNER, I927).

Un témoignage de l'interférence des spermatozoïdes surnuméraires dans le développement de l'œuf vient d'être fourni par l'étude de " femelles stériles " de Drosophila. Les femelles, homozygotes pour ce caractère, produisent des oufs incapables d'un développement normal (dûu aux anomalies du cytoplasme). Mais si un tel ouf est fécondé par un spermatozoïde, porteur d'un chromosome $\mathrm{X}$ normal, le développement devient entièrement (ou presque) régulier. Un effet semblable, bien que de moindre degré, se produit aussi après fécondation par un spermatozoïde porteur de chromosome $\mathrm{Y}$; dans ce cas, 1'amélioration du développement doit être due, en toute probabilité, aux spermatozoïdes surnuméraires porteurs de chromosome $\mathrm{X}$. (CouncE, I956; WADDINGTON, I956, p. I35).

Chez 1'Abeille (Apis mellifera L.) 3 à 7 spermatozoïdes (jusqu'à Io) pénètrent normalement dans l'œuf ; les spermatozoïdes surnuméraires en général dégénèrent (Nachtsheim, IgI3). Toutefois, Rothenbuhler, Gowen et Park (I952) ont démontré que les noyaux surnuméraires peuvent se développer et participer à la formation des tissus embryonnaires, donnant naissance à une mosaïque (haploïde-diploïde). Les auteurs sont arrivés à cette conclusion par l'observation génétique de gynandromorphes, fréquents chez certaines lignées d'Abeilles, en ratilisant les méthodes suivantes : I., gènes "marqueurs " chez les animaux appariés pour la production de mosaïques ; 2 ., testage de la constitution génétique des tissus (testicules) supposés androgénétiques, par leur descendance ; 3 ., insémination mixte avec du sperme de mâles génétiquement différents.

La tendance à la production de gynandromorphes (par la coexistence des iissus androgénétique et zygogénétique) est héréditaire et dépend, selon toute apparence, de l'état du cytoplasme de l'œuf (ROTHENBUHLER et Gowen, I955; v. aussi KERR et LAIDLAW, I956).

Ia monospermie parait habituelle chez la Guêpe parasite Habrobracon juglandis, où SPEICHER (I936) ne signale que deux œufs dispermiques sur I5o œufs examinés. Toutefois, des individus gynandromorphes avec des tissus mâles d'origine androgénétique ont été décrits (WHITrNG, r943) ; la fréquence de ces mosaïques est significativement plus élevée dans une des souches.

I1 semble donc que le clivage indépendant de spermatozoïdes surnuméraires soit une occasion importante de gynandromorphisme chez les Insectes, comme l'avait déjà présumé T. H. MoRGAN (IgO5).

\section{c) Aranéides (Arachnides; Arthropodes)}

D'après Montgomery (Igo8), chez l'Araignée Theridium l'œuf est fréquemment pénétré par deux spermatozoïdes, mais jamais par plus de trois. Les pronuclei mâles, qui en résultent, ressemblent l'un à l'autre en tous points. Un noyau mâle s'unit au pronucleus femelle, au centre de l'œuf. Les noyaux surnuméraires restent, au contraire, près de la périphérie et, selon toute apparence, peuvent se diviser par des mitoses normales, avec le nombre haploïde de chromosomes. L'auteur n'écarte pas la possibilité que ces cellules haploïdes puissent ultérieurement entrer dans le blastoderme, donnant comme résultat une "variation somatique marquée ». 


\section{d) Sélaciens (Elasmobranches ; Poissons)}

C'est chez les Sélaciens que la polyspermie physiologique fut décrite comme telle pour la première fois par RückERT qui lui consacra des études approfondies (RïCKERT, I89I a et b, I892, I899, I9IO).

L'œuf des Elasmobranches est très riche en deutoplasme (œuf télolécithe); la segmentation est discoïdale. Au cours de la fécondation, de Io à 50 spermatozoïdes pénètrent normalement dans le blastodisque. Un seul des spermatozoïdes s'unit au pronucleus femelle. La sphère puissante de l'amphycaryon refoule celles des noyaux surnuméraires vers la périphérie du blastodisque. Cette répulsion, qui s'achève à la deuxième division amphimixique, est rendue possible par la formation tardive des sillons embryonnaires ; ainsi, les noyaux surnuméraires (haploïdes), qui se divisent dès le début avec un synchronisme rigoureux à chaque segmentation, ne peuvent pas provoquer la formation de blastomères. Au bord du blastodisque, les noyaux surnuméraires (nommés généralement " mérocytes ") continuent à se multiplier dans un cytoplasme insegmenté et contribueraient à constituer le "syncytium vitellin », ce dernier ayant pour fonction de participer à la digestion du vitellus.

Bien que les « merocytes " semblent ainsi jouer un rôle utile dans le développement embryonnaire, RüCKERT (I8gIb, I89g) juge improbable leur participation éventuelle à la formation du corps de l'embryon " pour les raisons générales ".

RüCKERT (I899) décrit également 1'adhésion fréquente des spermatozoïdes à la membrane vitelline et la pénétration directe de ceux-ci dans le vitellus; ces derniers subissent une dégénérescence précoce.

Contrairement aux Sélaciens, les Téléostéens (RücKERT, IgIo) et probablement aussi les Chondrostéens (GInzBURG, I957) ont une fécondation normalement monospermique.

\section{e) Urodèles (Amphibiens)}

Le caractère polyspermique de la fécondation était depuis longtemps établi chez plusieurs espèces de Salamandres : Axolotl (FICk, I893 ; Jenkinson, I905), Triturus viridescens (JORDAN, I893), Triturus alpestris (BRAUs, I895), Triturus taeniatus (MrchaElis, I897). Mais c'est surtout grâce aux travaux de BATAILLON (I927), de Bataillon et 'TChou-Su (I929, I930), de FANkhauser (I925, I932, I948, I955) et de FAnkhauser et MoORE (I94I a, b) que l'évolution des spermatozoïdes surnuméraires a été parfaitement élucidée. Il nous est impossible de discuter ici ces expériences, bien que fort intéressantes, en détail et nous nous bornerons à un bref résumé des événements cytologiques.

Jusqu'à une dizaine de spermatozoïdes (rarement plus) pénètrent dans l'œuf. Le nombre des spermatozoïdes surnuméraires, ainsi que l'hémisphère préféré de la pénétration, varient d'après les espèces. Tous les spermatozoïdes développent un spermaster. Les asters dans l'hémisphère animal sont plus puissants et se repoussent les uns les autres. L,e pronucleus femelle pénètre, au cours de sa descente à partir du pôle animal, dans la première aire spermastérienne rencontrée. La copulation du pronucleus femelle avec le noyau mâle devenu "principal " (pendant la $4^{\mathrm{e}}$ heure après la fécondation) marque un point critique dans l'évolution, jusqu'ici normale, des noyaux surnuméraires. Dès ce moment, ces derniers commencent à montrer 
des altérations et, refoulés par la sphère puissante de la première mitose normale dans les zones équatoriales et végétatives de l'œuf, dégénèrent définitivement par fragmentation au cours du deuxième cycle mitotique. Les fragments des noyaux surnuméraires peuvent être retrouvés jusqu'au stade de blastula près de la périphérie de l'hémisphère végétatif ou alors, dans le blastocèle, renfermés dans une petite masse vitelline.

Il faut noter cependant que la réaction des noyaux surnuméraires est assez variable, suivant l'espèce, et quelquefois aussi suivant 1'œuf. Le spermaster peut (Triturus palmatus et Triturus viridescens), ou non (Triturus alpestris et Triturus cristatus) se diviser. Les mitoses marquent toujours un retard appréciable sur celle du noyau amphimixique, mais les stades atteints varient considérablement : les unes dégénèrent même avant la prophase, tandis que d'autres évoluent jusqu'à la télophase. FANKHAUSER et MOORE (I94Ia) ont trouvé un seul ouf (sur 52) au stade de deux blastomères, contenant une mitose bipolaire entièrement normale d'un noyau surnuméraire. Rien n'aurait indiqué une segmentation anormale de cet ouf et il aurait pu donner une mosaïque In/2n (FANkHAUSER, I955). Les mitoses surnuméraires normales peuvent être observés à l'occasion dans les oufs excessivement polyspermiques ; mais cet état aboutit toujours à un clivage anormal (FANKHAUSER et MOORE, I94I a). Chez le Triton alpestre, l'accouplement entre eux de deux ou plusieurs noyaux mâles a été également observé (BATAILLON et TCOHU-Su, I929).

En ce qui concerne le mécanisme qui assure le maintien d'un seul système mitotique, il y a au moins deux facteurs en cause (FANkHAUSER et MoORE, I94rb) : I., la dégénérescence automatique des éléments surnuméraires " mitotiquement inférieurs " (en effet, les expériences d'androgenèse et d'andromérogonie ont montré une variabilité remarquable dans la capacité mitotique des spermatozoïdes individuels pour une division indépendante) et $2 ., 1$ 'influence inhibitrice du système mitotique diploïde qui bloque la division des noyaux surnuméraires "plus dangereux " (probablement par un changement du cytoplasme les entourant).

\section{f) Reptiles}

La structure et la segmentation des œufs de Reptiles ressemblent beaucoup à celles observées chez les Sélaciens. Aussi, la polyspermie physiologique fut reconnue peu après les découvertes de RüCKERT (I8gI) par plusieurs auteurs, notamment par OpPel (I892) chez Anguis, Tropidonotus et Lacerta; par Nicolas (I900, I904) chez Anguis; et par Ballowitz (I903) chez Vipera berus.

Un nombre variable de spermatozoïdes, allant en général de Io à 30 , pénètre dans l'œuf. Un seul spermatozoïde copule avec le pronucleus femelle. Tous les noyaux surnuméraires forment un spermaster et, à leur tour, commencent à se diviser, mais avec un retard par rapport au noyau amphimixique. Au cours des premiers stades de la segmentation, leur activité se manifeste par la présence de sillons accessoires, isolés à une certaine distance autour des sillons principaux. Sur leur sort ultérieur, les opinions divergent. OPPEL (I892) pense qu'ils dégénèrent bientôt et ne prennent probablement aucune part directe à la formation de l'embryon (il leur attribue pourtant une signification possible : " doch dürften dieselben wohl kaum ganz bedeutungslos sein "p. 284). D'après BALIOwITz (I903) chez Vipera berus les noyaux surnuméraires contribueraient à former le syncytium vitellin et participe- 
raient peut-être à la formation du blastoderme. NrCoLAS (Ig00, I904) souligne, chez l'Orvet (Anguis fragilis), la variabilité du comportement des noyaux surnuméraires, allant d'une dénégérescence plus ou moins précoce jusqu'à une segmentation accessoire; les éléments superficiels de cette segmentation pourraient se mélanger aux blastomères véritables.

Récemment PASTEELS (I956) a publié une étude des phases de segmentation chez trois Lacertiliens africains, avec une revue critique des travaux de Nicolas. Il conclut que l'évolution des spermatozoïdes surnuméraires chez les Lacertiliens est identique à celle qui a été décrite chez les Urodèles. Les têtes spermatiques installent une première mitose anastrale, bloquée, sans orientation des chromosomes et appelée à la dégénérescence ; leur "segmentation " ainsi que leur participation au syncytium vitellin paraissent exclues.

\section{Discussion et conclusions}

"La polyspermie physiologique suppose (et c'est ce qui légitime son nom) l'union d'un seul noyau mâle avec le pronucleus femelle et, par suite, l'exclusion des spermies surnuméraires, dont l'intervention créerait une hétérogénéité fatale à l'ébauche embryonnaire. " Cette constatation de BATAILLON et TCHOU-Su (1930, p. 533) reste, en général, valable pour les cas examinés.

La cause directe de la polyspermie est à chercher, sans doute, dans la lenteur de la réaction propre de l'œuf encombré d'enclaves vitellines qui permet à plusieurs spermatozoïdes de pénétrer avant que la modification du cortex soit complète. Mais que le blocage de la polyspermie existe dans ces œufs, est prouvé par les faits suivants : I., le nombre des spermatozoïdes ayant pénétré dans l'œuf est normalement limité ; 2., un bon nombre des spermatozoïdes reste accroché à la membrane vitelline sans pouvoir la franchir (par exemple chez les Sélaciens).

Les mécanismes assurant la souveraineté du système mitotique amphimixique, ainsi que l'évolution des spermatozoïdes surnuméraires, sont variables. Chez les Bryozoaires, les spermatozoïdes surnuméraires dégénèrent sans aucun effort de division. Dans l'œuf télolécithe méroblastique des Sélaciens (et à un moindre degré dans celui des Reptiles) les noyaux surnuméraires sont refoulés du territoire de clivage dans une zone insegmentée où ils peuvent se diviser sans effet nuisible pour l'embryon. Dans l'œuf oligolécithe holoblastique des Amphibiens urodèles il n'y a pas de "zone neutre ". Ici, l'élimination des noyaux surnuméraires est due à deux facteurs : I., dégénérescence automatique et 2 , influence inhibitrice du système mitotique diploïde. Cependant, le sort des noyaux spermatiques varie beaucoup selon l'espèce et aussi selon l'individu. Dans l'œuf des Insectes la dégénérescence automatique des noyaux haploïdes, par asphyxie (?) aurait le rôle principal.

Si la polyspermie est excessive, le mécanisme d'inhibition peut échouer ; le développement devient anormal et ressemble à bien des points de vue à la polyspermie pathologique véritable. Aussi en cas de polyspermie modérée, des noyaux surnuméraires peuvent échapper à la dégénérescence et débuter une mitose indépendante normale (Insectes, Urodèles). La formation de certaines mosaïques peut être expliquée de cette façon.

La question se pose:la polyspermie physiologiquea-t-elle une utilité ? Le fait qu'elle s'observe spécialement dans les œufs à réserves deutoplasmiques abondantes, a 
suscité l'hypothèse, qu'elle accroît dans ces œufs volumineux les chances de la fécondation (BoverI, I89I, p. 40I). Dans 1'œuf des Sélaciens, les noyaux surnuméraires, participant à la formation du "syncytium vitellin ", pourraient avoir une importance pour le développement; un rôle semblable paraît exclu chez les Lacertiliens.

La question des noyaux dégénérés et absorbés ultérieurement par l'embryon mérite attention. Que leur présence ne soit pas une nécessité absolue (abstraction faite peut-être des Bryozoaires), est montré par le fait, que la pénétration dans les œufs normalement polyspermiques d'un seul ou de peu de spermatozoïdes est suivi par un développement normale (WITsCHI, I956, p.56). D'autre part, les substances spécifiques contenues dans les noyaux surnuméraires pourraient avoir un effet utile pour le développement de l'embryon. En fait, des preuves indirectes, témoignant d'une intervention des spermatozoïdes surnuméraires dans le développement de l'œuf, ont été fournies récemment chez le Ver à Soie et chez la Drosophile. Les changements observés sont d'ordre morphologique et physiologique (augmentation de la vitalité).

A la base de ses observations, faites sur la "stérilité femelle " de Drosophile, CoUnCE (I956, III) arrive à des conclusions fort intéressantes concernant le rôle possible des spermatozoïdes surnuméraires dans l'embryogenèse : I. Une interaction entre gènes et cytoplasme serait possible au moment de l'entrée des spermatozoïdes dans l'œuf et avant la fusion des pronuclei, comme l'avaient observé déjà Glass et PlaINE (I950). 2. Les spermatozoïdes surnuméraires pourraient ainsi jouer un rôle actif aux stades précoces du développement de l'œuf. 3 . Il est présumable que non seulement la qualité mais aussi la quantité des spermatozoïdes surnuméraires ont une importance (" effet de seuil »). 4. L'effet des spermatozoïdes surnuméraires pourrait participer à l'explication de certains phénomènes complexes de la génétique comme la pénétrance et l'expressivité.

L'action des spermatozoïdes surnuméraires pourrait être liée au rôle fondamental des acides nucléiques dans le métabolisme cellulaire et dans l'hérédité ( $\mathrm{v}$. CAspersson, I950; J. BracheT, I957) et relever de plusieurs mécanismes : I.Participation au métabolisme des cellules embryonnaires, surtout en ce qui concerne la synthèse de protéines, 2. Libération dans le cytoplasme de l'œuf de produits géniques specifiques formés à partir de spermatozoïdes surnuméraires avant leur dégénérescence (v. GLAss, I957), 3. Provocation de mutations de type "transformation bactérienne".

Ces différents faits permettent de remettre en question la signification possible de la polyspermie physiologique. Jusqu'ici, on avait généralement considéré qu'elle est indifférente pour le développement embryonnaire. Mais il n'est pas impossible que les spermatozoïdes surnuméraires puissent jouer un rôle dans le développement et qu'ils soient la source d'une sorte d'hétérosis pour l'embryon. La Drosophile pourra fournir un matériel de premier ordre pour résoudre ce problème d'un intérêt biologique considérable. 


\section{B. - Polyspermie pathologique}

\section{POLYSPERMIE PATHOLOGIQUE ACCIDENTELLE}

\section{a) Oursin (Echinides)}

La polyspermie fut déjà observée par O. HERTWIG (I875, p. 383 ; I878). FoI (I877) a décrit la pénétration de jusqu'à $I_{5}$ spermatozoïdes dans des aufs immatures ou autrement anormaux. Une étude systématique de la production artificielle de la polyspermie a été faite par O. et R. HERTwIG (I887). Tous ces auteurs ont souligné le caractère pathologique de la fécondation polyspermique et ils ont conclu que la fécondation normale suppose la pénétration de l'œuf par un seul spermatozoïde appartenant à la même espèce. Les abberrations du comportement des nuclei et de la segmentation (formation de polyasters) ont été décrites.

DRIESCH (I892) a étudié le développement de 83 œufs dispermiques; le stade le plus avancé obtenu par lui était une blastule anormale (" stéréoblastule »).

Nos connaissances actuelles sur le mécanisme des processus dans l'œuf dispermique ont été établies par BoVERI dans une série d'études résumée en I907. Les principaux points en sont les suivants :

Dans le cas typique chacun des deux noyaux spermatiques copulent avec le pronucleus femelle, avec la division d'un ou des deux spermocentres (types triasters et tétrasters). La première mitose est tri- ou tétrapolaire et les chromosomes sont distribués entre les pôles au hasard. Les premiers blastomères (3 ou 4 ) contiendront un nombre différent de chromosomes et cette hétérogénéité nucléaire sera reproduite à chaque division successive. Le développement reste fréquemment bloqué au stade blastula.

En analysant la cause de la mort de ces embryons, Boveri (I902, I907) conclut que ce n'est pas le nombre anormal de chromosomes mais l'association fausse des chromosomes, qualitativement différents, dans un ou plusieurs territoires de l'embryon qui provoque 1'arrêt du développement. Autrement dit, ce n'est pas la présence de deux noyaux spermatiques, mais le nombre élevé des pôles de division qui est troublant.

La distribution anormale des chromosomes entre les cellules filles de la première segmentation peut être d'un degré variable. Ainsi s'expliquerait la grande variabilité qui existe parmi les embryons dispermiques depuis la "stéréoblastule " jusqu'au pluteus parfaitement normal. Ces derniers pourraient, en toute probabilité, terminer leur métamorphose avec succès (Boveri, I907; Boveri et STEvens, I904).

Dans un type moins fréquent de dispermie, un des deux noyaux spermatiques s'unit seulement au pronucleus femelle et compose un fuseau bipolaire normal, tandis que 1'autre forme un fuseau indépendant ("Doppelspindeltypus "). Il pourrait alors se développer un individu haploïde-diploïde (BOVERr, I907).

\section{b) Ascaris megalocephala (Nématodes)}

D'après Boveri et STEVENS (I904), les œufs supposés dispermiques de l'Ascaris du Cheval, se développent essentiellement de la même façon que ceux de l'Oursin. Après une division d'emblée en 3 ou 4 blastomères, la segmentation procède norma- 
lement jusqu'au stade de 40 à 48 cellules. Après, le développement devient irrégulier et reste complètement bloqué au stade blastula.

BOVERI et S'TEVENs concluent, que l'arrêt du développement serait dû, à la différence de l'Oursin, aux troubles de l'organisation du cytoplasme; c'est ce qui expliquerait aussi la moindre variabilité et le sort toujours fatal. Mais la cause primaire serait la même : l'introduction dans l'œuf de plusieurs pôles de division.

Récemment, Makarov (I953) a décrit l'incidence de la dispermie aux premiers stades de la fécondation chez Ascaris megalocephala, dans les œufs fixés.

\section{c) Esturgeon (Acipenséridés, Chondrostéens)}

Au cours de l'incubation industrielle de l'Esturgeon, une segmentation atypique est couramment observée chez un certain pourcentage d'œufs : l'œuf se divise d'emblée à 3 blastomères ou plus. Le développement est anormal et d'habitude, il se bloque complètement au stade gastrula. L'anomalie s'expliquerait par une fécondation polyspermique. La polyspermie provoquée par du sperme fortement concentré, révèle une corrélation étroite entre le pourcentage des oufs polyspermiques d'une part, et la proportion de segmentations aberrantes d'autre part (GINzBURG, I953, I957).

L'étude cytologique (GInzBurg, I957) a dévoilé l'image suivante : la polyspermie est dans plus de la moitié des cas dispermique; mais il y a aussi des œufs tri- ou tétraspermiques. Tous les spermatozoïdes se transforment en pronucléi; leur développement est synchrone. A leur tour, les noyaux mâles copulent avec le pronucleus femelle; les centrosomes se divisent et forment un polyaster. La polyspermie est donc du type Oursin.

GinzBuRG (I957) arrive à la conclusion que la fécondation de 1'Esturgeon est normalement monospermique et que la polyspermie y est toujours pathologique (contrairement à la constatation de PERSOV, I954).

\section{d) Anoures (Amphibiens)}

La polyspermie des Anoures représente un type spécial de polyspermie pathologique dont les caractères, plus particulièrement chez Rana fusca, ont été établis de façon définitive par les mémoires classiques de A. BRACHET (IgIo) et HERLANT (IgII). (Pour résumé et discussion des résultats voir aussi A. BRACHE'T, I9I2, I93I.)

La polyspermie se produit quand on met les oufs au contact de sperme concentré, contenant 2,5 pour mille de chlorure de sodium, pendant 20 à 30 minutes. Cette méthode donne des œufs pénétrés par 2 à Ioo spermatozoïdes. Nous laisserons de côté la polyspermie forte ( $\mathrm{I}_{5}$ à 60 spermatozoïdes), entraînant bientôt la mort de 1'embryon, et la polyspermie très forte (60 à Ioo spermatozoïdes) qui n'aboutit jamais à un développement, et examinerons de plus près les cufs contenant moins de ro spermatozoïdes.

Pett après leur pénétration, les têtes spermatiques se transforment en pronucléi ; autour de leurs centrosomes, le cytoplasme s'irradie : il en résulte autant « d'énergides spermatiques ». Ces "énergides" se repoussent l'une l'autre (comme le trahit l'écartement des traînées pigmentées) et se partagent le protoplasme de l'œuf, arrivant à un état d'équilibre. Un pronucleus mâle (qui est le plus près) copule avec 
le pronucleus femelle pour former un unique noyau amphimixique. Au moment de la segmentation, tous les noyaux se divisent synchroniquement : 1'œuf sera découpé en un nombre de blastomères égal à celui des spermatozoïdes (clivage baroque). Les figures mitotiques restant toujours séparées, la division se poursuit régulièrement avec un fuseau bipolaire normal.

Au début, les blastomères sont binucléaires ; mais, par réglage du cloisonnement cellulaire, cette anomalie peut disparaitre jusqu'au stade blastula et l'embryon contiendra alors des cellules uninuclées de deux types : cellules normales diploïdes provenant du noyau amphimixique et cellules haploïdes issues de noyaux surnuméraires. Cette blastula peut continuer à se développer sans anomalie appréciable et donner naissance à un têtard en apparence bien conformé (chez les œufs di et trispermiques dans ro p. Ioo des cas). HERLANT (IgII) a pu même élever pendant 93 jours un têtard éclos d'un œuf dispermique et qui avait atteint à ce moment une taille considérable.

Pourtant, les embryons issus de fécondation polyspermique sont toujours voués à la mort et la fin survient d'autant plus promptement que la polyspermie était plus forte.

Le syndrôme des embryons polyspermiques est extrêmement variable. Souvent ils présentent des plages, où la segmentation s'arrête de façon précoce (avec la formation de " polykaryons " ) ; elles sont dues aux troubles de la cellularisation. Dans les stades plus avancés, l'œdème, l'assymétrie, divers troubles de morphogénèse sont fréquents. Dans les rares cas, où les larves sont apparemment normales et tout à fait vigoureuses, des anomalies fonctionnelles apparaissent qui s'aggravent rapidement et entraînent bientôt la mort.

L'examen histologique confirme la coexistence des territoires haploïdes et diploïdes C'est cette dualité, selon toute apparence, qui est la cause de la mort de l'embryon et la situation est encore aggravée par l'hétérogénéité héréditaire des tissus d'origine paternelle (A. BRACHET, I9Io, I93I). Les effets de la disharmonie se font surtout sentir au moment où commence la différenciation organogénétique et cytologique : l'embryon " bâti sur deux mesures se trouvera dans des conditions physiologiques défectueuses qui entraîneront inévitablement sa mort prématurée ". (A. BRACHET, I93I).

L'examen biochimique des embryons polyspermiques a révélé que ceux-ci sont "de véritables montres dysharmoniques où la synthèse des protéines se fait normalement dans certains organes, alors qu'elle est réduite dans d'autres. " (A. BRACHET, I944, p. 7I). Il semble donc que l'arrêt du développement chez les larves polyspermiques, ainsi que chez d'autres larves à constitution nucléaire anormale, soit étroitement lié, ou même attribuable, à des troubles du métabolisme nucléoprotéique (J. BRACHET, I947, p. 496.)

\section{POLYSPERMIE EXPÉRIMENTALE}

O. et B. HERTwIG ( 1887 ) ont été les premiers à faire une étude systématique des facteurs de l'induction artificielle de la polyspermie. Clark (I936) a confirmé et élargi les observations des HERTwIG et a donné une revue générale de la question. Plus récemment RoTHSCHILD (I953, I954, I956) et HAGSTRöm (I956 a, b) ont contribué 
à l'étude de la fécondation polyspermique. (Tous ces travaux ont été faits chez l'Oursin).

Les facteurs capables de provoquer la polyspermie sont extrêmement variables comme l'illustre un tableau de Clark (I936), reproduit ci-après.

\section{TABLEAU I}

Liste des agents et conditions pouvant provoquer la polyspermie chez l'oursin (d'après CLARK, 1936).

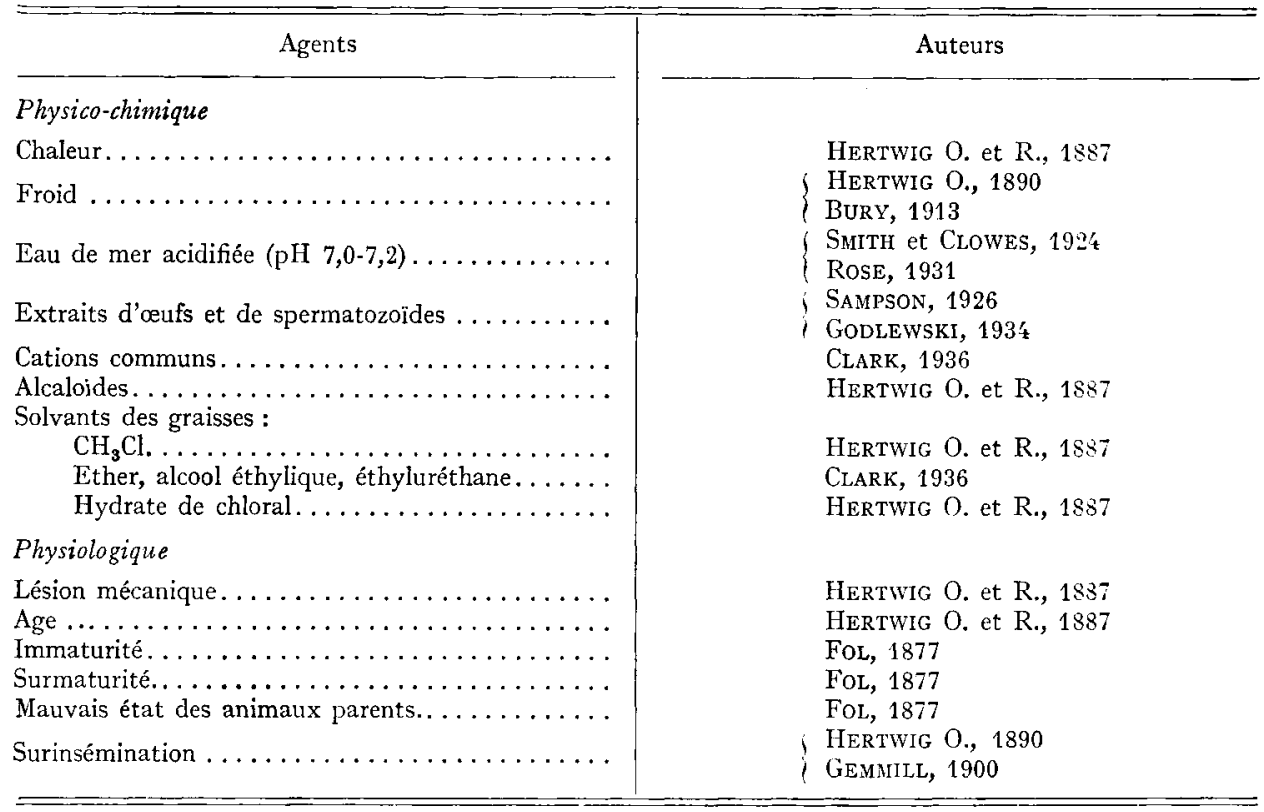

a) Polyspermie par action d'agents chimiques

O. et R. HERTwIG (I887) donnent la liste suivante des agents qui, dans les conditions indiquées, provoquent une polyspermie accusée (tetra- et pentaspermie fréquente) (p. 480) :

\begin{tabular}{|c|c|c|c|c|c|}
\hline I. Nicotine & $20 \mathrm{mn}$ & I goutte/I ooo & ou & $5 \mathrm{mn}$ & I goutte/Ioo \\
\hline 2. Strychnine & $20 \mathrm{mn}$ & o,oI p. IOO & ou & $5 \mathrm{mn}$ & o, I p. IOO \\
\hline 3. Morphine & $5 \mathrm{~h}$ & 0,4 p. IOO & ou & $2 \mathrm{~h} \mathrm{I} / 2$ & 0,6 p. I0o \\
\hline 4. Cocaïne & $5 \mathrm{mn}$ & o,I p. IOO & & & \\
\hline 5. Quinine & I h & 0,005 p. I00 & out & ro $\mathrm{mn}$ & 0,05 p. IOO \\
\hline 6. Chloral & $3 \mathrm{~h}$ & 0,2 p. I00 & our & $5 \mathrm{mn}$ & 0,5 p. Ioo \\
\hline 7. Chaleur & $45 \mathrm{mn}$ & $3 \mathrm{I}^{\circ} \mathrm{C}$ & out & $5 \mathrm{mn}$ & $35^{\circ} \mathrm{C}$ \\
\hline
\end{tabular}

Dans la discussion des rést1tats, les auteurs arrivent à la conclusion importante que le degré de la polyspermie est fonction de l'intensité et de la durée d'action des agents employés (p. 489).

Clark (I936), en employant les " réactifs de HerTwIG ", a obtenu chez Avbacia punctulata des résultats parfaitement analogues. Il divise les " réactifs de HERTWIG ", d'après leur mécanisme d'effet, en deux groupes: 
I. - Hydrate de chloral (0,2 p. I0o), Cocaine HCl (o,025 p. Ioo) et nicotine (I goutte pour $200 \mathrm{ml}$ ), caractérisés par le pourcentage élevé de polyspermie ; la réversibilité de l'effet; innocuité pour la fécondation et au moins pour les premiers stades de la segmentation. Ces agents semblent donc avoir une action plus ou moins spécifique sur le mécanisme assurant la monospermie.

2. - Morphine $\mathrm{SO}_{4}$ (o,6 p. Ioo), Strichnine $\mathrm{SO}_{4}$ (O,I p. Ioo) et Quinine $\mathrm{SO}_{4}$ (0,05 p. I0O), caractérisés par un moindre degré de la polyspermie; une moindre réversibilité d'effet; une diminution du taux de fécondation. Ces réactifs nuisent à la cellule entière et la polyspermie n'est qu'une des manifestations de 1'état empoisonné.

Les solvants des graisses : alcool éthylique (concentration optimum 3,0 à 5,0 p. I0o), éther (2,0 p. IO0), chloroforme (0,2 p. IOO) et éthyluréthane (2,0 p. IOo) ont une efficacité à peu près égale dans la provocation de la polyspermie. Tous ces agents se caractérisent par la zone extrêmement étroite qui sépare la dose efficace (Ioo p. Ioo polyspermie) de la dose léthale (cytolyse).

Par contre, la nicotine, un des agents les plus efficaces, excelle par 1'échelle très large de concentrations efficaces (de I à 50 gouttes pour $\mathrm{x}$ ooo $\mathrm{ml}$ de l'eau de mer), produisant une augmentation progressive dans le degré de la polyspermie (CLARK, I936). Cette observation a été confirmée par RothschILD (I953). D'après cet auteur, 1'effet de la nicotine serait dû à l'abolition du blocage rapide de la polyspermie (voir plus bas). La nicotine est toxique aux spermatozoïdes de l'Oursin et cause une brusque réduction dans l'assimilation d'oxygène de ceux-ci. Les oufs polyspermiques nicotinisés se divisent plus tôt que les œufs monospermiques (RoTHSCHILD, I953).

HaGström (I956b) rend compte de l'effet de plusieurs substances capables de provoquer la polyspermie : hydrate de chloral, clupéine, lysozyme, N-éthylmaléimide, enzymes proteolytiques (ovomucoide, "soy bean trypsin inhibitor "), colchicine, nicotine et nitrate de strychnine. PERLManN et HAGSTRöM (I957) ont ajouté à cette liste le sérum homologue antiovule de Lapin. HaGsTröm (I956) explique l'effet de toutes ces substances, très hétérogènes au point de vue chimique, par la même base, notamment par leur interférence avec la réaction corticale, avec la transformation des granules corticales et avec le développement de la couche hyaline. L'ablation de la gangue muqueuse et l'augmentation de la concentration du sperme accélère considérablement le rythme de refécondation. La présence de la nicotine ou de la colchicine au moment de la fécondation n'est pas une nécessité absolue tandis que les enzymes protéolytiques ne sont efficaces que quand ils sont présents à l'insémination. Ajoutées après la réaction corticale ces substances sont sans effet sur le blocage à la polyspermie.

La nicotine (et peut être d'autres substances inductrices de la polyspermie) peut fréquemment provoquer un clivage anormal (d'emblée en 4) des œufs monospermiques par la suppression de la première segmentation (HAGSTRÖM et ALLEN I956).

Chez les Amphibiens, comme l'a démontré BATAILION (I9I9), l'eau salée d'une concentration voisine de $2 \mathrm{I} / 2$ pour mille peut provoquer la polyspermie par l'inhibition de la membrane de fécondation. Mais pour que la polyspermie se produise il faut aussi une forte concentration du sperme et que les œufs restent dans le mélange pendant 20 à 30 minutes. Sans cela on obtient une fécondation monospermique parfaite (A. BRACHET, I93I p. 95). 


\section{b) Polyspermie par modifications physiologiques de l'ovocyte}

\section{Fécondation de l'auf double ou polynuclée.}

Chez Ascaris, la fusion de deux ovocytes de premier ordre (p. e. sous l'influence du froid) peut aboutir à la formation d'un œuf double, binucléé (ZUR STRASSEN I898). Si un œuf de ce genre est fécondé par un seul spermatozoïde, les trois pronucléi formeront une première mitose normale bipolaire ; il se développera un embryon normal triploïde. Par contre, si la fécondation est dispermique, un polyaster se forme et la segmentation devient anormale. Néanmoins dans quelques cas, l'œuf double et dispermique peut amorcer un développement normal avec le nombre tétraplö̈de de chromosomes ; mais dans ce cas, les mitoses sont toujours bipolaires (par élimination ou fusion des centrosomes? Zur Strassen n'a pu l'établir).

LEGHISSA (I95I) a obtenu, par traitement avec une solution de trypsine, la fusion de plusieurs œufs vierges d'Ascidies dans une seule masse ooplasmique; le nombre de futurs pronuclei est le même que celui des œufs fusionnés. La fécondation est polyspermique et donne naissance à la formation de plusieurs asters. Cette circonstance, ainsi que l'absence des gaines ectoplasmiques de ces œufs, expliquent les troubles de la segmentation qui est toujours anormale.

La production d'œufs binucléés, et leur fécondation par deux spermatozoïdes, a été signalée chez plusieurs Insectes : Abraxas (DONCASTER, I9r4); Habrobracon (Whiting, I928) ; Bombyx (Gol,dsmith et Ka'tsuki, I93i); Drosophila (CRew et LAMY, I939). Certains cas de mosaïques autosomiales et de gynandromorphes s'expliqueraient ainsi. Cependant, pour Drosophila, L. V. MoRGan (I929) juge très pet1 probable l'origine binucléée des gynandromorphes. Une revue sur la fréquence et l'origine des œufs binucléés chez les Insectes est donnée par RICHARDS et MILLER (I937).

\section{$2^{0}$ Androgénèse di- et polyspermique.}

Si le noyau femelle dans l'œuf de Bombyx est inactivé par traitement à haute température, la fusion de deux noyaux spermatiques peut aboutir au développement d'un androgénone parfaitement normal (toujours mâle) (voir AsTaURov, I948; TANaka, I953). Astaurov et Ostriakova-Varshaver (I957) ont pu pour la première fois obtenir, par ce moyen, des hybrides androgénétiques diploïdes adultes issus de l'insémination hétérospermique entre $B$. mori $L$. et $B$. mandarina $M$.

L'évolution des noyaux spermatiques dans l'œuf (androgenèse) ou dans des fragments d'œufs (andromérogonie) dépourvus du noyau femelle, a été particulièrement bien étudiée chez les Amphibiens urodèles (Triturus palmatus: FankHadSER, I934 a et b; Triturus viridescens : Kaylor, I94I ; FANkHAUSER et MOORE, r94Ib ; v. aussi FANKHAUSER, I948, I952, I955). Rarement, un seul spermatozoïde commence à se diviser tandis que les atutres dégénèrent comme dans la fécondation normale; il peut se développer un embryon uniformément haploïde. Cependant, dans la majorité des cas le développement est polyspermique, avec la formation de plusieurs systèmes mitotiques, y compris des figures pluripolaires. La distribution des chromosomes est irrégulière et la situation est encore compliquée par la présence et l'intermittence d'autres figures aberrantes. Le clivage est anormal et les embryons qui sont des mosaïques complexes (avec le nombre aneuploïde de 
chromosomes dans la majorité de ses cellules), ne survivent jamais au delà de la gastrulation.

Pourtant, un androgénone diploïde, apparemment viable, a été obtenu d'un œuf de Triton (Molge vulgaris) fécondé par du sperme de Molge cristata (P. HeRTwig, I9I6) ; ce cas pourrait être expliqué par la copulation de deux noyaux spermatiques (BATAIILON et 'TCHOU-SU, I9I9).

\section{$3^{\circ}$ Hybridation.}

O. et R. HeRTwig ( $\mathrm{r} 887$ ) ont signalé la tendance à la polyspermie comme conséquence de l'hybridation. Cette observation a été confirmée par de nombreuses expériences sur l'hybridation, en utilisant quelquefois des croisements d'espèces très lointaines, par exemple Echinus (femelle) X Annélide ou Mollusque (mâle) (KUPELWIESER, I9O9, I9I2 ; GoDLEWSKI, I9II, I9I3) ; Urodèles X Anoures (BATAILIoN et TCHOU-SU, I929). Le sort des spermatozoïdes ayant pénétré dans l'œuf, ainsi que le résultat de l'hybridation varient beaucoup selon les espèces appariées (v. Grassé, I94I). Les facteurs relatifs à la spécificité de la fécondation ont été discutés par TYLER (I955) et ROTHSCHILD (I956).

\section{$4^{\mathrm{o}}$ Fécondation de l'auf immature ou surmature. Surinsémination.}

Les aufs immatures d'Oursin, pourvu qu'ils aient dépassé le stade du flétrissement de la vésicule germinative, sont fécondables et régulièrement polyspermiques. La formation de l'aster et l'évolution des têtes spermatiques varient selon le stade de maturation où la fécondation a été effectuée ; cependant, il y a une harmonisation morphologique remarquable entre les noyaux mâle et le noyau femelle (bloqué) ( (mise à l'unisson des chromatines mâles et femelle »; A. BRACHE’r, I93I, p. I4I). Les centrosomes ne se divisent jamais : les mitoses mâles sont toutes du type monastérien et demeurent, elles aussi, figées (A. BRACHET, I922, I93I).

Les cuts immatures des Amphibiens, lorsqu'ils sont fécondés, deviennent aussi toujours polyspermiques et les noyaux spermatiques forment quelquefois des mitoses bipolaires anastrales (tout à fait semblables à la mitose normale de maturation).

TCHOU-SU et CHEN-ChAO-SI (I942) ont examiné en détail la fécondation des oufs immatures chez Bufo et ils ont distingué 7 stades. Voici brièvement leur conclusion : l'œuf au stade de la vésicule germinale est pratiquement imperméable aux spermatozoïdes. Au début de la rupture de la vésicule germinative, les œufs sont très fortement polyspermiques (jusqu'à 200 spermatozoïdes). Au fur et à mesure que la maturation de l'œuf avance, la polyspermie diminue et l'évolution des noyaux mâle et femelle avance plus loin, les mitoses mâles pouvant aboutir à l'expulsion des chromosomes spermatiques (" globules polaires mâles "). Enfin, l'amphimixie peut avoir lieu mais le développement normal nécessite aussi l'achèvement de la maturation du cytoplasme.

Soumis pendant 2 heures à un milieu de $\mathrm{CO}_{2}$, les œufs mûrs de $H y l a$, se comportent comme les œufs immatures et se laissent pénétrer par plusieurs spermatozoïdes (BATAILION, I929; Batailion et TCHOU-SU, I934).

En examinant l'effet du vieillissement de l'œuf et celui de surinsémination, Cl,ARK (I936) a observé des différences interspécifiques considérables. Les œufs $\mathrm{d}$ 'Asterias âgés de 2 heures, sont devenus à 86 p. Ioo polyspermiques sous l'effet d'une 
insémination modérée, tandis que les œufs d'Arbacia, dans les conditions semblables ont résisté à la polyspermie pendant I6 heures. D'une manière analogue, la dose décuplée de la "suspension standard ", pouvant assurer une fécondation normale, a rendu polyspermique roo p. Ioo des œufs de Cerebratulus pendant que chez Arbacia, même la dose élevée 75 fois n'a provoqué que I4 p. Ioo de polyspermie.

\section{c) Polyspermie par refécondation de l'cứ fécondé.}

TyLER et Schultz (I932) ont montré que la réaction de défense contre la polyspermie de l'œuf peut être renversée chez Urechis caupo (Echiurien) : si on traite les cufs récemment fécondés (depuis moins de 3 minutes) avec de l'eau de mer légèrement acidifiée, ils se comportent, au bout de $I_{5}$ minutes ou plus, comme des cufs vierges et se montrent à nouveau fécondables. Le clivage est typiquement polyspermique et aboutit à la formation d'embryons anormaux.

Sugryama (I95I) et HaGsTröm et HaGs'Tröm (I954) ont montré chez l'Oursin que la refécondation est possible à des stades plus avancés et même après la première segmentation si les œufs démembranés sont exposés à un milieu dépourvu de Ca ou de Mg ou des deux ; la possibilité de la refécondation serait conditionnée par la dissolution ou la destruction plus ou moins complète de la couche hyaline de l'œuf (HAGSTRÖM, I956 b).

Toutefois, TYLER, MONROy et METz (I956) ont réussi à reféconder les oufs de Lytechinus pendant une période allant jusqu'à 40 minutes après la première fécondation sans aucun autre traitement que la démembranation mécanique. Les œufs refécondés ont tendance à une polyspermie accusée. La refécondation deviendrait possible par la présence de " cytofertilizines " à la surface đe l'œuf dénudé ; la dissolution de la couche hyaline exposerait plus de substances de genre fertilizine. Les auteurs indiquent que les écarts observés dans les résultats de refécondation seraient en grande partie attribuables aux différences interspécifiques.

\section{CAUSES DE LA MONOSPERMie}

Chez l'Oursin, où les causes de la monospermie ont été le mieux étudiées, la membrane vitelline se détache de la surface de l'œuf et forme une barrière infranchissable aux spermatozoïdes. Et c'est principalement à l'effet protecteur de cette "membrane de fécondation" que les auteurs anciens (FOL, I877, O. et R. HERTWIG, I887) ont attribué la monospermie. Pourtant, la relative lenteur de soulèvement de la membrane (env. 2 minutes), et surtout le fait que 1'œuf fécondé et dépourvu de membranes est aussi normalement imperméable au spermatozoïde (v. LILLIE, IgI9) ont suggéré l'existence possible d'autres facteurs liés à la réaction propre du cytoplasme qui déterminent la monospermie. D’après la "théorie de la fertilizine " de IIILLE (I9I9), l'inhibition de la polyspermie serait due à la neutralisation de la fertilizine par l'antifertilizine déchargée par l'œuf au moment de la fécondation (Pour l'aspect immunobiologique de la fécondation v. TYLER I948, I955).

Plus récemment, le rôle possible des changements de la surface de l'œuf après fécondation dans 1 'inhibition de la polyspermie ont été le sujet des études approfondies qui cependant jusqu'ici ne semblent pas avoir abouti à une conclusion définitive (voir ROTHSCHIL, I956). 
RoTHSCHIL (I956) donne du blocage à la polyspermie la tentative de schéma suivant (p. I2I) : au moment où le spermatozoïde s'attache à la surface de l'œuf, il se produirait un changement rapide de la structure corticale (en partant du point d'attache du spermatozoïde) couvrant l'œuf en environ 2 secondes. Ce qui réduirait les chances d'une seconde pénétration de $95 \mathrm{p}$. Ioo et catalyserait également la production d'une couche entièrement imperméable à la surface de l'œuf ; cette couche serait établie en environ 60 secondes (c'est-à-dire avant le soulèvement de la membrane de fécondation).

D'aptès HAGSTRöm (I956b) c'est la gangue muqueuse in situ et la formation de la couche hyaline qui défendent l'œuf contre la polyspermie (chez Psammechinus miliaris la couche hyaline devient visible en 20 à 30 secondes après la fécondation ; HaGsTröm et HAGSTRöm, I954). La gangue muqueuse agirait comme un obstacle mécanique d'une part et d'autre part, par élimination d'un certain nombre de spermatozoïdes avant qu'ils puissent être attachés à la surface propre de l'œuf. L'enlèvement total de la gangue muqueuse a facilité la fécondation chez plusieurs espèces d'Oursin, en augmentant sensiblement les chances de polyspermie. La membrane de fécondation ne présenterait une barrière efficace qu'après son durcissement (environ 5 minutes après la fécondation).

Pourtant, les expériences de Tyler, Monroy et METz (I956) sur la " refécondation " de Lytechinus, montrent l'importance de la membrane de fécondation dans le blocage à la polyspermie. Ces auteurs présument que la surface imperméable de l'œuf récemment fécondé (avant le soulèvement de la membrane) est identique à la surface de la membrane de fécondation. Les observations n'excluent cependant pas un certain rôle de la couche hyaline dans l'inhibition de la polyspermie : en effet, les œufs de Lytechinus, aisément "refécondables " après simple démembranantion mécanique, se distinguent par la lenteur et la faiblesse de la formation de la couche hyaline.

\section{Discussion et conclusions}

Dans la polyspermie pathologique typique, on peut distinguer deux types principaux : le type Oursin et le type Anoure.

Dans le type oursin tous les spermatozoïdes ayant pénétré dans 1'œuf s'unissent au pronucleus femelle. Il en résulte un fuseau pluripolaire aboutissant à une segmentation anormale et la plupart des embryons ne se développent pas au delà d'une " stéréoblastule ". Comme BOVERI (IgO2, Ig07) 1'a démontré, la cause principale du développement anormal est la distribution qualitativement fausse des chromosomes dans les blastomères, due au nombre élevé des pôles de division. Mais dans les rares cas où l'association de chromosomes est normale, le développement des œufs dispermiques peut se faire normalement. Si dans l'œuf dispermique, l'un des deux spermatozoïdes s'unit seulement au pronucleus femelle et l'autre forme un fuseau indépendant ("Doppelspindeltypus »), il peut se développer une mosaïque n/2n.

La polyspermie chez 1'Ascaris et chez l'Esturgeon suit, dans les grandes lignes, le type Oursin. Mais chez 1'Ascaris, l'arrêt du développement est dû principalement aux troubles de 1'organisation du cytoplasme.

Le type Anoure est caractérisé par le fait qu'ici généralement un seul spermatozoïde s'accouple avec le pronucleus femelle; les noyaux issus des spermatozoïdes surnuméraires commencent une segmentation indépendante donnant naissance à une 
mosaïque plus ou moins complexe. Le développement aboutit toujours à la mort et cela d'autant plus promptement que la polyspermie est plus forte. Les périodes critiques sont la gastrulation (" crise épigénétique »; WADDINGTON, I956) et la différenciation organogénétique et cytologique. Les larves apparemment normales succombent, elles aussi, à cause de diverses anomalies fonctionnelles (un têtard dispermique de HERLANT, I9II, a pu survivre pourtant pendant 93 jours). La mortalité doit être attribuée à l'hétérogénéité nucléaire des larves polyspermiques. L'arrêt du développement est étroitement lié à des troubles du métabolisme nucléoprotéique.

Chez 1'Oursin et les Amphibiens, la polyspermie expérimentale a été le sujet d'études systématiques.

Parmi les agents physiques et chimiques capables de permettre la polyspermie, citons : la chaleur, le froid, les solvants des graisses, les alcaloïdes, les cations communs. Leur mode d'action varie : les uns semblent avoir une action spécifique sur le mécanisme de blocage de la polyspermie (nicotine, hydrate de chloral, cocaine), tandis que les autres nuisent à la cellule entière (morphine, strichnine, quinine). Les solvants des graisses se caractérisent par leur zone d'action extrêmement étroite, alors que la nicotine se distingue par l'échelle très large de concentrations efficaces. Certains agents (enzymes protéolytiques), ne sont efficaces que s'ils sont présents au moment de la fécondation. En général le degré de la polyspermie est fonction de 1'intensité et de la durée d'action des agents employés (O. et R. HERTwiG, I887).

Parmi les agents physiologiques qui peuvent entraîner la polyspermie, le vieillissement de l'œuf ou l'élévation de la densité spermatique au voisinage de l'œuf sont les plus actifs. L'interaction de plusieurs facteurs (par exemple vieillissement de l'œuf et surinsémination) augmente considérablement les chances de la polyspermie. Mais il existe aussi des variations interspécifiques et individuelles remarquables dans le pourcentage de la polyspermie, quels que soient les agents employés.

Chez les Amphibiens, l'interaction de l'eau salée (2 I/2 p. Iooo), de la surinsémination et d'un contact assez long (20 à 30 minutes) du sperme et des oufs, aboutit à une polyspermie accusée.

L'inhibition de la réaction propre ou la destruction de la membrane de fécondation permet une seconde pénétration spermatique, même au stade de deux blastomères. Mais cette propriété varie considérablement avec l'espèce. Le clivage des cufs " refécondés » est typiquement polyspermique.

Si l'œuf contient deux noyaux ou plus, par la fusion de deux oufs ou par un autre moyen, la fécondation peut intéresser tout ou partie de l'œuf. Les noyaux peuvent fusionner et donner un embryon polyploïde (Ascaris) ou bien certains noyaux peuvent se développer indépendamment et donner une mosaïque (Insectes).

Dans les œufs physiologiquement polyspermiques, les noyaux spermatiques peuvent amorcer un développement en l'absence de noyau femelle (androgonie, andromérogonie). Chez Bombyx, la fusion de deux noyaux spermatiques peut donner un androgénone diploïde normal (même hybride). Chez les Urodèles, il se développe généralement une mosaïque complexe qui meurt à un stade précoce ; néanmoins, un androgénone diplö̈de (hétérospermique) a été obtenu, peut-être par la fusion de deux spermatozoïdes.

L'hybridation - parfois entre des espèces très lointaines aboutit fréquemment 
à la polyspermie ; le sort des spermatozoïdes est très variable suivant les espèces appariées.

La fécondation des oeufs immatures est régulièrement polyspermique (Oursin, Amphibiens). L'évolution des têtes spermatiques varie selon le stade de maturation de l'œuf mais, en général, elle imite d'une manière frappante le stade atteint par le noyau femelle ( " mise à l'unisson » de A. BRACHET) fournissant un bel exemple de l'interaction entre le noyau et le cytoplasme.

Les causes de la monospermie ont été étudiées en détail chez l'Oursin sans aboutir à une conclusion définitive. Les facteurs mis en cause dans le blocage de la polyspermie sont les suivants : la gangue muqueuse; le soulèvement de la membrane de fécondation et le changement de la structure corticale ; la formation de la couche hyaline; des réactions immunobiologiques liées à la fécondation.

\section{RÉFÉRENCES BIBLIOGRAPHIQUES}

Astaurov B. L. 1948. Signification des expériences de mérogonie et d'androgenèse pour la théorie du développement et de l'hérédité (en russe). Usp. sourem. Biol., 25, 49-88

Astaurov B. L. et Ostriakova-Varshaver V. P. I957. Complete heretospermic androgenesis in silkworms as a means for experimental analysis of the nucleus-cytoplasm problem. $J$. Embryol. exp. Morph., 5, $449 \cdot 462$.

Ballowitz E. 1903. Die Abfurchung von Paraspermiumzellen um Paraspermiumkerne und das Auftreten von Paraspermiumfurchen in der polyspermen Keimscheibe der meroblastischer Wirbeltiereier. Anat. Anz. 23, 281-290.

Bataillow E. I919. Analyse de l'activation par la technique des œufs nus et la polyspermie expérimentale chez les Batraciens. Ann. Sci. nat. Zool., Io série, 3, I-39.

Bataillon E. 1927. La polyspermie chez le Triton et le clivage simultané en quatre obtenu par centrifugation. C. R. Acad. Sci., Paris, 185, rogo-rog2.

Bataillon E. I929. Etudes cytologiques et expérimentales sur les œufs immatures de Batraciens. Arch. EntwMech. Org. 117, I46-г 78 .

Batallon E. et Tchou-su I928. Maturation, fécondation et polyspermie chez l'œuf de Bombyx mori. C. R. Acad. Sci., Paris, 186, 338-340.

Bataillon E. et TCHou-su r 1929 . Analyse de la fécondation chez les Batraciens par l'hybridation et la polyspermie physiologique. Arch. Entw Mech. Org. 115, 779-824.

Bataillon E. TChou-su 1930. Etudes analytiques et expérimentales sur les rythmes cinétiques dans l'œuf (Hyla arborea, Paracentroius lividus, Bombyx mori)., Arch. Biol., Paris, 40, 439-540.

Batallon E. et Tchou-su I 93.3 . Les processus cinétiques dans l'œuf de Bombyx mori (Fécondation normale; parthénogénèse ; activation polyvoltinisante; dissociation expérimentale des rythmes). Arch. Anat. micr., 29, 285-372.

Batallon E. et TCHOU-SU 1934. L'analyse expérimentale de la fécondation et sa définition par les processus cinétiques. Ann. Sci. nat. Zool., ro série, 17, 9.36.

BonneviE K. I907. Untersuchungen über Keimzellen. II. Physiologische Polyspermie bei Bryozoen. Jena Z. Naturw., $35(42), 567-598$.

Boveri T. I89r. Befruchtung. Ergebn. Anal. EntwGesch. 1, 386-485.

Boveri T. rgo2. Ueber mehrpolige Mitosen als Mittel zur Analyse des Zellkernes. Verh. phys. med. Ges., Würsb., N.F. 35, 67-9o.

Boveri T. I907. Zellen-Studien. VI. Die Entwicklung dispermer Seeigeleier. Ein Beitrag zur Befruchtungslehre und zur Theorie des Kernes. Jena Z. Naturw. 36 (43), I-292.

Boveri T. et Stevens N. M. I904. Ueber die Entwicklung dispermer Ascaris-Eier. Zool. Anz. 27, 406-4I 7 .

BRAChet A. I9ro. Recherches sur l'influence de la polyspermie expérimentale dans le développement de l'ceuf de Rana fusca. Arch. Zool. exp. gén., $5^{\mathrm{e}}$ série, 6, I-10o.

Brachet A. rgi 2. La polyspermie expérimentale dans l'œuf de Rana fusca. Arch. mikr. Anat. 79, 2. Abt., 96-II2.

BRACHET A. 1922. Recherches sur la fécondation prématurée de l'œuf d'Oursin (Paracentrotus lividus). Arch. Biol., Paris, 32, $205-248$.

Brachet A. 1931. L'œuf et les facteurs de l'ontogenèse. 4,38 pp., G. Doin et Cie, Paris.

BraCHET J. 1944. Acides nucléiques et morphogenèse au cours de la parthénogenèse, la polyspermie et l'hybridation chez les Anoures. Ann. Soc. zool. Belg. 75, 49-74.

Brachet J. I947. Embryologie chimique. 535 pp., Masson et Cie, Paris.

BRAChET J. I957. Biochemical cylology. Acad. Press, New-York.

Braus H. I895. Ueber Zellteilung und Wachstum des Triton-Eies. Jena Z. Naturw. 29, 443-5 I I.

BARY J. I9I3. Experimentelle Untersuchungen über die Einwirkung der Temperature $0^{\circ} \mathrm{C}$ auf die Entwicklung der Echinideneier. Arch. Entw.Mech. Org. 36, 537-594.

CASPERSSON T. 1950. Cell growth and cell function. $185 \mathrm{pp}$., W. W. Norton Inc. New-York. 
Clark J. M. 1936. An experimental study of polyspermy. Biol. Bull., Wood's Hole, 70, $3^{6 \mathrm{I}-384 .}$

Counce S. J. I956. Studies on female-sterility genes in Drosophila melanogaster. I. The effects of the gene deep orange on embryonic development. Z. indukt. Abstamm. Vererblehre., 87, 443-461. II. The effects of the gene fused on embryonic development. Ibid., 462-48I. III. The effects of the gene rudimentary on embryonic development. Ibid., 482-492.

CREW F. A. E. et LAMY R. I939. Mosaicism in Drosophila pseudo-obscura. J. Genet. 37, 21 I-228.

Doncaster L. I9I4. On the relations betwen chromosomes, sexlimited transmission and sex-determination in Abraxas grossulariata. J. Genet. 4, 1-21.

Driesch H. I 892. Entwicklungsmechanische Studien. V. Von der Furchung doppeltbefruchteter Eier. Z. wiss. Zool. 55, 29-34.

ELtengors A. E. et Ridinina M. I. r953. A propos des travaux de Tchou-Su et Chang-Ko sur la destinée des spermatozoïdes "surnuméraires " ayant pénétré dans l'œuf (en russe). Izvest. Akad. nauk SSSR, Ser. biol., (I), 59-65.

Fanknauser G. I925. Analyse der physiologischen Polyspermie des Tritoneies auf Grund von Schnürungsexperimenten. Arch. Entw.Mech. Org. 105, 50I-580.

Fankhauser G. 1932. Cytological studies on egr fragments of the Salamander Triton. II. The history of the supernumerary sperm nuclei in normal fertilization and cleavage of fragments containing the egg nucleus. J. exp. Zool. 62 i $85-235$.

Fankhauser G. I934a. Cytological studies on egg fragments of the Salamander 'Triton. IV. The cleavage of egg fragments without the egg nucleus. J. exp. Zool. 67, 3+9-39.3.

FankHatser G. I9.34 b. Cytological studies on egg fragments of the Salamander Triton. V. Chromosome number and chromosome individuality in the clcavage mitoses of merogonic fragments. J. exp. Zool. 68, I -57 .

FANKIIAUSER G. I945. The effects of changing in chromosome number on amphibian development. Quart. Rev. Biol. 20, 20-78.

FANkhauser G. I948. The organization of the amphibian egg during fertilization and cleavage. Ann. N. Y. Acad. Sci. 49, 684-708.

Fankhauser G. I952. Nucleo-cytoplasmic relations in amphibian development. Inl. Rev. Cylol. 1, I65-I 93.

FankinuSer G. 1955. The nucleus and cytoplasm in development. In : Willier B. HI., Weiss P. A. et Hamburger V., Analysis of development, 126-1 29, W. B. Saunders Co., Philadelphia.

Fankilauser G. et MoOra C. Ig4 I a. Cytological and experimental studies of polyspermy in the newt, Triturus viridescens. I. Normal fertilization. J. Morph. 68, 347-385.

Fankhauser G. et Moore C. I94I $b$. Cytological and experimental studies of polyspermy in the newt, Triturus viridescens. II. The behaviour of the sperm nuclei in androgenetic eggs (in the absence of the egg nucleus). J. Morph. 68, $387-423$.

FICK R. 1893. Veber die Reifung und Befruchtung des Axolotleies. Z. wiss. Zool. 56, 529-614.

Fol II. I 877 . Sur quelques fécondations anormales chez l'Etoile de mer. $C$. $R$. Acal. Sci., Paris, 84, 659$66 \mathrm{I}$.

Gemmill J. J. igoo. On the vitality of the ova and spermatozoa of certain animals. J. Anat., Lond., 34, $163-181$.

Ginzburg A. S. i953. Troubles de développement chez l'Esturgeon en liaison avec les conditions de la fécondation (en russe). Dokl. Akad. Nauk SSSR, 92, 1097-1 roo.

Ginzburg A. S. I957. Monospermie chez l'Esturgeon dans la fécondation normale et conséquences de la pénétration dans l'œuf de spermatozoïdes surnuméraires (en russe). Dokl. Akad. Nauk SSSR, 114, $445-447$.

Glass B. et Plaine H. L. I950. The immediate dependence of the action of a specific gene in Drosophila melanogaster upon fertilization. Proc. nat. Acad. Sci., Wash., 36, 627-634.

GLASS B. I957. In pursuit of a gene. Science, 126, 683-689.

GoDlewski E. I9I I. Studien über die Entwicklungserregung. I. Combination der heterogenen Befruch. tung mit der künstlichen Parthenogenese. Arch. EntwMech. Org. 33, 196-254.

GoDlEWSKi E. I913. Polyspermie. In : Winterstein II., Handbuch der vergleichenden physiologie, vol. 3 (2), 888-903, G. Fischer, Jena.

GodLEWSKI E. I 934. Nouvelles recherches sur l'hétéroagglutination des spermatozoïdes et sur l'action d'extraits de cellules sexuelles d'espèces étrangères. Arch. Biol., Paris, 45, 735-807.

Gol.DSCHMIDT A. et KATSUKI K. I931. Vierte Mitteilung über erblichen Gynandromorphismus. Biol. Zbl. 51, 58-74.

GRASSE P.-P. 1941. La reproduction sexuée et l'analyse expérimentale de la fécondation. $244 \mathrm{pp}$, Les cours de Sorbonne ", Paris.

HaGSTRöM B. I956 a. Studies on polyspermy in sea urchins. Ark. Zool. 10, 307-315.

HAGSTRÖM B. 1956 b. The role of the jelly coat and the block to polyspermy in the fertilization of sea urchins. 20 pp., Almquist et Wiksells, Uppsala.

HAGströ̀ B. et AllEN R. D. I956. The mechanism of nicotine induced polyspermy. Exp. Cell Res. $10, \mathrm{I}_{4}-23$.

Hagström, B. et Hagström, B. i954. Re-fertilization of the sea urchin egg. Exp. Cell. Res. 6, $49 \mathrm{I}-496$.

HENKING H. 1892. Untersuchungen über die ersten Entwicklungsvorgänge in den Eiern der Insekten. III. Specielles und allgemeines. Z. wiss. Zool. 54, I-274.

Herlast M. IgII. Recherches sur les cufs di- et trispermiques de grenouille. Arch. Biol., Paris, 26, Io3-

HERTwig O. I875. Beiträge zur Kenntniss der Bildung, Befruchtung und Theilung des thierischen Eies. Morph. Jb. 1, 347-434.

Hertwig O. I878. Beiträge zur Kenntniss der Bildung, Befruchtung und Theilung des thierischen Eies. Dritter Theil. Morph. Jb. 4, I56-I 75 et I $77-213$. 
Hertwig O. I890. Experimentelle Studien am tierischen Ei vor, während und nach der Befruchtung. Jena Z. Naturio., 24, 268-313.

Hertwig O. et HerTwig R. I887. Ueber den Befruchtungs- und Teilungsvorgang des tierischen Eies unter dem Einfluss äusserer Agentien. Jena Z. Naturv. 20, i 20-24I et 477-5 10.

Hertwig P. 19i6. Durch Radiumbestrahlung verursachte Entwicklung von halbkemiger Triton-und Fischembryonen. Arch. mikr. Anat. 87, 63-г22.

HeteTneR A. F. 1927. Irregularities in the early development of the Drosophila melanogaster egg. $Z$ Zellforsch. 4, 599-6ro.

Jenkinson J. W. 1905. Observations on the maturation and fertilization of the egg of the axolotl. Quart. J. micr. Sci. 48, 407-482.

JoRdax E. O. I893. The habits and development of the newt (Diemyctylus viridescens). J. Morph. 8, 269-366.

KAYLOR C. T. I94I. Studies on experimental haploidy in salamander larvae. II. Cytological studies on androgenetic eggs of Triturus viridescens. Biol. Bull., Wood's Hole, 81, 402-4I9.

KERR W. E. et LAidlaw H. H. r956. General geneti's of bees. Advanc. Genet. 8, rog-I 53.

Klpelwieser H. Igog. Entwicklungserregung bei Seeigeleiem durch Molluskensperma. Arch. EntwMech. Org. 27, 434-462.

Kupelwieser H. I9I2. Weitere Untersuchungen über Entwicklungserregung durch stammfremde Spermien, insbesondere über die Befruchtung der Seeigeleier durch Wurmsperma. Arch. Zellforsch. 8, 352-395

Lighissa S. 195x. Fusioni sperimentali di uova vergini di Ascidia (Ascidia malaca, Phallusia mammillala) Ric. sci., 21, $216-22 \mathrm{I}$.

Lillie F. R. igrg. Problems of fertilization. University of Chicago Press, Chicago.

Makarov P. V. I95.3. Processus cytologiques de la fécondation chez l'Ascaris du Cheval (en russe). Izv. Akad. Nauk SSSR, Ser. biol., (1), 46-58.

Michaelis L. I897. Die Befruchtung des Tritoneies. Arch. mikr. Anat. 48, 523-544.

Montgomery T. H. I908. On the maturation mitoses and fertilization of the egg of Theridium. Zool. Jb. (Abi. Anat. Ont.) 25, 237-250.

Moore J. A. I955. Abnormal combinations of nuclear and cytoplasmic systems in frogs and toads. Advanc. Genet. 7, I39-182.

Morgan I. V. I929. Composites of Drosophila melanogaster. Publ. Carneg. Inst. n 399, 223-296.

MoRGAN 'T. H. I905. An alternative interpretation of the origin of gynandromorphous insects. Science, 21, $632-634$.

Nachtsheim H. rgr3. Cytologische Studien über die Geschlechtsbestimmung bei der Honigbiene (Apis mellifera L.). Arch. Zellforsch. 11, 169-241.

Nicolas A. Igoo. Recherches sur l'embryologie des Reptiles. II. Contribution à l'étude de la fécondation chez l'Orvet. Arch. Anat. micr. 3, 457-489.

Nicolas A. I904. Recherches sur l'embryologie des Reptiles. IV. La segmentation chez l'Orvet (Anguis fragilis). Arch. Biol., Paris 20, 6 I I-658.

OPPEL A. I892. Die Befruchtung des Reptilieneies. Arch. mikr. Anat. 39, $215-290$.

Pasteels J. J. 1956. La polyspermie chez les Lacertiliens. Arch. Biol., Paris, 67, 513-522.

Perlmann P. et Hagström B. 1957 . Cortical inhibitions and polyspermy in antiserum treated sea urchin eggs. Exp. Cell. Res. 12, 4 I8-421.

Persov G. M. r954. Polyspermie chez l'Esturgeon (en russe). Dokl. Akad. Nauk SSSR, 97, ro93-1095.

Ricilards A. G. et Miller A. I937. Insect development analyzed by experimental methods : a review. Part I. Embryonic stages. J. N. Y. ent. Soc. 45, r-6o.

Rose M. r93I. Recherches sur la fécondation chez l'Oursin, Paracentroltus lividus L. C.R. Soc. Biol., Paris, $10 \%, 83 \mathrm{I}-834$.

Rotienbuhler W. C. et Gowen J. W. 1955. Chromosomal localization of the hereditary basis for gynandromorph production in honey bees (Apis mellifera L.). Gentics, 40, 592-593.

Rothenbuhler W. C., Gowen J. W. et Park O. W. 1952. Androgenesis with zygogenesis in gynandromorphic honeybees (Apis mellifera L.) Science, 115, 637-638.

ROTHSCHILD Lord i953. The fertilization reaction in the sea-urchin. The introduction of polyspermy by nicotine. J. exp. Biol. 30, $57-67$.

RothscrildD Lord 1954. Polyspermy. Quart. Rev. Biol. 29, 332-342.

RoTHSCHIL Lord I956. Fertilization. I 79 pp., Methuen and Co. Ltd., London.

Rückert J. r8gr a. Ueber die Befruchtung bei Elasmobranchiern. Verh. anat. Ges., 5. Vers., München, 253-254.

RüCKERT J. I89r b. Zur Befruchtung des Selachiereies. Anat. Anz. 6, 308-322.

Rückert J. i892. Ueber physiologische Polyspermie bei meroblastischen Wirbeltiereiern. Anat. Anz. 7, 320-333.

RüCKERT J. I899. Die erste Entwicklung des Fïies der Elasmobranchier. Festschr.'zum 7o. Geburtstag von Carl von Kupffer., Jena, 581-704.

RüCKert J. rgro. Ueber Polyspermie. Anat. Anz. 37, r6r-18r.

SAMPSON M. M. 1926. Sperm filtrates and dialyzates. Their action on ova of the same species. Biol. Bull., Wood's Hole, 50, 301 -338.

Smiti H. et Clowes G. H. A. 1924. The influence of hydrogen ion concentration on the fertilization process in Arbacia, Asterias and Chaetopterus eggs. Biol. Bull., Wood's Hole, 47, 333-344.

Sonnenblick B. P. I950. The early embryology of Drosophila melanogaster. In : Demerec M., The bio$\log y$ of Drosophila, 62-167, John Wiley and Sons, Inc., New-York.

SPEICHER B. R., r936. Oogenesis, fertilization and early cleavage in Habrobracon. J. Morph., 59, 4or-42r.

Strassen O. zur i898. Ueber die Riesenbildung bei Ascariseiern. Arch. EntwMech. Org. 7, 642-676.

Sugryama M. r95I. Re-fertilization of the fertilized eggs of the sea urchin. Biol. Bull., Wood's Hole, 101, 335-344. 
TANAKA Y. I953. Genetics of the silkworm, Bombyx mori. Advanc. Genet. 5, 239-317.

Tsou-SU I953. L'insémination hétérospermique chez le ver à soie et sa signification au point de vue de l'hérédité (en russe). Izv. Akad. Nauk SSSR, Ser. biol., (5), 55-62.

TCHOU-SU et CHANG-Ko I949 et I95 r : cit. Ellengorn et Riabiaina 1953.

Tsou-su et Chen-ChaO-HSI 1942. Fertilization of artificially ovulated premature eggs of Bufo. Sci. Rec., Chungking, 1, 203-208.

Tyler A. I948. Fertilization and immunity. Physiol. Re\%. 28, 180-219.

Tyler A. r955. Gametogenesis, fertilization and parthenogenesis. In: Willier B. H., Weiss P. A. et Iamburger V., Analysis of development, I $70-2 \mathrm{2} 2$, W. B. Saunders Co., Philadelphia.

Trler A., Monroy A. et MIETz C. B. 1956. Fertilization of fertilized sea urchin eggs. Biol. Bull., Wood's Hole, 110, I84-195.

Tyler A. et SCHultz J. 1932. Inhibition and reversal of fertilization in the eggs of the echiuroid worm, Urechis caupo. J.exp. Zool. 63, 509-532.

VAN BENEDEN E. I 875 . La maturation de l'œuf, la fécondation et les premières phases du développement embryomaire des mammifères d'après des recherches faites chez le Lapin. Bull. Acad. roy. Soc., Belg. 40, 686-736.

VAN Benteden E., 1883. Recherches sur la maturation de l'cuf et la fécondation. Ascaris megalocephala. Arch. Biol., Paris, 4, 265-640.

Waddington C. H. 1956. Principles of embryology. 5 I o pp., George Allen and Unwin, London.

Whitixg P. W. 1928. Mosaicism and mutation in Habrobracon. Biol. Bull., Wood's Hole, 54, $300-302$.

Whiting P. W., I943. Androgenesis in the parasitic wasp IIabrobracon. J. Hered., 34, 335-366.

Wigglesworth V. B. 1947. The principles of Insect physiology. 436 pp., $3^{\text {rd }}$ ed., Methuen and Co. Ltd. London.

WILsoN B. 1925. Monospermy, dispermy, polyspermy. In: The cell in development and heredity, pp 416422, Macmillan, New-York.

WiTsCHI E. I956. Development of Vertebrates. 588 pp., W. B. Saunders Co., Philadelphia. 


\section{LA POLYSPERMIE CHEZ LES OISEAUX ET LES MONOTRÈMES}

L'œuf des Oiseaux et des Monotrèmes, comme celui des Sélaciens et des Reptiles, est mégalécithe ; sa segmentation est discoïdale. La fécondation est normalement polyspermique, sauf peut-être chez les Monotrèmes, et des observations indi- rectes ont attiré l'attention sur la possibilité de l'influence des spermatozoïdes surnuméraires sur le développement et la composition du corps de l'embryon. Aussi, traiterons-nous d'abord de l'aspect cytologique de la fécondation et ensuite nous passerons en revue les observations indirectes relatives à ce deuxième aspect.

\section{A. - OisEaux \\ I - Observations cytologiques.}

HARPER (I904) fut le premier à étudier les détails cytologiques de la maturation, de la fécondation et des premiers stades de la segmentation chez les Oiseaux, notamment chez le Pigeon. La pénétration des spermatozoïdes dans le disque germinatif se produirait immédiatement après l'ovulation; l'œuf renfermé dans l'infundibulum contient de nombreuses têtes spermatiques à des stades précoces de transformation ; quelquefois elles ont déjà subi un changement considérable, ce qui montre la rapidité du développement des têtes spermatiques en pronucléi.

Le nombre des spermatozoïdes ayant pénétré dans 1'œuf de Pigeon varie de I2 à 25. L'entrée des spermatozoïdes peut s'effectuer en n'importe quelle région du disque germinatif ; cependant, ils paraissent entrer plus nombreux dans une zone hyaloplasmique autour du noyau femelle et leur transformation y est plus rapide.

HARPER (Ig04) signale également la présence de nombreuses cellules larges (ainsi que des érythrocytes) dans l'espace périvitellin; celles-ci seraient d'origine folliculaire et se distingueraient des noyaux spermatiques par leur forme et leurs dimensions.

Il n'a jamais vu plus d'un spermatozoïde dans le voisinage immédiat du noyau femelle et apparamment un seul noyau spermatique s'unit à celui-ci.

Les noyaux surnuméraires, à leur tour, s'éloignent du noyau amphimictique vers la périphérie du disque. La rapidité et la précocité de leur déplacement laissent supposer qu'il s'agit - d'après HARPER - plutôt d'une migration active que d'un refoulement par la sphère du noyau amphimictique (à la différence des Sélaciens).

Les noyaux surnuméraires peuvent se diviser ; leur division précède même celle du syncaryon. C'est ainsi, qu'au moment du stade deux blastomères le nombre des noyaux surnuméraires peut s'élever jusqu'à une centaine. Cette activité mitotique 
est indiquée par la présence de sillons accessoires à la surface de l'œuf, au bord du blastodisque. Le clivage accessoire serait provoqué par la deuxième division mitotique des noyaux surnuméraires au moment où le premier sillon du clivage embryonnaire devient visible. A ce stade, les noyaux surnuméraires sont entourés par un large territoire cytoplasmique dépourvu de granules vitellins ( ( substance sphérique »). Ia "substance sphérique " serait le centre de la formation d'éléments "plastiques" et nutritifs.

La mitose des noyaux surnuméraires se déroulerait d'une façon normale, au moins au début de la segmentation ; le fuseau et les centrosomes sont bien développés et le nombre haploïde des chromosomes se retrouve à chaque division.

En ce qui concerne les stades plus avancés, les observations de HARPER (Ig04) sont incomplètes et ne permettent pas de se faire une image nette du sort ultérieur des noyaux surnuméraires. Ceux-ci se retrouveraient encore $I_{5}$ heures après la fécondation, refoulés dans le vitellus alentour et formant des "nids ". Les figures de division à ce stade seraient plus ou moins anormales ; fusion ou désintégration des noyaux, amitose, caryolyse pourraient être observées. Il y aurait aussi des noyaux " géants " au repos, et de caractéristiques " corps réfractifs " en forme de vésicule ou de bâtonnet. Il y a donc lieu de supposer que les noyaux surnuméraires subissent finalement une désintégration et une dissolution ; les produits de cette activité caryolytique seraient sans doute absorbés par les cellules embryonnaires. Par contre, HARPER (I904) n'a jamais pu observer l'incorporation directe des novaux "vitellins " dans le territoire du clivage embryonnaire, les blastomères marginaux restant toujours bien séparés du vitellus.

Blount (Igog) a consacré une étude spéciale à la destinée des spermatozoïdes surnuméraires, également chez le Pigeon, en examinant une série d'œufs prélevés à différents intervalles après la fécondation. Ses observations confirment l'essentiel des constatations de HARPER sur la migration précoce (qui pourrait être due - selon BLount - à l'attraction du cytoplasme périphérique non fécondé) et sur la division des noyaux spermatiques ; le nombre de ceux-ci augmente considérablement jusqu'au stade de 8 à 16 blastomères comme le montrent les nombreux sillons accessoires. Ils se situent alors aux bords du disque germinatif ou dans le périblaste central (le périblaste est la zone qui sépare le blastodisque du vitellus de l'œuf ; il contient très peu de granules cytoplasmiques. D'après BLount I909, le périblaste serait analogue au pôle végétatif des œufs holoblastiques des Vertébrés).

Les noyaux surnuméraires disparaîtraient complètement Io à I2 heures après la fécondation (c'est-à-dire au stade 32 cellules).

BLount (IgOg) insiste sur le fait que les cellules résultant du clivage primaire restent toujours distinctement séparées de la région du clivage accessoire, par un cloisonnement périphérique et ventral des blastomères marginaux. Par contre, en l'absence de clivage accessoire ou après la disparition des noyaux spermatiques, les blastomères marginaux s'ouvrent vers le vitellus; leurs noyaux migrent dans le périblaste et forment une "zone de jonction " entre ce dernier et le blastodisque, comme on l'observe chez les Téléostéens.

Blount (I909) rend compte également de l'existence de noyaux, observés quelquefois en nombre considérable, dans l'espace périvitellin ou dans les sillons du clivage accessoire. Ils ne se trouvent que dans environ un tiers des œufs examinés entre 4 et $\mathrm{I}_{5}$ heures après la fécondation et sont particulièrement nombreux dans le région 
du périblaste. Après cette période ils dégénèrent mais quelques noyaux peuvent subsister 39 heures après la fécondation. L,eur origine reste inexpliquée, mais BLoUNT suppose qu'ils sont probablement d'origine spermatique ; peut-être proviendraientils des noyaux spermatiques ayant pénétré tard par la membrane vitelline.

En ce qui concerne le rôle possible des spermatozoïdes surnuméraires, BLounT (Igog) estime qu'ils n'accomplissent aucune fonction essentielle. S'il est vrai qu'ils semblent bien digérer le vitellus alentour, leur présence est une question de chance et n'est nullement indispensable pour le développement de l'œuf.

PatTterson (Igro) a étudié la cytologie de la fécondation et des stades précoces de développement chez la Poule. Chez cette espèce, en général 5 ou 6 spermatozoïdes pénètrent dans le blastodisque mais il a pu observer 25 noyaux surnuméraires dans un œuf récemment fécondé et d'apparence tout à fait normale. La destinée des noyaux spermatiques est variable suivant leur position. Une partie d'entre eux (ou peutêtre tous en certains cas) descendent dans les couches profondes du disque ; ici, après s'être divisé deux fois, ils peuvent former des "nids " contenant quatre noyaux. Mais leur division s'arrête d'une façon précoce et, après fragmentation, ils disparaissent complètement.

D'autre part, les noyaux spermatiques restant plus en surface, ont tendance à migrer vers la périphérie du disque, comme chez le Pigeon. En arrivant dans le périblaste, ils peuvent déclencher la formation de quelques sillons accessoires qui font leur apparition au stade de quatre blastoméres. PA'TTERSON (I9IO) a observé deux œufs où le clivage accessoire aboutissait à la formation de petites cellules, entièrement séparées.

Mais ce clivage accessoire rudimentaire s'efface peu après le stade huit blastoméres (environ 7 heures après la ponte précédente). Sa disparition est parallèle à la dégénérescence des noyaux surnuméraires, processus qui s'achève au stade 32 cellules.

Le caractère rudimentaire du clivage accessoire et la dégénérescence précoce des noyaux surnuméraires font penser (PATTERSON IgIo) qu'une participation éventuelle des cellules accessoires à la formation de l'embryon est encore moins problable que chez le Pigeon.

PATTERSON (IgIO) signale également la présence de nombreux spermatozoïdes " supplémentaires " (jusqu'à une centaine), adhérant à la membrane vitelline, ou bien quelquefois renfermés dans celle-ci. Leur nombre est plus grand dans la région du centre du disque, il diminue vers la périphérie et aucun spermatozoïde ne se trouve au delà du périblaste. Cette observation montrerait que les spermatozoïdes sont attirés vers le blastodisque et que cette attraction cesse subitement.

VAN DURme (IgI4) rend compte de recherches sur la fécondation et le début de la segmentation, chez la Poule, le Pigeon, l'Hirondelle et le Moineau. L'auteur ne signale aucune différence substantielle entre les caractères de la fécondation chez ces espèces. Des noyaux accessoires, provenant évidemment des têtes de spermatozoïdes surnuméraires, peuvent être observés dès le début de la segmentation. Ils siègent à la périphérie du disque germinatif, près de la surface du vitellus et sont, en général, plus petits et moins chromatiques que ceux provenant des pronucléi conjugués. Leur nombre n'est cependant jamais aussi considérable que celui observé par HARPER (Ig04) chez le Pigeon et ils pourraient même être complètement absents. 
L'ovoplasme entourant les noyaux spermatiques peut subir une segmentation incomplète, avec formation des sillons accessoires. VAN DURME n'écarte pas la possibilité que ces éléments accessoires puissent véritablement s'incorporer au disque segmenté ; mais leur évolution aux stades plus avancés n'a pas été suivie.

Selon Or,sen (I942), l'œuf de Poule est pénétré, en général, par 3 ou 4 spermatozoïdes; leur pénétration s'effectue normalement dans l'infundibulum, immédiatement après l'ovulation. Dans un œuf obtenu I 5 minutes après le temps supposé de l'ovulation (45 minutes après la dernière oviposition), les spermatozoïdes auraient déjà atteint un stade avancé du développement en pront1cléi. Des sillons rudimentaires du clivage accessoire sont visibles dans les stades de 4 à 8 blastomères $(5$ à 6 h. I / 2 après la fécondation), mais leur présence n'est pas constante. Le devenir des noyaux surnuméraires ne fut pas examiné.

Des sillons accessoires (jusqu'à 8 à Io) ont été également observés dans l'œuf de Dinde, indiquant la possibilité de fécondation polyspermique chez cette espèce (OLSEN et FRAPS, I945).

Tout récemment, BEKH'TINA a repris l'étude de la fécondation chez la Poule. Les travaux publiés jusqu'ici (BEKHTINA, I95 $8 \mathrm{a}, \mathrm{b}$ ) portent sur l'examen d'environ 90 œufs, dont une cinquantaine à des stađes précoces de développement (jusqu'à 5 heures après l'ovulation). Les cufs provenaient de poules constamment avec des coqs (I coq pour Io poules).

Selon BEKhtina (I958 b), de nombreux spermatozoïdes (maximum 40o) pénètrent dans la région du disque, pendant une période de Io à 30 minutes après l'ovu1ation. La plupart d'entre eux restent bloqués dans la membrane vitelline (ce qui est en accord avec l'observation de PATTERSON I9Io), mais ils se trouvent également dans l'espace périvitellin et dans le cytoplasme superficiel.

Malheureusement, BEKHTINA n'a pu suivre ni la transformation des têtes spermatiques, ni le développement des pronucléi. Elle signale cependant la présence de corps caractéristiques " ressemblant à des noyaux " qui se trouveraient surtout dans la région périphérique du disque. Ils pourraient être observés, en nombre allant de Io à 50 , dès les stades les plus précoces de la pénétration des spermatozoïdes et ensuite à n'importe quel stade au cours du passage de l'œuf dans l'oviducte; par contre, ils seraient absents des œufs non fécondés. Leur origine reste inexpliquée. Il n'y a pas de renseignements précis non plus, sur la provenance des noyaux véritables (quelquefois en groupes) qui s'observent entre les blastomères ou dans le périblaste des œufs aux stades plus avancés.

BEKHTINA (I958 a, b) décrit également la présence de spermatozoïdes inchangés dans le blastodisque, pendant toute la période de clivage de l'œuf. Ils se trouveraient en nombre assez considérable dans l'espace périvitellin, entre les sillons de clivage, dans la cavité sous-germinale, et dans une moindre mesure, dans le cytoplasme ou même incorporés à l'intérieur des blastomères (l'auteur a pris garde aux artefacts). Ces spermatozoïdes non transformés subiraient finalement tune désintégration directe. Des spermatozoïdes plus ou moins modifiés sont fréquemment observés aussi dans le voisinage des cellules folliculaires (sur la surface extérieure de la membrane vitelline), ou même semble-t-il à l'intérieur de celles-ci.

Mentionnons encore les observations de LECAILLON (IgIO) sur la segmentation parthénogénétique de l'œuf de Poule. L'auteur signale la présence de nombreux noyaux cellulaires (généralement en dégénérescence) dans la partie non-segmentée du 
disque, à une petite distance des blastomères marginaux. Le stade avancé des œufs examinés (après la ponte) et le caractère abortif de la segmentation parthénogénétique rendent impossible toute comparaison de ces noyaux avec les noyaux supplémentaires d'origine spermatique.

\section{2 - Observations indirectes sur l'effet des \\ spermatozoides surnuméraires (mosaique, bipaternité).}

HOLI.ANDER (I944) donne une revue exhaustive des mosaïques chez les oiseaux domestiques. Des mosaïques dites "sectorielles" (avec une asymétrie plus ou moins distincte des caractères observés) ont été décrites chez la Poule, le Pigeon, le Dindon, la Perruche et le Canari. La presque totalité des oiseaux présentant des mosaïques provenait de croisements. Parmi les causes possibles du développement de ces mosaiques, l'auteur n'exclut pas la polyspermie : un œuf binucléé pourrait être fécondé par 2 spermatozoïdes ou bien certaines régions du corps pourraient se développer à partir de spermatozoïdes surnuméraires.

L'hypothèse d'une participation éventuelle des spermatozoïdes surnuméraires à la formation de tissus embryonnaires fut corroborée récemment par une étude morphologique, généalogique et génétique de sept cas de mosaïques "sectorielles " de Pigeon (Hollander I949). Dans tous les cas, la mosaïque portait sur des gênes de couleur liés au sexe. Les explications habituelles (à savoir : mutation et ségrégation somatiques, non-disjonction) ou même la fécondation double d'un œuf binucléé, parraissaient exclues ou peu problables. L'auteur présume que des noyaux surnuméraires, leur diploïdie rétablie, pourraient échapper à la dégénérescence et s'intégrer au corps de l'embryon comme une greffe. Cependant, la présence de tissus d'origine androgénétique passe inaperçue à moins qu'ils ne diffèrent du reste du corps par un caractère morphologique aisément reconnaissable. L'examen de la descendance a montré que la mosaïque peut s'étendre au tissu germinatif. Une prédisposition héréditaire à la production de mosaïques serait possible. Certains cas de mosaïques "énigmatiques " comme les oiseaux décrits par ROBERTS et QUISENBERRY (I935) et par VECCHI (I936), ainsi que par Asmundson (I937) (dindon) pourraient être expliqués par le développement d'îlots androgénétiques.

HOLIANDER (I949) estime que la fréquence de mosaïques "sectorielles " nettes est de 1'ordre d'un pour mille chez les oiseaux issus de croisements. Enfin, il recommande une étude expérimentale de la théorie de la " bipaternité " par le moyen d'inséminations mixtes avec du sperme de mâles de races différentes.

GREENWOOD et BLYTH (I95I) ont décrit deux coqs, provenant du croisement Light Sussex (femelle) X Rhode Island (mâle) et présentant une asymétrie bilatérale. L'examen génétique de la descendance a montré que le tissu germinatif était également du type mosaïque. Aucune théorie n'explique d'une manière convaincante l'origine de ces coqs ; cependant le développement d'une moitié du corps à partir de spermatozoïdes surnuméraires n'a pas été exclu.

BLYTH (I954) décrit une poule avec une asymétrie latérale, fille d'un des coqs mentionnés ci-dessus et d'une poule Leghorn dorée. L'ovaire était également du type mosaïque, contenant en partie du tissu pur Leghorn doré. On peut supposer qu'une moitié du corps de la poule mosaïque serait d'origine purement maternelle, peut-être par rétention d'un globule polaire. Il est intéressant de noter cependant que les fils, 
Leghorn doré, de la Poule mosaïque issus de fécondation par des mâles Leghorn doré purs, ont montré quelques déviations du type standard de la race Leghorn doré par leur poids vif plus élevé et par la couleur de leur plumage plus foncée. D'après BLYTH (I954) ces différences pourraient être dues au milieu maternel, composé pour moitié de tissus d'une race lourde.

Un cas de mosaïque irrégulière chez la Poule, vient d'être signalé par Cock (I959). La poule mosaïque provenait d'un croisement entre L,eghorn blanche (mère) X Rhode Island (père). Une mutation somatiqueou des aberrations chromosomiques paraissant improbables, l'auteur conclut à l'incorporation dans le corps de l'embryon d'un ou plusieurs noyaux spermatiques. Selon les résultats du testage génétique, l'ovaire de cette poule n'était apparemment pas de type mosaïque.

Les effets d'accouplements ou d'insémination mixtes furent étudiés récemment par plusieurs auteurs russes. Des poules Leghorn blanches furent inséminées avec du sperme mixte de coqs Australorp et New-Hampshire (MERkURIEvA, I95 I a et b). Une cinquantaine de poussins $\mathrm{F}_{1}$ ont été obtenus dont quelques-uns auraient montré à la fois des caractères des deux coqs : par exemple plumage avec une teinte fauve (New Hampshire), bec et pattes ardoisées (Australorp).

LEBEDEV (I95I, I954) a étudié la descendance de Io poules New-Hampshire, saillies une fois tous les 2 jours, et à intervalle de 5 à ro minutes, par des coqs Australorp et Wyandotte (témoin : deux groupes de deux poules New-Hampshire, saillies par un coq Australorp ou par un coq Wyandotte seul). Il a obtenu 5 I poussins expérimentaux qui ne différaient en aucun point des témoins ; 25 d'entre eux provenaient du coq Australorp (plumage noir, crête simple) et $26 \mathrm{du}$ coq Wyandotte (plumage blanc et doré, crête rose " dans la plupart des cas "). En reproduisant entre eux les oiseaux $F_{1}$ à l'intérieur de chaque groupe, il est apparu que beaucoup de poussins $\mathrm{F}_{2}$ (appréciation aussitôt après l'éclosion) montraient des caractères du deuxième père (couleur du plumage et dans une moindre mesure, forme de la crête), caractères qui étaient demeurés "cachés " chez les $F_{1}$. Cette " ségrégation " se serait observée chez la plupart des poules $F_{1}$. L'auteur suppose que, dans les saillies doubles, les deux pères pourraient participer aux potentialités héréditaires de la descendance grâce à " l'assimilation mutuelle des gamètes » au cours de la fécondation.

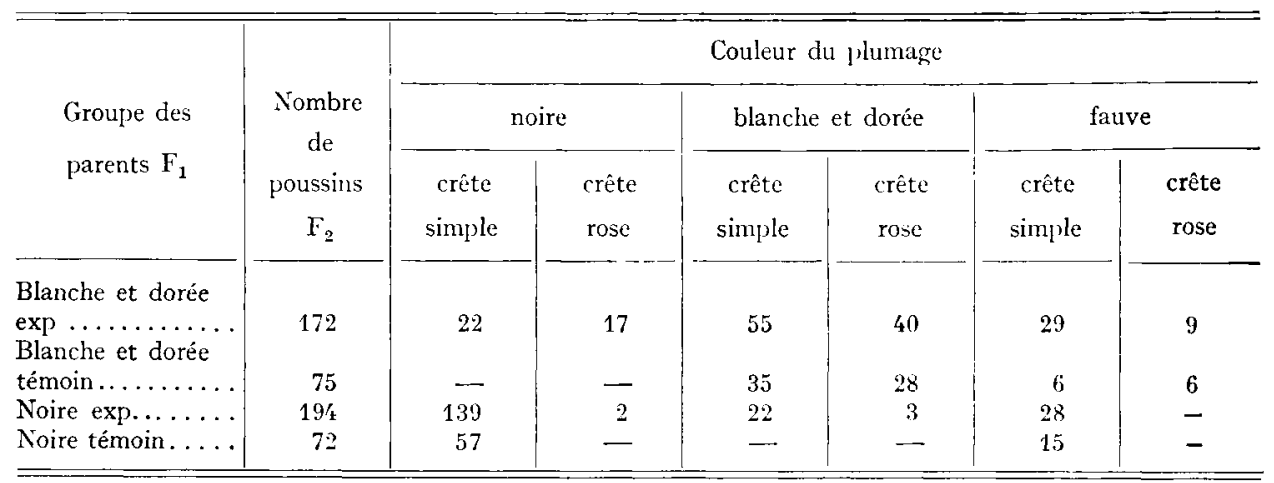

Dans une expérience de Kushner (I954) deux groupes de poules Leghorn blanche (22 poules par groupe) ont été saillies toujours par le même coq (groupes témoins), 
tandis que dans un troisième groupe les 2 mêmes coqs ont servi successivement (groupe hétérospermique). Les poussins obtenus dans le groupe hétérospermique auraient montré une vitalité accrue et un développement plus rapide par rapport aux poussins témoins. L'auteur suppose que les spermatozoïdes surnuméraires pourraient jouer un rôle actif dans le métabolisme de l'œuf fécondé et que ce métabolisme serait intensifié en présence de spermatozoïdes d'origine différente. Mais, comme Thibault (1956) 1'a fait remarquer, la croissance des poussins hétérospermiques et a fortiori celle des poussins témoins sont sensiblement inférieures à la vitesse de croissance habituellement admise dans cette race.

Dans une deuxième expérience (KusHNER, I954) a introduit simultanément dans un lot de poules Leghorn blanche des coqs de trois races différentes: Australorp, Plymouth-rock barée et Leghorn blanche. Trois types de poussins $F_{1}$ furent obtenus, dont chacun aurait une vitalité et un poids vif supérieurs à ceux des croisements simples ou bien à ceux des Leghorns de race pure (non "hétérospermiques "). Les produits $F_{1}$ de phénotype Leghorn ont été reproduits entre eux et ont fourni plusieurs centaines de descendants ; ces derniers ont toujours eu un plumage Leghorn typique.

GALPERN (I958) a étudié le croisement suivant : poules Australorp saillies par des coqs Australorp et Russe blanche. Les coqs des deux races se sont succédés soit tous les jours, soit toutes les semaines (témoins: Australorp X Australorp). Les poussin Australorp "hétérospermiques » ont montré une vitalité accrue (taux de mortalité de Io à I2 p. Ioo inférieur à celui des Australorps "purs " jusqu'à l'âge de 5 mois); l'augmentation de la vitalité a été plus évidente chez les poussins Australorp ayant immédiatement succédé, selon l'ordre de ponte des oufs, à un poussin de croisement. Par contre, aucun changement morphologique n'a pu être décélé ni chez les oiseaux " hétérospermiques " $F_{1}$, ni dans leur descendance (en les reproduisant entre eux). GALPERN (I958) fait 1'observation intéressante que la proportion de poussins malformés est considérablement plus élevée dans les deux groupes "hétérospermiques " que dans le groupe témoin ( 2,0 et 3,0 p. Ioo contre 0,2 p. IOO). Nous avons calculé avec les chiffres donnés par GALPERN que cette différence est statistiquement significative $(\mathrm{P}<0,05$ et $\mathrm{P}<0,0 \mathrm{I})$.

\section{b) MONOTRÈMES}

L'œuf des Monotrèmes, par sa structure et ses caractères de segmentation ressemble étroitement à celui des Oiseaux. Les travaux consacrés aux premiers stades de la fécondation et de la segmentation sont peu nombreux et portent sur un nombre réduit d'œufs.

GatenBy et Hill (I924) ont examiné un œuf d'Ornithorynque, supposé à un stade précoce de la fécondation. Trois corps, ressemblant aux globules polaires, se trouvaient à la surface du disque. Les noyaux mâle et femelle, ou le noyau amphimixique, n'ont pas été retrouvés. Les auteurs rendent compte, cependant, de la présence de dix noyaux "vésiculaires " (dont cinq formant un " nid ") dans la zone marginale du disque. Ils concluent qu'il s'agit de noyaux spermatiques et que, par conséquent, la fécondation serait polyspermique chez l'Ornithorynque.

FLynN et HIL, (I939) ont réexaminé cet cuf et concluent à une erreur d'interprétation. Le blastodisque aurait été arraché au cours de la préparation. Les trois globules polaires correspondraient à des blastomères restant attachés à la surface ; 
les noyaux spermatiques "surnuméraires " seraient en réalité des noyaux vitellins (mais les auteurs ne précisent pas l'origine de ces derniers).

Flynn (1930) décrit deux oufs d'Echidnés (Tachyglossus), l'un peu après la deuxième division de maturation et l'autre au moment de la fusion des pronucléi. Dans le premier, aucun noyau spermatique n'a été trouvé, malgré la présence de nombreux spermatozoïdes dans la couche albumineuse ; 1'auteur suppose cependant que l'œuf vient d'être fécondé mais qu'il est difficile de distinguer la tête spermatique à ce stade. Dans le deuxième œuf, il n'y avait aucun noyau surnuméraire dans aucune région du disque. Il conclut done que la fécondation chez les Echidnés n'est pas nécessairement polyspermique.

Cette dernière conclusion devait être confirmée, au moins pour les Echidnés, par l'examen d'une splendide série de coupes d'œufs (FLyNN et HiLL, r939). Douze œufs d'Ėchidnés furent examinés, dont six au stade pronucléi et six au début de la segmentation. Aucun noyau "surnuméraire " n'a été trouvé dans ces œufs bien qu'en général, de nombreux spermatozoïdes soient emprisonnés dans la couche albumineuse. Mais un $\mathrm{I}^{\mathrm{e}}$ œuf d'Ornythorynque était irrégulièrement divisé : à côté de 8 blastomères apparemment normaux il se trouvait, dans une région du disque, 7 petits blastomères dont certains à plusieurs noyaux et 6 petites masses de contour mal déterminé dont quelques-uns contenaient deux ou trois noyaux. Les auteurs ont pensé que cette segmentation anormale pourrait résulter d'une fécondation polyspermique.

\section{Discussion et Conclusions}

Les observations cytologiques concernant le Pigeon et la Poule, permettent les conclusions suivantes sur la fécondation chez les Oiseaux.

Le pénétration des spermatozoïdes dans l'œuf ne se fait que pendant une durée très courte après la ponte, durée probablement inférieure à 15 minutes. La fécondation est normalement polyspermique, mais le nombre de spermatozoïdes ayant pénétré dans l'œuf est différent selon l'espèce : I2 à 25 chez le Pigeon, 5 ou 6 seulement chez la Poule. Il est possible cependant, que ce nombre varie aussi selon la race, ou selon le type et la fréquence des accouplements, ce qui pourrait expliquer le chiffre considérablement plus élevé, signalé par BeKhtrNa (1958 a, b). En tout cas, le nombre limité des spermatozoïdes dans le vitellus et leur blocage apparent par la membrane vitelline, montrent l'existence d'un mécanisme défensif contre une polyspermie excessive.

La meilleure description de la tranformation, de la division et de la migration des noyaux spermatiques reste celle de HARPER (1904). Les premières divisions sont apparemment normales et provoquent la formation de sillons accessoires. Ce clivage accessoire, habituel chez le Pigeon, peut être absent chez la Poule. La rapidité du déplacement des noyaux surnuméraires vers les bords du disque a suscité l'hypothèse qu'il s'agirait, à la différence des Sélaciens, d'une migration active provoquée peutêtre par l'attraction du cytoplasme périphérique non-fécondé.

Mais la division des noyaux spermatiques devient rapidement anormale et leur sort ultime est la dégénérescence et la caryolyse. Ils disparaitraient complètement au stade 32 cellules chez le Pigeon et probablement encore plus tôt chez la Poule. Les noyaux " vitellins " qui se trouvent dans la région marginale du disque après ce 
stade se formeraient à partir des blastomères marginaux résultant de la segmentation normale (Blount, Igog).

Notons cependant que le processus de la dégénérescence et de la disparition des noyaux spermatiques n'a pas été suffisamment suivi et l'origine de certains noyaux, qui se trouvent quelquefois sous la membrane vitelline et entre les sillons de clivage, reste inexpliquée. La cytologie de la fécondation chez les Oiseaux nécessite donc de nouvelles recherches utilisant du sperme marqué (Novik, I956 ; MAmziNA, I958).

L'observation des oiseaux " mosaiques " adultes a fourni récemment des données intéressantes concernant l'effet possible des spermatozoïdes surnuméraires. Le travail soigné de Holiander (r949) sur des pigeons mosaïques rend fort probable l'hypothèse que les régions de type mosaïque peuvent être issues d'îlots embryonnaires androgénétiques provenant de spermatozoïdes surnuméraires. Les gonades peuvent être également de type mosaïque. La fréquence de mosaïques dites "sectorielles " serait de l'ordre d'un pour mille chez les oiseaux issus de croisements. Mais la diagnose des tissus androgénétiques est difficile à moins qu'ils ne diffèrent du reste du corps par un caractère morphologique distinct. Il nous semble que dans cette diagnose des méthodes immunobiologiques pourraient compléter avec avantage les méthodes utilisées jusqu'ici, c'est-à-dire l'étude morphologique, généalogique et génétique. L'individu chimère composé de tissus d'origine différente pourrait montrer des réactions immunobiologiques altérées, à l'image des parabiontes embryonnaires (v. BilingGham, Brent et MEDAWAR, I956).

Plusieurs auteurs russes ont examiné l'effet d'inséminations " hétérospermiques " (avec utilisation simultanée de coqs de races différentes) sur la descendance. Ils rendent compte d'une augmentation de la vitalité chez les poussins " hétérospermiques ", à savoir : taux d'éclosion augmenté, moindre mortalité, développement accéléré, précocité, quelquefois meilleure productivité. Il est à regretter que l'absence d'évaluations statistiques rende difficile la mesure exacte de l'amélioration de ces caractères. Les résultats favorables des inséminations " hétérospermiques " s'expliqueraient par l'effet stimulateur des spermatozoïdes surnuméraires d'origine différente sur le métabolisme de l'œuf fécondé (Kushner, I954). Cette hypothèse est soutenue par quelques observations faites chez des Insectes ( $v$. chapitre précédent). Le taux significativement élevé de poussins anormaux dans les groupes " hétérospermiques " (GALPERN I958) pourrait indiquer cependant que la présence des spermatozoïdes surnuméraires peut dérégler le processus normal de développement.

Aucun changement morphologique n'a été observé dans la plupart des expériences sur l'effet " hétérospermique ". Une exception notable est l'expérience de LEBEDEV (I95I, I954) ou la bipaternité se serait manifesté dans la deuxième génération. En fait la ségrégation obtenue par LEBEDEV est surprenante et semble difficile à expliquer (par exemple, par l'état mosaïque des gonades chez les individus $F_{1}$ ) faute d'une étude génétique plus approfondie. Il nous semble que ces résultats sont de caractère exceptionnel et qu'ils doivent être acceptés sous réserve jusqu'à vérification ultérieure.

En ce qui concerne les Monotrèmes, il semble bien que la fécondation est normalement monospermique chez les Echidnés. Mais rien ne prouve que cela soit vrai pour tous les Monotrèmes. Chez l'Ornithorynque deux œufs seulement ont été examinés à un stade précoce de développement et ils sont "suspects 》 de polyspermie : il est difficile de déterminer si les noyaux marginaux de l'œuf observé par GATENBY et HiL, 
(I924) sont d'origine spermatique ou bien si ce sont des noyaux "vitellins", provenant par exemple de blastomères marginaux. L'autre œuf a montré un clivage accessoire important, dû probablement à une fécondation polyspermique.

\section{RÉFÉRENCES BIBLIOGRAPHIQUES}

Asmlindson V.s., 1937. Note on a Bronze-Bourbon Red mosaic. J. Genet., 35, 25-30.

Benirtrina V. G., I958 a. Sur les caractères morphologiques de la fécondation chez la Poule (lín russe). irkh. Anal. Gist. Embr., 35, $92-100$.

Brkitina V. G., r958 b. La morphologie de la fécondation chez la Poule (En russe). Trut. pushkinsk. ninuch.-issled. Lab. Razvel. sel.-khoz. Zhiv., 8, 2 I4-229.

Bllingham R. E., Brent L. et Mronwar P. B., 1956. Quantitative studies on tissue transplantation immunity. III. Actively acquired tolerance. Phil. Trans. B, 239, 357-4I4.

Buown M., 1909. The early development of the pigeon's egg, with special reference to polyspermy and the origin of the periblast nuclei. J. Morph., 20, I-64.

BLiTH J. S. S., I954. The mosaic daughter of a mosaic cock. Poult. Sci., 33, 310-31.5.

Cock A. G., 1959. Irregular mosaicism in a hen. 7 . Hered., 50, 171-176.

FLYNN T. T., i930. On the unsegmented ovum of Echidna (Tachyglosstus). Quart. J. micr. Sci., 74, г I9-131.

Fly'N T. T. et Hill J. P., I939. The development of the Monotremata. IV. Growth of the ovarian ovum, maturation, fertilization and early cleavage. Trans. Zool. Soc. Lond., 24, 445-622.

GatPern I. L.., i958. Effet du sperme de races différentes sur la qualité de la descendance chez la Poule (lin russe). "Zh. obsch. Biol., 19, $217-225$.

Gatenby J. B. et Hill J. P., I924. On an ovum of Ornithorhynchus exhibiting polar bodies and polyspermy. Quart. J. micr. Sci., 68, $229^{-238 .}$

GreENwood A. W. et BLYTH J.S.S., I95.. Genetic and somatic aberrations in two asymetrically marked fowls from sex-linked crosses. Heredity, 5, $215-23 \mathrm{I}$.

HARPER E. H., 1904. The fertilization and early developnent of the pigeon's egg. Amer. J. Anat., 3, 349386.

Hollander W. F., i944. Mosaic effects in domestic birds. Quart. Rev. Biol., 19, 285-307.

Hollander W. F., r949. Bipaternity in pigeons. J. Hered., 40, 275-27\%.

Kushner K. F., I954. Eifficacité de la fécondation hétérospermique chez les animaux. Sa nature biologique (En russe). Izv. Akad. Nauk SSSR, Ser. biol., (1), 32-52.

LEBEDEV M. M., I95I. Fécondation polyspermique chez les animaux. (En russe). Izv. Akad. Nank SSSR, Ser. biol., (3), 63-72.

LEBEDEV M. M., I954. Quelques aspects de la reproduction chez les animaux de ferme (En russe). In: TuRBIN N. V., Problèmes de la biologie de la reproduction, zi 2-245, Univ. de Léningrad.

LE:Aillon"A., igro. La parthénogenèse chez les Oiseaux. Segmentation et dégénérescence de l'œuf nonfécondé. Arch. Anat. micr., 12, 510-638.

Manziva E.A., 1958 Accumulation du ${ }^{32} \mathrm{P}$ dans le sperme de coq. Trud. pushkinsk. nauch.-issled. Lab. Rasved. sel.-khos. Zhiv., 8, 269-S74.

MerkuRieva E. K., I9.5 I a. Caractères de la descendance obtenue après inséminations répétées et hétérospermiques chez les animaux de ferme (En russe). Agrobiol., (I), 85-98.

MerkuRieva F. K., I95I $b$. Apparition des caracteres de deux coqs dans la descendance de poules après inséminations hétérospermiques (En russe). Agrobiol., (3), 94-97.

Novik I. E., 1956. Caractère de l'accumulation du ${ }^{32} \mathrm{P}$ dans le sperme de coq. Dokl. Akad. Nauk SSSR, $107,597-599$.

OLSEN M. W., rg42. Maturation, fertilization and early cleavage in the hen's egg. J. Morph., 70, 513-533.

OLSEN M.W. et Fraps R.M., 1944. Maturation, fertilisation, and early cleavage of the egg of the domestic turkey. J. Morph., 74, 297-309.

PATTERSON J. T., I9to. Studies on the early development of the hen's egg. I. History of the early cleavage and of the accessory cleavage. J. Morph., 21, 10I-I34.

Roberts E. et QuisenberRY J. H., i 935. A Brahma-Plymouth Rock mosaic. J. Hered., 26, i I-I4.

Thibault C., I956. Quelques considérations sur la physiologie de la reproduction en rapport avec l'insé-

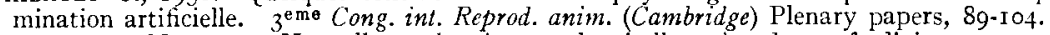

VAN DURME M., IgI4. Nouvelles recherches sur la vitellogenese des ceufs d'oiseaux aur stades d'acroissement, de maturation, de fécondation et du début de la segmentation, Arch. Biol., Paris, 29, 71-20o.

Vecchi A., i 936 . Un caso di ginandromorfismo bipartito con mosaico somatico nel pollo. Arch. Zool. (ital.), Napoli, 23, 377-395. 


\section{CHAPITRE III}

\section{LA POLYSPERMIE CHEZ LES MAMMIFÈRES}

L'œuf des Mammifères, abstraction faite des Monotrèmes, est pauvre en deutoplasme. Par conséquent, l'œuf est relativement peu volumineux : son diamètre se situe chez la plupart des espèces entre 60 et $5_{50}$ microns. Le cytoplasme de l'œuf (ou vitellus) est limité par la membrane vitelline et entouré par une membrane épaisse, transparente : la zone pellucide. Entre la membrane vitelline et la pellucide se trouve un espace plus ou moins important selon l'espèce, rempli de fluide : l'espace périvitellin.

I a fécondation chez les Mammifères est normalement monospermique : un seul spermatozoïde pénètre dans le cytoplasme de l'œuf, se transforme en pronucleus et s'unit au pronucleus femelle. Chang et Pincus (I95I) dans leur revue sur la fécóndation chez les Mammifères affirment (p. I4) : "L'entrée de plus d'un spermatozoïde dans l'ovoplasme in vivo n'a jamais été authentiquement observée ". Cependant les anciens auteurs signalent déjà chez plusieurs espèces la présence - quoique rare - de trois pronucléi et l'expliquent parfois par une fécondation dispermique, sans toutefois apporter des preuves cytologiques indubitables.

En fait, ce n'est que récemment que la fécondation polyspermique chez les Mammifères fut établie d'une façon exacte, surtout grâce aux travaux de AusTIN et ses collaborateurs. A ce jour, la polyspermie a été décrite chez la plupart des animaux de laboratoire et parmi les animaux domestiques chez la Truie.

Dans les pages qui suivent, nous passerons en revue les observations sur la fréquence de la polyspermie chez les différentes espèces dans des conditions naturelles; les facteurs et les conditions expérimentales pouvant influencer sur la fréquence de la polyspermie et les données sur la morphologie et la destinée des œufs polyspermiques.

\section{a) POLYSPERMIE NATURELIA}

Ce résumé comprend, en ordre chronologique selon l'espèce, non seulement les cas de polyspermie sure mais aussi les œufs trinucléés d'origine incertaine. Nombre de ces derniers proviennent probablement d'une fécondation polyspermique; leur fréquence peut donc servir comme base d'estimation chez les espèces où la polyspermie n'a pas encore été observée d'une façon exacte. (Les critères de polyspermie et les mécanismes qui peuvent aboutir à des œufs trinucléés sont discutés par Austro et Bishop I957 b, p. 327).

$$
\text { I. - Rat }
$$

TAFAnI (1889) a examiné des œufs de I50 femelles, récupérés dans les 50 heures qui suivent la copulation; l'examen a été fait soit sur l'œuf vivant, soit sur l'œuf fixé et coloré (carmine boracique) in toto, soit enfin sur l'œuf en coupes sériées. Il 
a signalé deux œufs avec trois pronucléi et selon lui "dans l'un des cas on pouvait regarder comme certain que deux pronucléi étaient de provenance mâle ". En tenant compte des observations correctes de TAFANI sur la pénétration des spermatozoïdes et sur le développement des pronucléi, et aussi de nos connaissances actuelles sur la fécondation chez le Rat, il reste peu de doute que cet œuf (ou les deux) provienne effectivement d'une fécondation dispermique. Ainsi, TAFANi paraît être le premier à avoir observé la dispermie chez les Mammifères.

Le rapport suivant d'un œuf dispermique de Rat est celui de AUstin et SMILES (I948). Utilisant pour la première fois le microcospe à contraste de phase pour l'examen des œufs de Mammifères, ils ont observé deux pièces intermédiaires de spermatozoïde dans un ouf au stade deux blastomères.

AUSTIN (I95I) fait état de quatre cufs polyspermiques, trois dispermiques et un trispermique, au stade précoce de la conjugaison des pronucléi.

Mais c'est le mémoire classique de AUSTIN et BRADEN (I953 a, b) qui établit d'une façon définitive l'existence et l'importance de la fécondation polyspermique chez le Rat. La preuve formelle de l'état di- ou trispermique de ces oufs est fournie par la démonstration de la présence de deux ou trois pièces intermédiaires de spermatozoïde à l'intérieur du cytoplasme, grâce à la transparence remarquable de l'œuf de Rat à l'examen au microscope à constraste de phase ; ces auteurs signalent Io oufs dispermiques ( $\mathrm{r}, 2$ p. IOO) sur 8 Io oufs fécondés de 87 femelles accouplées dans des conditions naturelles (c'est-à-dire au début des chaleurs). Parmi 955 œufs fécondés de 75 Rates impubères (après ovulation artificielle), il y avait 20 œufs polyspermiques (2,I p. I00), y compris un œuf trispermique. Plus récemment Austin (I956 a) a observé 7 œufs dispermiques ( 1,7 p. IOo) sur 406 œufs fécondés de Rates saillies normalement.

Parallèlement il faut noter les résultats négatifs de ODor et BLANDAU (I95I), Blandau et Odor (I952) au cours de recherches étendues sur différents stades de la fécondation et de la segmentation. Ces auteurs n'ont observé aucun œuf polyspermique sur environ I 800 œufs fécondés examinés soit au microscope à contraste de phase (environ I 200 œufs), soit en coupes histologiques. Dans une étude plus récente, ODOR et BLANDAU (I956) signalent un setil ouf dispermique (o,3 p. IOO) sur 3 I9 œufs obtenus après accouplements normaux.

Dans nos propres recherches (Prkó, I958 et observations non publiées) effectuées sur 3 souches de Rat, nous avons obtenu un total de 16 œufs dispermiques (soit I,4 p. IOO) sur I I05 œufs fécondés, examinés au microscope à contraste de phase.

\section{2. - Souris}

GERBACH (I906) fait état d'un œuf contenant trois pronttcléi à peu près de la même taille ; il considère cet œuf comme étant d'origine dispermique. D'après l'illustration donnée par l'auteur, et parce que cet œuf parait avoir deux globules polaires, une fécondation dispermique semble en effet plausible.

KREMER (I924) décrit également un œuf à trois pronucléi d'origine inconnue. Il pourrait s'agir, selon l'auteur, ou bien d'un ouf dispermique, ou bien de la fécon. dation monospermique d'un œuf binucléé (provenant d'un oocyte primaire binucléé).

PESONEN (I949) a observé un œuf à trois pronucléi et sans aucun globule polaire, sur 42 cufs tubaires. Il suppose qu'une division de maturation anormale où aucun globule polaire n'était formé, a été suivie par la fécondation de l'œuf par 
un seul spermatozoïde. Il est possible en effet, que cet œuf soit le résultat d'une suppression de la deuxième division de maturation. L'absence d'un globule polaire s'explique par le fait que chez la Souris le premier globule polaire ne subsiste à l'ovulation que dans 9 à $5 \mathrm{I}$ p. Ioo des œufs, chiffre variable selon la souche (observation de BRADEN, citée par AUSTin et Brshop, I957 b). Par contre, la suppression de la première mitose de maturation semble aboutir à deux métaphases de deuxième maturation et à la formation de deux " deuxièmes " globules polaires (BRADEN, I957).

DoKUKIN et BASHKaIEV (1954) signalent trois œufs à trois pronucléi (dont un au stade de conjugaison des pronucléi) chez 24 femelles examinées. Ils supposent qu'il pourrait s'agir d'une fécondation polyspermique. Le manque de détails cytologiques ne permet pas de discuter cette observation.

BRADEN, Austin et David (I954) ont obtenu deux œufs dispermiques ( 1,2 p. IOo) sur I69 œufs fécondés de 20 femelles. Les œufs étant examinés au microscope à contraste de phase, la dispermie est confirmée par la présence de deux pièces intermédiaires dans le cytoplasme.

En étudiant les anomalies de la maturation et de la fécondation chez différentes souches de Souris, BRADEN (I957) a observé 33 œufs polyspermiques (o,8I p. IOo) sur un total de 4076 œufs fécondés. La fréquence des autres anomalies aboutissant également à des œufs à trois pronucléi a été de 22 œufs $(0,54$ p. IOO) avec suppression du deuxième globule polaire et de 1 œuf sur environ 5000 œufs fécondés avec suppression du premier globule polaire. Mais ces deux dernières anomalies ont été considérablement plus fréquentes $(4,4$ et 2,3 p. Ioo) dans une des souches ( V V stock").

Edwards et SirLin (r956 et r958) ont obtenu un œuf à trois pronucléi sur I 2 œufs de souris fécondés avec du sperme marqué au ${ }^{14} \mathrm{C}$. L'autoradiographie de l'œuf trinucléé révèle deux pronucléi marqués, prouvant ainsi l'origine dispermique de l'œuf.

$$
\text { 3. - Campagnol }
$$

Austrin (I957) a observé un œuf dispermique sur 57 œufs (soit environ 2 p. IOo) au stade pronucléaire de développement. Les cufs ont été examinés au microscope à contraste de phase. L'œuf dispermique contenait trois pronucléi ( dont deux plus grands) et deux pièces intermédiaires dans le cytoplasme.

Après la segmentation la pièce intermédiaire est difficilement discernable ce qui empêche la vérification de la polyspermie aux stades plus avancés. Il est à noter que dans environ $45 \mathrm{p}$. Ioo des cas la queue de spermatozoïde fécondant reste entièrement en dehors du cytoplasme, dans l'espace périvitellin.

\section{4. - Hamster doré}

LUDWIG (I954) décrit'un œuf dispermiquesur 67 œufs examinés après fixation etcoloration in toto dès la pénétration du spermatozoïde jusqu'à la première segmentation ; l'œuf dispermique contenait deux têtes spermatiques au stade précoce de transformation.

AUSTin (I956 c) a examiné 5 Ig œufs fécondés aux stades de I à 8 cellules. Il a observé 5 cufs dispermiques (soit 0,96 p. IOO). La présence de deux pièces intermédiaires de spermatozoïde dans ces œufs a pu être démontrée au microscope à contraste de phase. Dans un travail ultérieur (AUSTrN et BRADEN I956), le nombre d'œufs examinés fut porté à 725 , avec Io œufs dispermiques (I,6 p. IO0). 
Hamiton et SAMUei (I956) signalent quatre oufs à trois pronuclëi chez des œufs examinés en coupes histologiques; ils considèrent l'origine dispermique de ces œufs comme possible.

Chang et Fernandez-Cano (I958) ont obtenu 3 oufs dispermiques ( 1,5 p. Ioo) sur I94 œufs fécondés, aux stades de I à 8 cellules. Les œufs étaient examinés d'abord au microscope à contraste de phase in vivo, et ensuite après coloration in toto par le colorant lacmoïle acétique (pièces intermédiaires visibles).

\section{5. - Lapin}

REIN (I883) décrit dans un ceuf obtenu I7 heures après la copulation : deux globules polaires, deux noyaux en conjugaison et un troisième "corps », éloigné des deux noyaux, dans le cytoplasme qui pourrait corespondre - selon l'auteur - soit à un " troisième globule polaire " non encore entièrement émis, soit à un deuxième noyau spermatique. Il semble en effet possible, d'après la description et 1'illustration de l'auteur, qu'il s'agisse d'un troisième pronucléus et que l'œuf soit - vu la présence de deux globules polaires - dispermique.

AUSTIN et BRADEN (I953 b) font état d'un cas douteux (I,4 p. IOo) de polyspermie sur 69 œufs examinés au microscope à contraste de phase au stade pronucléaire ; mais les "pronucléi » sont difficiles à voir dans l'œuf de lapine, et pouvaient être en réalité des fragments pronucléaires.

KHVATOV (I954) mentionne un œuf à trois pronucléi (sans détails cytologiques) ; il considère l'œuf comme ayant été fécondé par deux spermatozoïdes.

MERKURIEVA (I954) a examiné 390 oufs vivant pendant une période de I3 à 72 heures après copulation normale. Flle a signalé quatre œufs à trois pronucléi. Des œufs trinucléés ont été également observés en coupes histologiques.

DAUZIER et THIBAULT (communication personnelle) ont obtenu deux cufs dispermiques (soit environ I,I p. IOO) sur I 89 œufs fécondés. Les œufs dispermiques étaient au stade précoce de la fécondation et contenaient deux têtes spermatiques gonflées dans leur cytoplasme.

\section{6. - Cobaye}

LAMs (IgI3) fait état d'un œuf polyspermique qu'il décrit comme suit (p. 27I) : " La polyspermie est toujours pathologique. Nous n'en avons observé qu'un cas : il s'agit d'un œuf recueilli plus de 24 heures après le coït... I1 présente des signes manifestes de dégénérescence du cytoplasme et de la partie chromatique, éparpillée sous forme de grumeaux dans tout le vitellus. Plusieurs spermatozoïdes entiers, non modifiés, siègent dans le cytoplasme, à côté d'autres dont la tête, pourvue de la queue, est partiellement transformée en pronucléus mâle. "Il est évident qu'il s'agit dans ce cas d'un œuf anormal, dégénéré peut-être à cause du vieillissement (comme le suppose l'auteur).

\section{7. - Furet}

MAINLAND (I930) a examiné IOI œufs en coupes histologiques dont 7 I au stade pronucléaire. Dans un œuf $(I, 4$ p. Ioo) il y avait trois pronucléi. Deux pronucléi plus grands se situaient au centre de l'œuf tandis que le troisième était à une petite 
distance vers la périphérie du vitellus. MAINLAND suppose cet œuf issu d'une fécondation dispermique. Il juge improbable l'hypothèse faite par KREMER (I924), à savoir qu'un œuf originellement binucléé soit fécondé par un spermatozoïde : en fait, il n'a pu observer aucun oocyte binucléé sur des coupes de 496 ovaires adultes. Mais il ne considère pas la possibilité de la suppression d'une division de maturation et ne donne pas de renseignement sur les globules polaires de l'œuf trinucléé.

\section{8. - Chat}

VAN DER STrRicht (IgII) fait état d'un œuf trinucléé (soit environ 3 p. IOO) sur $3^{6}$ œufs examinés en coupes sériées au stade pronucléaire. Il caractérise $1^{\prime} œ u f$ de la façon suivante (p. 457) : "A côté de deux pronucléi, rapprochés dans la moitié plastique et disposés comme dans les ovules normaux à la fin de la période de fécondation, nous avons trouvé un troisième pronucléus, distant des deux premiers et situé dans un segment de vitellus pauvre en éléments graisseux. Il faut admettre dans ce cas la pénétration, qoique exceptionnelle, de deux spermatozoïdes ". Puisque l'auteur signale également la présence de deux globules polaires dans cet œuf, une fécondation dispermique semble en effet 1'hypothèse la plus plausible.

HILL et TRIBE (I924) ont examiné II œufs au stade pronucléaire pardes méthodes histologiques. Ils ont trouvé deux cufs à trois pronucléi, d'une structure à peu près identique, qu'ils décrivent ainsi (p. 530) : "Il y a deux pronucléi, un plus grand et un plus petit, qui sont en contact vers un côté de l'ovule et qui correspondent aux pronucléi de l'œuf normal, tanđis que le pronucléus surnuméraire se situe près de la surface du côté opposé de l'œuf et est pratiquement de la même taille que le plus grand de l'autre paire ». Les auteurs pensent que le pronucléus " surnuméraire » provient d'un deuxième spermatozoïde ayant pénétré dans l'œuf. Ils supposent en effet que dans les œufs normalement fécondés le plus petit pronucléus correspondrait — d'après sa situation plus rapprochée des globules polaires — au pronucléus femelle. Mais il y a une autre raison : les auteurs signalent dans les deux oufs la présence de deux globules polaires apparemment normaux. Ainsi, ces œufs peuvent résulter d'une fécondation dispermique.

$$
\text { 9. - Truie }
$$

Pitkianen (I955) a étudié l'ovulation, la fécondation et les stades précoces de la segmentation chez 394 femelles. Sur 50 œufs examinés en coupes sériées au stade pronucléaire, cinq œufs (Io p. Ioo) contenaient trois pronucléi. L'auteur considère que ces œufs avaient été pénétrés par deux spermatozoides, pour les raisons suivantes :

$I^{0}$ sur les coupes fixées au Bouin, et colorées à 1'hématoxyline de Heidenhain, deux pronucléi ont une structure semblable à celle du pronucléus mâle chez les œufs monospermiques ;

$2^{\circ}$ dans le voisinage de ces deux pronucléi on peut discerner un morceau de queue de spermatozoïde (v. fig. 5). Notons que sur la fig. 5 on voit apparemment le deuxième globule polaire, avec le reste du fuseau, dans le voisinage du pronucléus femelle; cet œuf peut donc raisonnablement être considéré comme dispermique. Sur un autre œuf trinucléé (fig. 4) on voit deux noyaux en contact vers la périphérie du cytoplasme tandis que le troisième pronucléus se trouve éloigné vers le côté opposé de l'œuf. L'auteur n'a jamais observé trois pronucléi en conjugaison. 
Récemment HANCOCK (1959) a noté un œuf trinucléé (I,6 p. I00) supposé dispermique, sur 64 œufs provenant de truies accouplées moins de 24 heures après le début des chaleurs. Thibault (I959) a obtenu un œuf dispermique (I,8 p. 100) sur 54 œufs appartenant à des truies inséminées pendant les premières 36 heures des chaleurs. (Nous discuterons les détails cytologiques de ces travaux plus tard, à propos des effets des accouplements retardés).

$$
\text { Io. - Vache }
$$

Pitkianen et Ivankov (I956) ont examiné un total de 28 œufs tubaires en coupes sériées, dont I 3 avant la première segmentation. Ils décrivent un œuf à trois pronucléi, obtenu $\mathbf{2} 2$ heures après la fin des chaleurs. Deux des pronucléi sont en contact près de la phériphérie du cytoplasme; le troisième se trouve éloigné vers le côté opposé de l'œuf. Les auteurs considèrent cet œuf comme polyspermique, mais la description et l'illustration qu'ils en donnent ne permettent pas de l'affirmer.

$$
\text { II. - Brebis }
$$

Pitkianen (I958) fait état d'un œuf à trois pronucléi sur 29 œufs tubaires non encore divisés, examinés en coupes histologiques. Les trois pronucléi sont à peu près de la même taille à une certaine distance l'un de l'autre. L'origine du troisième pronucléus n'est pas précisée.

\section{b). MÉCANISME D'INHIBITION DE LA POLYSPERMIE.. " REFÉCONDATION ». SPERMATOZOIDES SUPPLÉMENTAIRES.}

Récemment Austin et Bishop (I957 a) ont passé en revue les conditions préliminaires de la fécondation (transport, activation, survie et rencontre des gamètes) et les premières réactions de l'œuf à la pénétration des spermatozoïdes. Selon leurs conclusions, trois facteurs sont en je11 pour assurer la fécondation normale (monospermique) :

Io le nombre limité des spermatozoïdes aux environs de l'œuf au moment de la fécondation.

$2^{\circ}$ la "réaction de la zona ".

$3^{\circ}$ la " réaction vitelline " ou "blocage de la polyspermie ".

Ici nous nous bornerons à une brève discussion de ces facteurs (v. aussi BrADEN et Austin, I954 a ; Braden, Austin et David, I954 ; Austin et BradEN, I956).

\section{Nombre de spermatozoides sur les lieux de la fécondation.}

Il est généralement admis que la fécondation a lieu chez la plupart des Mammifères dans 1'ampoule de la trompe de Fallope (v. discussion de Strauss, I954 et 1958). Or, le nombre de spermatozoïdes relevé dans cette partie de la trompe est de 1'ordre de quelques dizaines chez la Rate et chez la Souris, ou de quelques centaines chez la Lapine (v. Chang, I953; Austin et BISHOP, I957 a). La réduction du nombre de spermatozoïdes est due surtout à la fonction restrictive du cervix (chez les espèces 
à éjaculation intra-vaginale) et de la jonction utéro-tubaire (v. discussion de DAUZIER I958).

BRADEN et AUSTIN (I954 a) ont étudié la fréquence de collisions entre œufs et spermatozoïdes chez quatre espèces (Rat, Souris, Lapin, Brebis) et l'ont trouvée à peu près du même ordre malgré les différentes dimensions du lieu de la fécondation. Cette fréquence serait telle qu'elle offrirait de bonnes chances de fécondation mais éviterait en même temps la pénétration d'un nombre excessif de spermatozoïdes dans 1'œuf. En effet, les auteurs ont trouvé, chez le Rat, une corrélation significative entre le nombre de spermatozoïdes sur les lieux de fécondation d'une part et le nombre de spermatozoïdes supplémentaires dans les œufs d'autre part.

\section{2. - Réaction de la zona pellucida.}

Chez beaucoup d'espèces, le passage du premier spermatozoïde provoque une réaction dans la zone pellucide, tendant à empêcher la pénétration de spermatozoïdes successifs. La nature de cette réaction est inconnue.

La rapidité de la réaction varie considérablement selon l'espèce. Un ou plusieurs spermatozoïdes supplémentaires sont fréquemment rencontrés dans l'espace périvitellin chez nombre d'espèces : Rat, Souris, Cobaye, Chat, Furet, Chauve-Souris. Le nombre de spermatozoïdes supplémentaires ayant pénétré dans l'espace périvitellin est généralement élevé (on a signalé des moyennes de 20 à 70 spermatozoïdes) dans l'œuf de la Lapine et peut-être aussi dans celui de la Taupe.

Mais chez la plupart des Mammifères, la présence des spermatozoïdes dans l'espace périvitellin est un phénomène exceptionnel, bien que des têtes spermatiques se trouvent fréquemment, et quelquefois en très grand nombre, adhérant à la surface de la pellucide, ou incluses dans la substance de celle-ci : par exemple Chien, Brebis, Chèvre, Vache, Truie, Macaque, Homme (v. la revue de Braden Austin et DAVID, I954).

\section{3. - Réaction vitelline.}

Chez certaines espèces, le contact du premier spermatozoïde avec la membrane vitelline provoque une réaction qui empêche l'attachement à cette membrane de spermatozoïdes ultérieurs. (L'attachement de la tête spermatique à la surface vitelline semble être en effet une phase préliminaire indispensable pour la pénétration du spermatozoïde dans le cytoplasme, Ausrin et BRADEN, I956).

Cette réaction est évidente surtout chez les espèces où la réaction de zona est pratiquement inexistante (Lapine) ou relativement lente (Rate, Souris). Par contre chez les espèces, où la réaction de zona est très rapide et efficace (chez la plupart des Mammifères), le rôle de la réaction vitelline paraît effacé. Son existence pourrait être déduite cependant du fait que, même chez de telles espèces, on trouve quelquefois des spermatozoïdes supplémentaires dans l'espace périvitellin, comme cela a été signalé chez la Hamster (Ludwig, I954 ; Chang et Fernandez-Cano, I958) et chez la Truie ('Thibaul, T, I959.)

AUSTIN et BRADEN (I956) supposent - surtout à partir d'observations chez la Souris - que la réaction de la zona et la réaction vitelline seraient liées entre elles et provoquées par l'attachement du premier spermatozoïde à la surface du vitellus L'attachement de la tête spermatique serait responsable de la réaction vitelline 
d'une part, et d'autre part de la décharge d'une substance ( " tanning agent ") induisant la réaction zonale. Chez le Hamster, de nombreux granules corticaux, présents dans l'œuf non fécondé, disparaissent au cours de la pénétration de spermatozoïdes (Austis, I956 b) ; cela pourrait être lié à la décharge de cette substance.

Bishop et 'Tyler (I956) font état dans l'œuf de plusieurs espèces de Mammifères de substances analogues aux "fertilizines " des animaux inférieurs; leur rôle possible dans la pénétration de spermatozoïdes et dans les premières réactions de l'œuf reste encore à élucider.

\section{4. - La "refécondation" d'cuts fécondés.}

La présence de têtes spermatiques intactes ou aux stades précoces de tranformation dans des œufs pronucléés ou segmentés a été décrite par plusieurs auteurs (v. Austin et Braden, 1953).

SoвотTA (1895) a observé des têtes spermatiques ou des petits noyaux supplémentaires dans des œufs de souris accouplées de nouveau 18 à 24 heures après $1 \mathrm{a}$ première copulation. Il conclut à une deuxième pénétration de spermatozoïdes dans les œufs déjà fécondés. D'après KREMER (I924), la pénétration ultérieure de spermatozoïdes dans l'œuf fécondé serait un phénomène relativement fréquent chez la Rate, "contrairement à la Souris "; ces spermatozoïdes resteraient inchangés, ne trouvant plus les conditions nécessaires pour leur transformation et subiraient finalement la dissolution. Rubaschkin (I905) décrit, dans l'œuf de Cobaye, de petits corps chromatiques, ressemblant au noyau mâle précoce; il suppose, "sous toute réserve ", qu'il pourrait s'agir d'une fécondation ultérieure.

Des têtes spermatiques inchangées ont été signalées également dans un œuf dégénéré de Cobaye, décrit ci-dessus (LAMs, I9I3) et après inséminations avec du sperme traité par des rayons X chez la Lapine (Amoroso et PARkEs, r947) et chez la Souris (EDWARDS, I957). REIN (I883) a observé, au cours d'expériences sur la fécondation in vitro, de nombreux spermatozoïdes pénétrer dans des cufs ovariens de Lapine et se mouvoir vigoureusement; mais il pense que les œufs étaient probablement morts au moment de la pénétration. BI,ANDAU et ODOR (1952) ont vu des spermatozoïdes supplémentaires pénétrer et faire des mouvements progressifs dans le cytoplasme d'œufs de Rate fécondés récemment et examinés in vivo ; ces spermatozoïdes supplémentaires n'ont cependant jamais été retenus dans le cytoplasme.

Récemment, des auteurs russes ont décrit la présence de têtes spermatiques dans le cytoplasme d'œufs au stade pronucléaire ou aux différents stades de segmentation, chez plusieurs espèces (œufs examinés en coupes sériées) : Souris (DokUkiN et Bashkaiev, I954 ; Korobova, I955), Lapine (Zybina, I953 ; Merkurieva, I954), Truie (Pitkianen, I955), Vache (Pitkianen et Ivankov, I956). Ces auteurs admettent la pénétration ultérieure de spermatozoïdes comme possible ou même comme un phénomène normale après la fécondation; les spermatozoïdes ayant pénétré ultérieurement seraient assimilés par l'œuf sans subir de transformations et joueraient ainsi un rôle utile dans le développement de l'embryon. Pitkianen et Ivankov (I956) pensent cependant que les têtes spermatiques pourraient être transportées sur le cytoplasme par le rasoir du microtome au cours de la coupe histologique.

AUSTrN et BRADEN (1953) critiquent les observations antérieures sur la " refécondation " et leurs conclusions nous paraissent parfaitement valables. D'après eux, 
les petits corps chromatiques de Sobotra (I895) et de Rubaschkin (I905) pourraient être des "pseudochromosomes " ou " corps énigmatiques " signalés par plusieurs auteurs, ou bien des "subnucléi " provenant de fragmentation nucléaire. La présence de têtes spermatiques inchangées dans le cytoplasme, comme décrite par KREMER (I924), s'explique probablement par des artéfacts au cours de préparations histologiques. La même raison peut expliquer, selon toute vraisemblance, les observations des auteurs russes, citées ci-dessus. La possibilité et les causes d'artéfacts de ce genre ont été démontrées expérimentalement par VoJTršková (I956) et PósaLAKY et 'Törö (I957). En tout cas, les observations faites pendant cette dernière décade sur des milliers d'œufs vivants de différentes espèces de laboratoire à l'aide du microscope à contraste de phase, ne confirme en rien 1'hypothèse d'une "refécondation " ultérieure. La possibilité d'une polyspermie "physiologique " où un spermatozoïde se transformerait en pronucléus tandis que les autres seraient assimilés directement par l'œuf, parait non moins catégoriquement exclue, au moins dans les conditions normales de la fécondation.

\section{5. - La destinée des spermatozoides supplémentaires.}

Le devenir et le rôle possible des spermatozoïdes supplémentaires (spermatozoïdes bloqués dans l'espace périvitellin ou dans la zone pellucide) sont insuffisamment connus.

En examinant des œufs de Cobaye, LAms (I9I3, p. 27I) déclare : "Ces germes non transformés n'ont aucune signification, car ils restent extraovulaires; ils dégénèrent et disparaissent. "

LaMs et DOORME (1908) supposent que, chez la Souris, cette disparition serait assez précoce puisqu'ils n'ent ont plus trouvé " la moindre trace à des stades plus avancés du développement de l'œuf ". Mais ils n'ont pas pu suivre les phases de la disparition. En outre, ils n'ont examiné que 36 œufs fécondés, dont 4 œufs segmentés ; leur observation est donc loin d'être concluante.

D'après ODOR et BLANDAU (I949), les spermatozoïdes supplémentaires de l'œuf de Rate sont sans influence sur le rythme de développement de l'œuf. Ils peuvent conserver leur aspect morphologique normal (sauf que leur tête se détache souvent) jusqu'au moment de la dissolution de la zone pellucide (peu avant l'implantation); ils sont alors rejetés dans la lumière de l'utérus où ils se désintègrent probablement.

ADAMs (I955) a étudié la fréquence des spermatozoïdes supplémentaires dans l'espace périvitellin et dans les membranes de l'œuf de Lapine de 30 à 50 heures après copulation. Selon lui (p. I33) : "Dans la plupart des cas, les spermatozoïdes ont été intacts et ont paru bien préservés au moment de l'examen ".

MERKURIEVA (1954) rend compte cependant d'une diminution considérable du nombre de spermatozoïdes supplémentaires dans l'espace périvitellin de l'œuf de Lapine entre les $I 7^{e}$ et $I 8^{e}$ heures après la copulation ; elle suppose que cela pourrait être dû à l'assimilation de ces spermatozoïdes par l'œuf. Par contre, Chang (I95I), BRADEN, AUSTIN et DAVID (I954) observent une augmentation significative du nombre de spermatozoïdes dans l'espace périvitellin de $1^{\prime} œ u f$ de Lapine jusqu'à $1 \mathrm{a} I 6^{\mathrm{e}}$ à $I 8^{\mathrm{e}}$ heure après la copulation; ensuite leur nombre reste à peu près constant, au moins pendant les 4 à 6 heures suivantes. La divergence pourrait s'expliquer peut-être par le fait que MERkURIEva (I954) a utilisé trois races différentes ; l'effet de la souche sur le nombre de spermatozoïdes supplémentaires a été observé chez la Souris (BRADEN, 1958 a) et chez le Rat (PIK6, I958). 
Mais s'il est peu probable qu'une dissolution ou désintégration de spermatozoïdes supplémentaires ait lieu dansl'espace périvitellin, il est possible quecertaines substances de ces spermatozoïdes puissent se libérer et être assimilées par 1'œuf. D'après AusTIN (I957), la queue du spermatozoïde fécondant de Campagnole, restant en dehors du cytoplasme de l'œuf, subirait des changements au cours de la segmentation et sa taille diminue. KUSHNER (I954) tente d'expliquer, en partie, les résultats favorables obtenus après saillies doubles ou insémination mixte (accélération de développement, augmentation de vitalitê) par un effet de spermatozoïdes supplémentaires.

Si des substances de spermatozoïdes supplémentaires peuvent influencer le développement de l'œuf, cette action pourrait être importante surtout chez la Lapine où le nombre de spermatozö̈des supplémentaires dans l'espace périvitellin de l'œuf est généralement élevé. MERKURIEVA (r954) constate en effet, qu'après double accouplement de Lapines avec deux mâles, les blastomères ont été plus grands et la segmentation plus rapide (par rapport aux saillies simples), Mais il n'apparaît pas clairement que ce résultat soit dû à l'effet des spermatozoïdes supplémentaires comme le suppose l'auteur (leur nombre varie peu ) ou à d'autres facteurs (différences raciales, ovulation plus précoce après saillie double). De plus dans l'expérience de SokocovsKAIA (I947), l'insémination des Lapines avec une dose minimum ( $\mathrm{I} \times$ IO $^{4}$ spermatozoïdes) a considérablement diminué le taux de fécondation et le nombre de spermatozoïdes supplémentaires'par rapport à la dose normale (Io millions de spermatozoïdes); mais il n'y avait aucune différence, ni dans le rythme de segmentation des œufs fécondés, ni dans la qualité de la descendance (développement, teneur en hémoglobine du sang). Notons que les expériences de BEATTY (I957), également chez le Lapin, n'ont mis en évidence aucun effet net de "vigueur hétérospermique " après inséminations mixtes avec du sperme de deux mâles différents.

D'après PITKIANEN (I955), le nombre de spermatozoïdes supplémentaires bloqués dans la pellucide de l'œuf de Truie est plus élevé après saillie double qu'après saillie simple, et les œufs se trouvent à un stade plus avancé 48 heures après la copulation. Mais l'accélération de la segmentation s'observe aussi bien au cas où la deuxième saillie est faite par un verrat vasectomisé ; la deuxième saillie agirait donc surtout par un déclenchement plus précoce de l'ovulation. Le nombre des spermatozoïdes bloqués dans la pellucide est apparemment sans effet sur la précocité du développement de l'œuf de la Vache (Pitkianen et Ivankov i956) et de la Brebis (Pitkianen, I958). Notons que chez les trois dernières espèces les spermatozoïdes supplémentaires ne se trouvent pratiquement que dans la pellucide. Or, la pellucide paraît imperméable, au moins chez la Lapine et la Rate, à des substances d'un poids moléculaire dépassant I6 ooo (AUSTIN et LOVEIOCK, I958), c'est-à-dire à la plupart des enzymes, aux antigènes, aux anticorps, aux acides nucléiques, etc...

\section{c) EFFETS DE DIFFÉRENTS FACTEURS ETT DES CONDITIONS EXPÉRIMENTALES SUR IAA FRÉQUENCE DE LA POLYSPERMIE.}

\section{I. - Fécondation retardée.}

Les œufs des Mammifères ne sont susceptibles d'une fécondation normale que pendant une période relativement courte après l'ovulation, période inférieure à 24 heures chez la plupart des espèces (discussion et références, voir HARTMAN, I939; 
Austin et Bishop, I957b, p. 305). Si la fécondation est considérablement retardée, la fécondité baisse et lle développement embryonnaire montre de nombreuses anomalies : Lapin (HAMmond, I934; ChANG, I952), Cobaye (BLANDAU et Young, I939) et Rat (BLANDAU et Jordan, I94I).

LAMS (I9I3) supposait déjà, en étudiant la fécondation chez le Cobaye, que " les rares cas de polyspermie " seraient conditionnés par le vieillissement de l'œuf. Mais l'importance, dans la fécondation polyspermique, de l'intervalle entre l'accouplement et l'ovulation n'était mise en évidence que par AusTin et BRADEN (I953 a et b) dans des recherches effectuées sur le Rat et sur le Lapin.

Rat.

AUSTin et BRADEN (I953 b) ont étudié quatre types d'accouplement, en utilisant une souche albinos croisée au hasard :

A. - Accouplement au début de l'œstrus (c'est-à-dire environ to heures avant l'ovulation) (Boling, Blandau, Soderwali et Young, I94I).

B. - Accouplement 3 à 4 heures avant l'heure moyenne de l'ovulation.

C. - Accouplement I à 2 heures après l'heure moyenne de l'ovulation.

D. - Accouplement 6 à 8 heures après 1'heure moyenne de l'ovulation.

Le pourcentage d'œufs polyspermiques (en général dispermiques) par rapport au nombre d'œufs fécondés a été le suivant : I,2 p. Ioo (groupe A) ; 3,7 p. Ioo (groupe B) ; 7,9 p. Ioo (groupe C) et 8,8 p. Ioo (groupe D). L'augmentation de la fréquence de la polyspermie est statistiquement significative entre les groupes $A$ et $B(P<0,02)$, et entre les groupes $\mathrm{B}$ et $\mathrm{C}(\mathrm{P}<0,05)$.

Le nombre d'œufs contenant plus d'un spermatozoïde (dans le cytoplasme ou dans l'espace périvitellin) était également augmenté, d'une façon significative, dans les groupes à accouplement retardé.

La cause de l'augmentation de la polyspermie est à chercher surtout dans la défaillance de la réaction vitelline dans ces groupes. Dans les œufs où plusieurs spermatozoïdes ont franchi la pellucide, $27 \mathrm{p}$. Ioo sont devenus polyspermiques dans les groupes $\mathrm{C}$ et $\mathrm{D}$, contre $\mathrm{I} 3 \mathrm{p}$. Ioo dans le groupe $\mathrm{B}$ et 5,5 p. Ioo dans le groupe A (les différences sont statistiquement significatives).

AUSTIN et BRADEN (I953 b) supposent qu'il pourrait y avoir deux facteurs principaux agissant sur la polyspermie : I. Les spermatozoïdes sont plus frais et par conséquent, probablement plus vigoureux au moment de la fécondation après accouplements retardés; ce facteur serait seul responsable de l'augmentation de la polyspermie dans le groupe $B$ où pratiquement aucun retard n'a pu avoir lieu dans la fécondation par rapport à l'époque normale; 2 . Le vieillissement de l'œuf dont l'effet s'ajouterait au facteur précédent dans les groupes $C$ et $D$. Le vieillissement devrait entrainer chez le Rat très rapidement une détérioration de la réaction vitelline, puisque dans le groupe $C$, le retard n'est que de deux heures environ sur l'époque normale de la fécondation (v. Austin et BRADEN, I954 a).

Austin et Braden (I954 b) font état de 9,2 p. Ioo d'œufs polyspermiques chez des Rates accouplées vers la fin de l'œetrus.

ODOR et BLANDAU (I956) ont étudié la fécondation chez une souche albino "Wistar ", après trois types d'accouplement : les femelles ont été accouplées au début de l'œstrus, après un délai moyen d'environ 6 heures ou II heures après le commencement de l'cestrus. La fréquence d'œufs polyspermiques dans les trois groupes a 
été de 0,3 , I, I et 3,3 p. Ioo et celle des spermatozoïdes supplémentaires de Io,2, I6,7 et $\mathrm{I} 8,3$ p. 100 .

PIKó (I958) a étudié la fréquence de la polyspermie chez trois souches après accouplements normaux et après accouplements retardés jusqu'à la fin de l'œstrus. Chez deux souches, le retard à la fécondation a significativement augmenté le degré de la polyspermie et le pourcentage d'œufs avec des spermatozoïdes supplémentaires (valeur moyenne de la polyspermie chez les trois souches 6 , I p. Ioo contre I, 2 p. Ioo après saillie normale). Dans la même étude, un œuf tétraspermique fut signalé, issu probablement d'un retard extrême de la fécondation; l'œuf avec ses cinq pronucléi ne montrait pas d'anomalies majeures.

BRADEN (I958 b) rend compte d'un pourcentage élevé d'œufs polyspermiques après accouplements différés chez deux souches (3,6 p. Ioo et 8,4 p. Ioo).

Mais il semble, que l'accouplement retardé n'est pas toujours accompagné d'une augmentation de la polyspermie. Ainsi, dans une étude ultérieure de AusTix (I955, I956 a), la fréquence de la polyspermie est restée pratiquement au même niveau (environ 2 p. IOo) après accouplements normaux et retardés. LUDWIG (I954) signale 2 cufs polyspermiques sur 95 œufs de Rates accouplées, selon toute apparence, vers la fin de l'cestrus.

Notons enfin, que BLANDAU (1952) n'a observé aucun œuf polyspermique sur 777 œufs fécondés provenant de Rates inséminées artificiellement avant ou de 3 à I2 heures après l'ovulation (v. discussion p. 372).

Souris.

BRAden et Austin (I954 b) n'ont observé qu'un seul œuf dispermique sur 375 œufs de 5I femelles accouplées de 3 à I2 heures après l'ovulation.

Gates et BEATTY (I954) ont examiné le nombre chromosomique des blastocystes de 3 jours $\mathrm{I} / 2$ provenant de femelles immatures accouplées avant ou de 5 $I / 2$ à I $6 \mathrm{~h}$ heures après ovulation artificielle; ils ont trouvé une fréquence d'embryons triploïdes sensiblement égale dans les 2 groupes (environ 2 p. I0O).

Il ne semble donc pas que l'accouplement retardé soit chez la Souris un facteur d'induction de la dispermie ou d'autres anomalies aboutissant à la triploïdie.

Hamster doré.

Selon Chang et Ferrandez-Cano (I958), environ 50 p. Ioo des cufs sont infécondables quand l'accouplement a lieu 3 à 4 heures après l'époque supposée de l'ovulation (c'est-à-dire que la fécondation a lieu au moins 6 heures après l'ovulation ; v. STrauss, I956). Parmi 88 œufs fécondés et examinés au stade pronucléaire, 30 œufs (soit 34 p. IOo) contenaient trois pronucléi à cause de la rétention du deuxiéme globule polaire. Cependant, la fréquence d'œufs polyspermiques n'était que de $\mathrm{I}, 8$ p. Ioo ( 2 œufs dispermiques et 2 oufs trispermiques) sur un total de 222 œufs fécondés après accouplement retardé.

Lapin.

Austin et BRAden (I953 b) ont examiné la fécondation chez I7 femelles accouplées au moment de l'ovulation provoquée par injection hormonale. Sur 67 oufs au stade pronucléaire, 9 œufs contenaient trois pronucléi tandis que 2 œufs contenaient six corps ressemblant à des pronucléi. Les auteurs pensent qau'au moins une partie 
de ces œufs provient d'une fécondation polyspermique. Ils considèrent également la possibilité d'une rétention du deuxième globule polaire. Notons que la tendance à une migration centripéte du fuseau de seconde division polaire de 1'œuf de Lapine après activation artificielle a été décrite par THuBAuLr (I949).

Truie.

HANCock (I959) a étudié I68 œufs provenant de truies de races Large White et Sussex, accouplées $0,24,30$ ou 40 à 48 heures après le début des chaleurs. La fréquence d'œufs à trois pronucléi ou plus dans les quatre groupes a été de 0 , de 3 , de II et de $30 \mathrm{p}$. Ioo environ; ces différences sont statistiquement significatives $(\mathrm{P}<$ 0,05). Les 20 œufs polynucléés comprenaient I5 œufs à 3 pronucléi, 3 œufs à quatre pronucléi et 2 œufs à cinq pronucléi. L'auteur considère ces œufs comme polyspermiques, pour les raisons suivantes :

I. Deux oufs trinucléés contenaient deux pièces intermédiaires dans le cytoplasme ;

2. Huit œufs trinucléés contenaient deux globules polaires. L'absence de deux pièces intermédiaires ou de deux globules polaires n'exclut par l'origine polyspermique puisque ces structures ne sont pas toujours visibles avec la technique employée (examen des cufs in toto au mictoscope à contraste de phase, après coloration par le carmin acétique).

Selon Thibauti (I959) cependant, l'origine de trois pronucléi chez des œufs âgés de Truie s'explique par deux mécanismes :

I. Fécondation dispermique ;

2. Formation de deux pronucléi femelles par migration interne du second fuseau de maturation.

Thibauli (I959) a étudié I70 œufs en coupes histologiques, appartenant à 20 truies de race Large White. Les truies ont été saillies ou inséminées selon trois plans : au début, au milieu ou vers la fin de l'œstrus. La fréquence d'œufs à trois pronucléi ou plus dans les trois groupes a été de $\mathrm{I}, 8 \mathrm{p}$. IOO, de $6 \mathrm{p}$. IOO (y compris deux oufs polyspermiques anormaux) et de 32 p. Ioo. Dans ce dernier groupe, I/3 des cufs polynucléés étaient d'origine polyspermique et $2 / 3$ d'origine polygynique, deux œufs étant à la fois dispermiques et digyniques. La différenciation des œufs polyspermiques et polygyniques s'appuie sur les critères suivants :

I. Certaines différences morphologiques entre les pronucléi mâle et femelle;

2. Présence de la pièce intermédiaire du spermatozoïde à côté des pronucléi mâles ;

3. Présence des restes fusoriels auprès de l'un des pronucléi femelles.

\section{2. - Choc thermique. Hypo- et hyperthermie.}

Le refroidissement des oufs de Rate in situ après 1'ovulation provoque régulièrement l'émission du second globule polaire (THibaulT, I949). Les oufs ainsi activés seraient capables d'une fécondation ultérieure et le mécanisme du blocage de la polyspermie paraît fonctionner normalement (AUSTIN et BRADEN, I954 b).

AUSTIN et BRADEN (I954 b) ont également étudié l'effet d'un réchauffement des oufs de Rate, in situ, en submergeant les trompes de Fallope dans un bain d'eau de $45^{\circ} \mathrm{C}$ pendant ro minutes après l'ovulation. La fréquence d'œufs polyspermiques 
(en général dispermiques) a atteint $\mathrm{x} 6 \mathrm{p}$. Ioo, contre 9,2 p. Ioo dans le groupe témoin (à accouplement retardé). L'augmentation de la polyspermie est due uniquement à la détérioration de la réaction vitelline : parmi les cufs dont deux ou plusieurs spermatozoïdes ont franchi la pellucide, $65 \mathrm{p}$. Ioo sont devenus polyspermiques, contre 23 p. Ioo dans le lot témoin. Cet effet est autant plus frappant que le pourcentage d'œufs contenant deux ou plusieurs spermatozoïdes (dans l'espace périvitellin ou dans le cytoplasme) a été considérablement diminué après le traitement par la chaleur (25 p. Ioo contre $39 \mathrm{p}$. Ioo dans le groupe témoin). Chez les oufs réchauffés, une suppression transitoire de la deuxième division de maturation a été également observée.

Selon Austin (I955 et I956 a), l'hyperthermie générale est un moyen non moins efficace d'augmentation de la polyspermie chez le Rat. L'élévation de la température centrale des femelles jusqu'à environ $42^{\circ} \mathrm{C}$ après l'ovulation jointe à un accouplement tardif, augmente la fréquence de la polyspermie à $2 \mathrm{I}, 2 \mathrm{p}$. IOO contre $2,8 \mathrm{p}$. IOO dans le groupe témoin. La cause de cette augmentation est de nouveau à chercher dans la lenteur de la réaction vitelline; il y a également une hausse de Ig à 3 I p. Ioo de la fréquence d'œufs où plus d'un spermatozoïde a traversé la pellucide.

A côté d'œufs dispermiques, plusieurs œufs tri- et tétraspermiques et un œuf pentaspermique ont été signalés ; ces derniers ont été cependant généralement anormaux, ayant subi des fragmentations nucléaires et cytoplasmiques. L'hyperthermie appliquée avant ou pendant la période de l'ovulation n'a eu que peu d'effet sur la fréquence de la polyspermie (5,6 p. Ioo d'œufs polyspermiques). L'hypothermie soit avant, soit après l'ovulation - est restée entièrement sans effet sur la polyspermie.

Chez la Souris, le réchauffement des œufs in situ après l'ovulation a également augmenté la polyspermie (de 0,3 à 4,6 p. Ioo y compris un œuf tétraspermique anormal) ; mais l'anomalie principale ( 12 p. IOo) a été la suppression de la deuxième division polaire (BRADEN et AUSTrN I954 b). Dans ce dernier cas, l'œuf contient deux pronucléi d'origine femelle à côté d'un pronucléus mâle. La rétention du deuxième globule polaire est donc probablement à l'origine de la plupart des blastocystes triploïdes obtenus par FISHBERG et BEATTY (I952) après réchauffement des trompes de Fallope 2 heures $I / 2$ après la copulation.

$$
\text { 3. - Age de la femelle. }
$$

En analysant les résultats obtenus après 1'hyperthermie générale, et discutés ci-dessus, AUstro (I956 b) a remarqué que l'augmentation de la polyspermie a été plus accusée chez les Rates plus lourdes (I70 à 200 grammes), et par conséquent plus agées que chez les Rates moins lourdes (Ioo à I3o grammes). Dans le premier groupe, la fréquence de la polyspermie a été de $34 \mathrm{p}$. Ioo contre I3 p. Ioo dans le deuxième. En outre, les cas de polyspermie supérieure (tri- et tétraspermie) sont observés presque exclusivement dans le premier groupe.

\section{4. - Souche.}

L'analyse de la littérature montre de fortes divergences dans la fréquence des cas de polyspermie, aussi bien après accouplement normal qu'après accouplement retardé. Cette variation est surtout évidente chez le Rat qui reste l'espèce la mieux 
étudiée. Austrin (I955), Odor et Blandau (I956) supposent que les différences pourraient être expliquées par un effet de la souche employée sur la fréquence de la polyspermie.

Les réstultats de BRADEN (I958 b) renforcent cette hypothèse : il existe une différence significative dans le pourcentage de polyspermie, après accouplement retardé, entre deux souches de Rat ; la fréquence de la polyspermie a été de 3,6 p. roo (souche PVG) et de 8,4 p. Ioo (souche WAG). La souche de la femelle serait déterminante et aurait influencé la fréquence d'œufs contenant deux spermatozoïdes ou plus, soit dans l'espace périvitellin, soit dans le cytoplasme.

Les observations de Pikó (I958 et observations non publiées) montrent également l'influence de la souche de la femelle sur la fréquence de la polyspermie après accouplement normal. Chez les 3 souches étudiées (après accouplement réciproques) cette fréquence a été de $2,6 \mathrm{p}$. Ioo (femelles WAG), de I,4 p. Ioo (femelles Wistar CF) et de 0,5 p. Ioo (femelles "Jouy "); la différence entre les résultats des femelles WAG et "Jouy " est statistiquement significative $(\mathrm{P}<0,05)$. L'origine de la femelle a aussi influencé le pourcentage des spermatozoïdes supplémentaires.

BRADEN (I957) a étudié la fréquence de la polyspermie et d'autres anomalies de la fécondation chez 4 souches "inbred " de Souris et chez 2 lots croisés au hasard. L'importance de la polyspermie a varié entre 0,4 et I, 0 p. IOO, sans toutefois atteindre le niveau de la signification statistique. Par contre, des différences significatives ont été obtenues, selon 1'origine de la femelle, dans la fréquence des anomalies suivantes : rétention du premier ou du deuxième globule polaire ; œufs uninucléés ou contenant des subnucléi ; "clivage immédiat" (clivage de l'œuf au cours de la deuxième méiose).

BRADEN (I958 a) rapporte également, chez les mêmes souches de Souris, une variation significative de la fréquence des œufs dont la pellucide a été traversée par plus d'un spermatozoïde. Mais dans ce cas, l'influence de l'origine du mâle semble être plus importante que celle de la femelle. L'auteur suppose que le phénomène pourrait être dû à une motilité accrue des spermatozoïdes de mâles de certaines souches dans le tractus génital femelle. Une interaction différente entre gamètes mâles et femelles serait également possible.

\section{5. - Milieu.}

Une explication des différences observées dans la fréquence de la polyspermie pourrait être également cherchée dans le fait que les expériences ont été conduites dans des laboratoires différents, situés quelquefois sur des continents différents. Les conditions de milieu - comme la lumière, la température, la nutrition, etc... - pourraient donc être des variables d'une expérience à l'autre. (AUSTIN, I955, I956 a). L'effet d'une hyperthermie relativement modérée sur la polyspermie chez le Rat semble corroborer cette hypothèse. L'élévation de la température du corps due à la chaleur extérieure ou l'état fiévreux de la femelle pourrait conduire à un résultat semblable. Les effets du régime d'éclairement et de la nutrition sur les phénomènes relatifs à la reproduction sont bien connus. A l'heure actuelle cependant, nous ne disposons pas d'observations directes de l'influence possible de ces facteurs sur le processus de la fécondation ou sur la polyspermie. 


\section{6. - Doubles accouplements successits.}

Selon Pitkianen (I955), les œufs de Truie contiennent plus de spermatozoïdes supplémentaires après saillies doubles, par deux verrats à un intervalle de 5 à Io minutes, qu'après saillies simples. De plus, après double accouplement, il y avait 4 œufs trinucléés (probablement dispermiques) sur 24 œufs, contre I œuf trinucléé sur 26 œufs après saillies simples. Bien que cette différence ne soit pas statistiquement significative, on peut supposer que les saillies doubles peuvent augmenter le nombre des spermatozoïdes sur les lieux de la fécondation et ainsi accroître les chances d'une fécondation polyspermique.

\section{7. - Insémination artificielle.}

BLANDAU (I952) a inséminé artificiellement 78 Rates réparties en quatre groupes : avant l'ovulation et $3-5,6-8$ et 9-I2 heures après l'ovulation. Parmi les 777 œufs fécondés il n'y avait aucun œuf polyspermique. Cette observation contraste avec les résultats de nombreuses expériences sur les effets d'accouplements retardés (v. discussion ci-avant). Elle pourrait être expliquée - comme le supposent AusTiN et BRADEN (I953) - par l'emploi de l'insémination artificielle par BLANDAU (I952) à la place de l'accouplement naturel. On ne voit cependant pas clairement comment l'insémination artificielle aurait pu provoquer l'absence de la polyspermie. BLANDAU (I952) signale qu'il y avait des spermatozoïdes en nombre suffisant sur les lieux de la fécondation ce qui est aussi montré par le fait qu'environ 28 p. Ioo des oufs fécondés contenaient des spermatozoïdes supplémentaires. Il ne resterait donc qu'à supposer que - malgré une motilité apparemment normale - la fécondance de ces spermatozoïdes a été affaiblie diminuant les chances de l'attachement d'un deuxième spermatozoïde à la surface vitelline.

Notons que chez la Truie, le nombre de spermatozö̈des supplémentaires dans la membrane vitelline paraît être toujours plus faible après insémination artificielle qu'après accouplement (HANCOCK, I957 ; THIBAULT, I959).

\section{8. - Irradiation des gamètes.}

Amoroso et PARkes (1947) ont examiné I56 œufs tubaires provenant de lapines inséminées avec du sperme irradié par des rayons $X$. La pénétration de spermatozoïde dans l'œuf a été retardée de 3 à Io heures. Il y avait plusieurs œufs, supposés polyspermiques, contenant plus de deux pronucléi (irradiation de Iooo à Io ooo r.). Dans un autre groupe d'œufs, plusieurs têtes spermatiques inchangées se trouvaient dans le cytoplasme (irradiation de 25000 à 50 ooo r.).

EDWARDS (I957 a) rend compte de résultats semblables après irradiation par

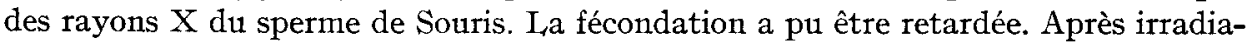
tion par Io ooor, il y avait deux cas probables de.polyspermie sur 4I ceufs examinés au stade pronucléaire. Après irradiation par 30 ooo à 50 ooor, il y avait deux cas possibles et deux cas certains de polyspermie sur 30 œufs pronucléés. Les deux œufs considérés comme sûrement polyspermiques contenaient chacun une tête spermatique inchangée dans le cytoplasme à côté de deux pronucléi normaux.

Chang, Hunt et Romanoff (I957 et I958) ont étudié les effets d'une irradia- 
tion au radiocobalt du sperme et des ovocytes de Lapine. Après l'irradiation du sperme, ils n'ont observé qu'un seul œuf dispermique sur I 44 œufs au stade pronucléaire ; il n'y avait pas de retard dans la fécondation. Après l'irradiation des œufs par 32 ooor avant fécondation, I2 œufs sur 32 (soit environ 38 p. roo) contenaient 3 à 5 pronucléi. Parmi les $\mathrm{I} 2$ œufs polynucléés il y avait un œuf certainement polyspermique (trispermique); dans le reste, la présence de pronucléi accessoires aurait été provoqué par la fragmentation du pronucléus femelle, mais la possibilité de la polyspermie n'a pas été exclue non plus.

Chang, Hunt et Romanoff (I957) donnent aussi une critique des observations de Amoroso et PARKES (I947), notamment concernant les critères de la polyspermie ; ils pensent que même s'il y avait effectivement des œufs polyspermiques, leur présence pourrait être attribuable au retard dans l'insémination (jusqu'à 2 heures $\mathrm{I} / 4$ avant l'ovulation dans quelques cas) plutôt qu'à l'effet de l'irradiation.

Notons que 1'irradiation aux ultraviolets du sperme est apparemment sans effet sur la polyspermie chez la Lapine (PrNcus et Enzmann, I936) et chez la Souris (EDWARDS, I957 b).

\section{9. - Autres traitements.}

Mentionnons enfin quelques traitements qui, ayant un effet plus ou moins marqué sur le processus de la fécondation, ne semblent cependant pas influer sur la fréquence de la polyspermie.

Rat : éther, protoxyde d'azote (inhalation) ; "Nembutal " (sous-cutané) ; colchicine (intrapéritonéale) (AUSTIN et BRADEN, I954 b). Nicotine, cocaïne, chloral (intrapéritonéale) (Pıkó, observations non publiées).

Souris : traitement du sperme par trypaflavine, bleu de toluidine ou gaz moutarde (EDWARDS, 1958 a) ; colchicine (intra-utérine) (EDWARDS, I958 b).

\section{D. - MoRphologie ET DÉVELOPPEMENT DES CEUFS POLYSPERMIQUES}

\section{I. - Cytologie de la fécondation et du début de segmentation.}

Les événements cytologiques dans les œufs polyspermiques ont été étudiés surtout chez le Rat. Austrn et Braden (I953 b) rendent compte d'observations concernant Iog œufs dispermiques et 3 œufs trispermiques obtenus après accouplements normaux ou retardés, et examinés aux premiers stades de développement. Les points principaux de ces observations peuvent être résumés ainsi :

Les deux ou les trois spermatozoïdes fécondants se transforment en pronucléi et amorcent un développement qui est en général normal. Un fait frappant est la ressemblance étroite des pronucléi mâles tout au cours de leur développement ce qui montre la simultanéité de la pénétration des spermatozoïdes d'une part, et 1'harmonisation du développement pronucléaire d'autre part. Il est à noter cependant que les pronucléi des œufs polyspermiques sont toujours plus petits que ceux des œufs normaux si bien que le volume total des pronucléi reste à peu près au même niveau (v. aussi Austin et BRADEN, 1955). Au terme de leur développement, les trois pronucléi des œufs dispermiques entrent en conjugaison au milieu de l'œuf et 
se transforment en trois groupes chromosomiques. Ensuite, les chromosomes se mélangent en un seul groupe, formant la prophase de la première division de segmentation, qui est ainsi triploïde. En effet, AUSTIN et BRADEN (I953 b) ont pu compter un nombre proche du nombre triploïde dans quatre œufs dispermiques se trouvant en prophase ou en métaphase de deuxième division de segmentation (le nombre diploïde normal chez le Rat est égal à 42 ). Le premier clivage qui suit est normal, bipolaire et l'œuf dispermique au stade deux cellules a, en général, un aspect parfaitement normal; il est seulement reconnaissable par la présence de deux pièces intermédiaires dans le cytoplasme.

Les conclusions ci-dessus de Austrn et BRADEN (I953 b) furent pour l'essentiel confirmées, également chez le Rat, par Odor et BLANDAU (I956) et par Pikó (I958). Austin et BISHOP (r957 b, p. 330) signalent cependant un œuf avec un fuseau de première segmentation tripolaire après polyspermie.

En ce qui concerne les autres espèces, la morphologie des œufs polyspermiques n'est qu'insuffisamment élucidée. On peut affirmer néanmoins, d'une façon générale, que chez toutes les espèces où la polyspermie fut établie, les spermatozoïdes fécondants semblent amorcer un développement parallèle comme chez le Rat (voir la partie sur la " polyspermie naturelle " et la discussion sur la "refécondation "). De plus, un fuseau de la première division de segmentation avec un nombre triploïde de chromosomes a été signalé chez le Hamster (Austin, I956 c). Mais, à notre connaissance, il n'existe aucune donnée sur l'existence d'œufs polyspermiques au stade deux blastomères, ou à des stades plus avancés, chez des espèces autres que le Rat.

Des œufs probablement polyspermiques contenant deux pronucléi en conjugaison et un troisième pronucléus éloigné, ont été observés chez le Chat (VAN DER Stricht, I9II, Hirl et Tribe, I924), chez la Truie (Pitkianen, I955) et chez la Vache (Pitkianen et Ivankov, I956). Selon Thibault (I959), des œufs polynucléés (polyspermiques ou polygyniques) de Truie n'étaient pas divisés, tandis que leurs témoins normaux se trouvaient à 3 ou 4 blastomères. Chang et Fernandez-Cano (I958) supposent que les œufs trinucléés de Hamster (en majorité digyniques), obtenus après des accouplements retardés, pourraient ne pas se diviser. Ces mêmes auteurs font état de deux œufs polyspermiques (sans pronucléi) toujours non divisés à l'époque théorique du stade de 2 à 8 cellules.

Mais dans ces derniers cas, l'absence de division a pu être due à d'autres facteurs que la dispermie ou la présence d'un troisième pronucléus (par exemple à l'effet du vieillissement même de l'œuf). La possibilité d'un développement triploïde avancé a été démontrée chez la Souris et récemment chez le Rat. Il ne reste pas moins vrai que le problème du développement précoce des œufs polyspermiques, à l'exception de ceux du Rat, subsiste entier.

\section{2. - La destinée des embryons polyspermiques.}

Le Rat est pratiquement la seule espèce où le devenir des embryons polyspermiques a été le sujet d'études spéciales. La dispermie chez cette espèce semble aboutir à la triploïdie ; l'étude de la destinée des embryons dispermiques est donc liée au problème général des embryons triploïdes.

AUSTIN et BRADEN (I953 b) ont suivi le développement d'œufs dispermiques (deux pièces intermédiaires) jusqu'au stade 8 cellules et l'ont trouvé normal. 
BRADEN et AUSTIN (I954 c) ont examiné, par dénombrement des chromosomes, des divisions spermatogoniales chez 40 à 45 rats adultes nés de femelles accouplées vers la fin de l'œstrus. Ils n'ont trouvé aucun individu triploïde, malgré la présence d'enviton 9 p. Ioo d'œufs dispermiques au moment de la fécondation. Ils concluent que les embryons triploïdes (dispermiques) meurent problablement au cours du développement embryonnaire, étant ainsi en partie responsable de la reduction du nombre des produits par portée après accouplement retardé.

BRADEN (I957) mentionne une observation faite en r955, selon laquelle les œufs dispermiques de Rate pourraient survivre jusqu'à au moins 3 jours et demi après la fécondation. Dans une autre étude, BRADEN (communication personnelle) n'a trouvé aucun embryon triploïde I5 jours après accouplements retardés.

I a destinée des embryons triploïdes a été étudiée surtout chez la Souris. Des embryons triploïdes, ou hétéroploïdes, ont été trouvés au bout de 3 jours et demi de gestation spontanément (BEATTY et FISCHBERG, I95I) ou après choc thermique (FISCHBERG et BEATTY, I952). FrSCHBERG et BEATTY (I95I) signalent des embryons triploïdes apparemment normaux, ou plus ou moins retardés, chez des femelles "silver " après une gestation de 9 jours et demi. Dans ce cas, la source principale de la triploïdie est la rétention du second globule polaire (BRAden et Austin, I954 b ; BRADEN, I957 ; v. discussion de BEATTY, I957).

Mais BEATTY (communication personnelle) n'a trouvé ancun individu triploïde parmi I5o souris " silver " âgées d'un mois ou plus. Il n'y avait également aucun cas de triploïdie (ou d'autres types d'hétéroploïdie accusée) parmi les descendants de Souris traitées par la colchicine, malgré la présence d'environ I9 p. roo d'embryons hétéroploïdes (surtout triploïdes) à 3 jours et demi de gestation (EDWARDS, I958 b). Il semblerait donc, que la plupart des embryons triploïdes ou tous, meurent entre la mi-gestation et la parturition.

Récemment, Pikó et Bomsei-Helmareich (I960) ont fait une étude spéciale de la destinée des embryons polyspermiques. La polyspermie a été provoquée par une hyperthermie modérée (températures centrales entre 40 et $4 \mathrm{I}^{\circ} \mathrm{C}$ pendant 3 heures après accouplement retardé) chez des Rates appartenant en majorité à la souche "Sherman "; la fréquence de la polyspermie, qui constituait pratiquement la seule anomalie au niveau de la fécondation, a été de 8 à ro p. roo.

Les chromosomes de 2 I9 embryons provenant de 2 I femelles ainsi traitées, ont été dénombrés, de 8 à 15 jours après la copulation. Parmi les I3o embryons âgés de 8 à I2 jours il y avait 8 embryons triploïdes et 6 embryons mosaïques; par contre, parmi 89 embryons âgés de I3 à I5 jours, il n'y avait que deux embryons mosaïques et aucun triploïde.

Six embryons triploïdes montraient un développement retardé; deux triploïdes cependant, âgés de Io jours, avaient un aspect et un stade de développement entièrement normaux. Environ la moitié des embryons mosaïques contenaient des mitoses triplö̈des à côté d'autres types de mitoses ; ils pouvaient donc se développer à partir d'œufs originellement triploïdes.

Ces observations apportent une preuve directe que la dispermie permet d'aboutir à des embryons triploïdes chez le Rat, qui peuvent s'implanter.

L'absence d'embryons triploïdes et la diminution du nombre des embryons mosaïques après $\mathrm{I} 2$ jours de gestation indiquent que les chances qu'ont ces formes hétéroploïdes d'arriver jusqu'à la naissance, sont réduites. Ce qui est en 
accord avec les insuccès répétés des tentatives d'obtention des animaux triploïdes adultes (v. BEATTY, I957).

Ainsi, la dispermie serait chez le Rat une cause de mortalité embryonnaire à l'époque de la mi-gestation.

\section{Discussion et Conclusions}

La fécondation chez les Mammifères est normalement monospermique. Mais les anciens auteurs supposaient déjà, et depuis le travail d'AUsTiN et BRADEN (I953 a, b) nous en avons la certitude, que la pénétration de deux ou plusieurs spermatozoïdes dans le cytoplasme de l'œuf peut se produire aussi bien dans les conditions naturelles, qu'après différentes conditions expérimentales.

A ce jour, la polyspermie naturelle (en général dispermie) a été mise en évidence chez le Rat, la Souris, le Campagnol, le Hamster, le Lapin et la Truie ; elle peut se produire probablement chez le Chat. De plus, des œufs trinucléés d'origine incertaine furent signalés chez le Furet, chez la Brebis et chez la Vache. Ces observations confirment 1'hypothèse selon laquelle la polyspermie pourrait advenir chez la plupart des espèces de Mammifères dans les conditions normales de la fécondation, mais à une fréquence faible ne dépassant pas en général de I à 2 p. Ioo.

Il existe deux mécanismes régulateurs principaux de la monospermie :

I : le nombre réduit de spermatozoïdes sur les lieux de la fécondation,

2 : la réaction propre de 1 'œuf.

La réaction propre de l'œuf, déclenchée par la pénétration du premier spermatozoïde, se manifeste, chez la plupart des espèces, à deux niveaux : réaction de la zona et réaction vitelline. Il est possible que les deux réactions soient liées entre elles. Il est toutefois certain que leur importance varie considérablement selon l'espèce : la réaction de zona s'observe chez la plupart des Mammifères, et ce n'est que lorsqu'elle fait défaut et que plus d'un spermatozoïde franchit la zona, que la réaction au niveau de la membrane vitelline peut s'observer.

Les observations cytologiques d'œufs polyspermiques montrent que la pénétration de deux ou plusieurs spermatozoïdes doit s'effectuer dans un court intervalle. En tous cas, nous ne possédons pas de preuves définitives qu'une " refécondation » ultérieure d'œufs déjà fécondés à des stades plus ou moins avancés de développement, puisse se produire dans les conditions normales.

La destinée des spermatozoïdes restant bloqués dans l'espace périvitellin et dans les membranes d'œufs fécondés, est encore peu élucidée. Ces spermatozoïdes " supplémentaires " paraissent subir peu de changements morphologiques au cours de la segmentation. Il est toutefois possible que certaines substances puissent se libérer et être assimilées par l'œuf, au moins chez les espèces où ces spermatozoïdes se trouvent dans l'espace périvitellin. Cette possibilité mériterait certes d'être examinée d'une façon approfondie par des méthodes cytologiques et cytochimiques modernes. A 1'heure actuelle, nous ne disposons pas d'observations prouvant sans équivoque l'effet des spermatozoïdes supplémentaires sur le développement ultérieur.

L'efficacité du blocage de la polyspermie dépend de plusieurs facteurs et peut être influencée par des conditions expérimentales.

Un des facteurs mis en évidence, et probablement le plus important au point de : vue pratique, est le délai entre l'ovulation et l'arrivée des spermatozoïdes fécondants. 
L'effet de l'accouplement retardé qui permet de différer de plusieurs heures la rencontre des gamètes, varie cependant selon l'espèce : chez le Rat la polyspermie peut être considérablement augmentée (jusqu'à environ 9 p. Ioo) ; chez le Hamster la formation du second globule polaire est supprimée dans une large proportion d'œufs; les deux anomalies se produisent côte à côte chez la Truie et peut-être chez la Lapine ; la Souris se distinguerait par l'absence de ces anomalies.

L'élévation de la température de l'œuf par choc thermique ou par hyperthermie générale après l'ovulation augmente considérablement la fréquence de la polyspermie chez le Rat (34 p. Ioo d'cufs polyspermiques signalés dans un cas extrême), tandis que chez la Souris l'anomalie principale est la rétention du second globule polaire. L'hy perthermie serait plus efficace chez des Rates plus âgées.

L'effet de la lignée, surtout de celle de la femelle, sur la polyspermie et la fréquence de spermatozoïdes supplémentaires vient d'être démontré chez le Rat, aussi bien après des accouplements normaux qu'après des accouplements retardés. Chez la Souris la fréquence des spermatozoïdes supplémentaires serait déterminée surtout par la souche du mâle.

Il est possible - mais non encore démontré - que les facteurs de milieu et le type d'accouplement (simple ou double, saillie naturelle ou insémination artificielle) puissent influer sur la fréquence de la polyspermie.

L'irradiation du sperme par des rayons $\mathrm{X}$ pourrait augmenter la polyspermie chez la Lapine et chez la Souris ; mais il est difficile, dans ces expériences, d'estimer s'il s'agit d'un effet de l'irradiation ou bien du retard de la fécondation. L'irradiation au radiocobalt du sperme, et peut-être celle de l'œuf non fécondé, serait sans effet sur la polyspermie chez la Lapine.

La cytologie et la destinée des œufs polyspermiques ont été étudiées surtout chez le Rat. Les spermatozoïdes fécondants subissent un développement parallèle et participent à la syngamie : la dispermie aboutit à la triploïdie. L'œuf dispermique triploïde de Rate amorce une segmentation et un développement précoce normaux (mais nous ne possédons pas de données sur la segmentation d'œufs polyspermiques dans les autres espèces). Des embryons triploïdes, provenant, selon toute probabilité, d'œufs dispermiques, ont été trouvés 8 à I2 jours après la copulation. Mais il semble que ces embryons, en général abortifs, ont peu de chance de dépasser ce stade et d'arriver jusqu'à la naissance. La dispermie serait donc chez le Rat une cause de mortalité embryonnaire surtout à l'époque de la mi-gestation.

Cependant, la possibilité qu'un individu triploïde exceptionnel puisse survivre jusqu'à la naissance est démontrée par la découverte récente d'un cas de triploïdie chez 1'Homme (Böök et Santesson, I960). Bien que l'origine de la triploïdie dans ce cas reste inconnue, une fécondation dispermique est l'une de ses causes possibles.

\section{REMERCIEMENTS}

Cette mise au point a été réalisée dans le cadre du travail de recherche que nous avons effectué à la Station de Physiologie Animale de l'I.N.R.A. Nous tenons à exprimer notre gratitude à Monsieur Thibault, Directeur de cette Station, pour l'intérêt qu'il a manifesté à ce travail et l'aide constante qu'il nous a apportée.

Nous remercions également la Direction de l'I.N.R.A. pour l'appui matériel et moral qu'elle a bien voulu nous accorder. 


\section{RÉFÉRENCES BIBLIOGRAPHIQUES}

Adams C. E., 1955. The frequency of occurrence of supernumerary spermatozoa in rabbit ova. Proc. Soc. Stud. Feriil., 7, 130-1 38 .

Amoroso E. C., PARKes A. S. I947. Effects on embryonic development of X-irradiation of rabbit spermatozoa in vitro. Proc, roy. Soc. B, 134, 57-78.

Austin C. R. I95I. The formation, growth and conjugation of the pronuclei in the rat egg. J.R. micr. Soc., 71, 295-306.

Austin C. R. I955. Polyspermy after induced hyperthermia in rats. Nature, Lond., 175, 1038.

Austin C. R., 1956 a. Effects of hypothermia and hyperthermia on fertilization in rat eggs. J.exp. Biol. 33, $348-357$.

Austin C. R., I956 b. Cortical granules in hanster eggs. Exp. Cell Res., 10, 53.3-540.

Austin C. R., I956 c. Ovulation, fertilization and early cleavage in the hamster (Mesocricetus auratus). J. R. micr. Soc., 75, I4I-154.

Austis C. R., 1957. Fertilization, early cleavagre and associated phenomena in the field vole (Microtus agrestis). J. Anat., Lond., 81, I-I1.

Austin C. R., Amoroso E. C., I959. The mammalian egg. Endeavour, 18, I30-I 43.

Austin C. R., Bishop M. W. H., I957 a. Preliminaries to fertilization in mammals. In: Tyler A., Metz C. B. et BORSTEL R. C. von, The beginnings of embryonic development,71-107, American Association for the Advancement of Science, Washington, D. C.

Austin C. R., Bishop M. W. H., r957 b. Fertilization in mammals. Biol. Rev., 32, 296-349.

Austin C. R., Braden A. W. H., 1953 a. Polyspermy in mammals. Nalure, Lond., 172, 82.

Austin C. R., Braden A. W. H., I953 b. An investigation of polyspermy in the rat and rabbit. Aust. $J$ biol. Sci., 6, 674-692.

Austin C. R., BRADEN A. W. H., I954a. Time relations and their significance in the ovulation and penetration of eggs in rats and rabbits. Aust. J. biol. Sci., 7, 179-194.

Austin C. R., BRADEN A. W. H., I955. Introduction and inhibition of the second polar division in the rat egg and subsequent fertilizatio:, Aust. J. biol. Sci., 7, 195-210.

Austin C. R., Braden A. W. H., i955. Observations on nuclar size and form in living rat and mouse eggs. Exp. Cell Res., 8, $163^{-172 .}$

AUSTIN C. R., BRADEN A. W. H. I956. Early reactions of the rodent egg to spermatozoan penetration. J. exp. Biol., 33, 358-365

Austin C. R., Lovelock J. E., 1958. Permeability of rabbit, rat and hamster egg membranes. Exp. Cell Res., 15, 260-26r.

AUstin C. R., Smiles. J., 1948. Phase-contrast microscopy in the study of fertilization and early development of the rat egg. J.R. micr. Soc., 68, 1.3-19.

Beatry R. A., 1957. Parthenogenesis and polyploidy in mammalian development, I40 pp., Cambridge University Press.

BeAtтy R. A., I957. A pilot experiment with heterospermic insemination in the rabbit. J. Genet., 55, $325-347$.

BEATTY R. A., Fischberg M., 195I. Heteroploidy in mammals. I. Spontaneous heteroploidy in preimplantation mouse eggs. J. Genet., 50, 345-359.

BISHOP D. W., TrLeR A., I956. Fertilizin of mammalian eggrs. J. exp. Zool, 132, 575-60z.

Blandau R. J., 1952. The female factor in fertility and infertility. I. Effects of delayed fertilization on the development of the pronuclei in rat ova. Fertil. Steril., 3, 349-365.

Blandau R. J., Jordan E. S., I94I. The effect of delayed fertilization on the development of the rat ovum. Amer. J. Anal., 68, 275-287.

BLANDAU R. J., ODOR D. L., 1952. Observations on sperm pernetration and changes in the cytoplasmic components of the fertilizing spermatozoon in rat ova. Ferill. Steril., 3, 13-26.

Blandau R. J., Young W. C., I 939 . The effects of delayed fertilization on the development of the guineapig ovum. Amer. J. Anat., 64, 303-329.

Boling J. L., Blandiu R. J., Soderwall A. L. et Young W. C., 194I. Growth of the graafian follicle and the time of ovulation in the albino rat. Anal. Rec., 79, 313-331.

Böök J. A., SAntesson B., I 960 . Malformation syndrome in man associated with triploidy 69 chromosomes). Lancet. 1, 858-859.

BRADEN A. W. H, 1957. Variation betwen strains in the incidence of various abnormalities of egg maturation and fertilization in the mouse. J. Genet., 55, 476-486.

BRADEN A. W. H., I $95^{8}$ a. Variation between strains of mice in phenomena associated with sperm penetration and fertilization. J. Genel., 56, I-I1.

BRADEN A. W. H., I958 b. Strain differences in the incidence of polyspermia in rats after delayed mating. Fertil. Steril., 9, 243-246.

BradeN A. W. H., Austin C. R., I954a. The number of sperms about the eggs in mammals and its significance for normal fertilization. Aust. J. biol. Sci., 7, 543-55I.

Braden A. W. H., AUstin C. R., I 954 b. Fertilization of the mouse egg and the effect of delayed coitus and of hot-shock treatment. Aust. J. biol. Sci., 7, 552-565,.

Braden A. W. H., Austin C. R., 1954 c. The fertile life of mouse and rat eggs. Science, 120, $36 \mathrm{I} \cdot 362$. 
Braden A. W. H., Austin C. R., David H. A., I954. The reaction of the zona pellucida to sperm penetration. Aust. J. biol. Sci., 7, 391-409.

Chang M. C., I95r. Fertility and sterility as revealed in the study of fertilization and development of rabbit eggs. Fertil. Steril., 2, 205-222.

Chang M. C., 1952. Effects of delayed fertilization on segmenting ova, blastocysts and fetuses in rabbit. Fed. Proc., 11, 24.

Chang M. C. I95.- Fertilizability of rabbit germ cells. In : Wolstenholme G. E. W., Mammalian germ cells, 226-242, J. \& A. Churchill Ltd., London.

Chang M. C., Fernandez-Cano L., I958. Effects of delayed fertilization on the development of pronucleus and the segmentation of hamster ova. Anat. Rec, 132, 307-3I9.

Chang M. C., Hunt D. M., Romanoff E. B., I957. Effects of radiocobalt irradiation of rabbit spermatozoa in vitro on fertilization and early development. Anal. Rec., 128, 21 1-229.

Chang M. C., Hunt D. M., RomanofF E. B., 1958. Effects of radiocobalt irradiation of unfertilized or fertilized rabbit ova in vitro, on subsequent fertilization and development in vivo. Anat. Rec., 132, I6I-180.

Chang M. C., Pincus G., i 951. Physiology of fertilization in mammals. Physiol. Rev., 31, I-26.

Dauzier L., I958. Physiologie du déplacement des spermatozoüdes dans les voies génitales femelles chez la Brebis et la Vache. Thèse Doct. Sci., 70 pp., Paris.

Dokukin A. V., BashKaikv I. S., 1954. Ia polyspermie physiologique chez les Mammifères (En russe). Byull. exp. Biol. Med., 37, 62-64.

EDWARDS R. G., I957 $a$. The experimental induction of gynogenesis in the mouse. I. Irradiation of the sperm by X-rays. Proc. roy. Soc. B., 146, $469^{-48} 8$.

EDWARDS R. G., I957 b. The experimental induction of gynogenesis in the mouse. II. Ultra-violet irradiation of the sperm. Proc. roy. Soc. B., 146, $488-50.4$.

EDWARDS R. G., I958 a. The experimental induction of gynogenesis in the mouse. III. Treatment of sperm with trypaflavine, toluidine blue, or nitrogen mustard. Proc. roy. Soc. B., 149, i i-i 29.

EDwards R. G., I95 $b$. Colchicine-induced heteroploidy in the mouse. I. The induction of triploidy by treatment of the gametes. J. exp. Zool., 137, $317 * 348$.

Edwards R. G., SIRLIN J. L., 1956. Labelled pronuclei in mouse eggs fertilized by labelled sperm. Nature, Lond., 177, 429 .

EDWARDS R. G., SiRLiN J. L., 1958. Radioactive tracers and fertilization in mammals. Endeavour, 17, $42-47$.

Fischberg M., Beatty R. A., I95I. Spontaneous heteroploidy in mouse embryos up to mid-term. J.exp. Zool., 118, 32I-335.

FischberG M., Beatty R. A., I952. Heteroploidy in mammals. II. Induction of triploidy in pre-implantation mouse eggs. J. Genet., 50, $455-470$.

GERLACH L., Igo6. Ueber die Bildung der Richtungskörper bei Mus musculus, 3 I pp., Bergmann, Wiesbaden.

Gates A. H., BeAtTy R. A., т954. Independence of delayed fertilization and spontaneous triploidy in mouse embryos. Nature, Lond., 174, 356 .

Hamilton W. J., Samuel D. M., I956. The early development of the golden hamster (Cricelus auralus). J. Anat., Lond., 90, 395-416.

Hammond J., I934. The fertilization of rabbit ova in relation to time. A method of controlling the litter size, the duration of pregnancy and the weight of the young at birth. J.exp. Biol., 11, 140-16I.

HANCOCK J. L., 1958. The fertility of natural and of artificial mating in the pig. Proc. Soc. Stud. Fertil., 9, I46-1 58.

Hancock J. L., 1959. Polyspermy of pig ova. Anim. Prod., 1, 103-106.

HaRTMAN C. G., I939. Ovulation, fertilization and the transport and viability of eggs and spermatozoa.

In : Allen E., Sex and internal secretions, 630-7 I9, Baillère, Tindall and Cox, London.

Hill J. P., Tribe M., 1924. The early development of the cat (Felis domestica). Quart. J. micr. Sci., 68, 5 I 3-602.

Khvatov B. P., 1954. Données nouvelles sur l'ovulation, le transport et la segmentation d'œufs dans les trompes chez les Mammifères (En russe). Arkh. Anat. Gist. Embr., 31, 3-10.

Korobova T. B., I955. Données sur la fécondation des Mammifères (En russe). Byull. exp. Biol. Med., 39, $54-56$.

KREMER J., I924. Das Verhalten der Vorkerne im befruchteten Ei der Ratte und der Maus mit besonderer Berücksichtigung ihrer Nucleolen. Z. mirk. anat. Forsch., 1, 353-390.

Lams H., r9r3. Etude de l'œuf de Cobaye aux premiers stades de l'embryogenèse. Arch. Biol., Paris, 28, 229-324.

Lams H., Doorme J., I908. Nouvelles recherches sur la maturation et la fécondation de l'œuf des Mammifères. Arch. Biol., Paris, 23, 259-366.

Ludwig K. S., I954. Das Verhalten der Thymonukleinsäure (DNA) während der Befruchtung und den ersten Segmentationsstadien bei der Ratte und dem Goldhamster. Arch. Biol., Paris, 65, I35-178.

Mainland D., i9.30. The early development of the ferret : the pronuclei. I. Anat., Lond., 64, $262-287$.

Merkurieva E. K., 1954. Du problème de la polyspermie chez le Lapin (En russe). Agrobiol., (4), 92- Iо I.

ODOR D. L., BLANDAU R. J., I 949 . The frequency of occurrence of supernumerary sperm in rat ova. Anat. Rec., 104, I-IO.

OdoR D. L., Blandau R. J., I95I. Observations on fertilization and the first segmentation division in rat ova. Amer. J. Anat., 89, 29-62.

ODOR D. L., BLANDAU R. J., I956. Incidence of polyspermy in normal and delayed matings in rats of the Wistar strain. Fertil. Steril., $7,456-467$.

Pesonen S., I949. On abortive eggs. III. On the cytology of fertilized ova in the mouse. Ann. Chirurg. Gynec. fenn., 38, (Suppl. 3), 337-352.

Pikó L., I958. Etude de la polyspermie chez le Rat. C. R. Soc. Biol., Paris, 152, I356-1 $35^{8}$. 
Pikó L., Bomsel-helmreich O., ig6o. Triploid rat embryos and other chromosomal deviants after colchicine treatment and polyspermy. Nature, Lond., 186, 737-739.

Piscts G., ExzmanN E. V., I936. The comparative behavior of mammalian eggs in vivo and in vitro. II. The activation of tubal eggs of the rabbit. J. exp. Zool., 73, I95-208.

Pitkianes I. G., 1955. Recherches sur l'ovulation, la fécondation et les premiers stades du développement embryonnaire chez la Truie (En russe). Izv. Akad. Nauk SSSR, Ser. biol., (3), 1 20-r 3 I.

Pitkiañex I. G., I958. La fécondation et les premiers stades du développement embryonnaire chez la Brebis (En russe). Izv. Akad. Nauk SSSR, Ser. biol., (3), 29г-298.

Pitkianen I. G., Ivankov M. F., I956. Recherches sur la fécondation et les premiers stades du développement embryonnaire chez la Vache (En russe). Izv. Akad. Nauk SSSR, Ser. biol., (3) 77-86.

PósALAKY Z., Törö I., I957. Experimental investigations into the destiny of spermatozoa not participating in fertilization. Acta biol. Acal. Sci. Hung., 8, г-1o.

REIN G., r883. Beitrage zur Kenntniss der Reifungserscheinungen und Befruchtungsvorgänge am Säugethierei. Arch. mikr. Anat., 22, 233-270.

Ríbaschkin W., I905. Ueber die Reifungs-und Befruchtungsprozesse des Meerschweincheneies. Anat. Hefle., 29, 509-553.

SobotTA J., I895. Die Befruchtung und Furchung des Eies der Maus. Arch. mikr. Anat., 45, r 5-93.

SokolovskaIA I. I., 1947. Importance du nombre de spermatozoïdes dans la fecondation des animaux domestiques (En russe). Dokl. vsesoyus. Akad. sel.-khoz. Nauk im. V. I. Lenina, 12, 7-Io.

Strauss F., I954. Das Problem des Befruchtungsortes des Säugetiereies. Bull. schweiz. Akad. med. Wiss., 10, $239-248$.

STRAuss F., 1956. The time and place of fertilization of the golden hamster. J. Embryol. exp. Morph., 4. $42-5^{6}$.

TAFAni A., r889. La fécondation et la segmentation étudiées dans les œufs des Rats. Arch. ital. Biol., 11, II $2-I$ I 7 .

Thibault C., r949. L'œuf des Mammifères. Son développement parthénogénétique. Ann. Sci. nat. Zool., 11, I36-2I9.

Thibault C., I959. Analyse de la fécondation de l'œuf de la Truie après accouplement ou insémination artificielle. Ann. Zootech. (Suppl.), I65-I77.

VAN DER STRICHT R., rgi . Vitellogenèse dans l'ovule de Chatte. Arch. Biol., Paris, 26, 365-48I.

VoJTIŠkoví M., I956. The question of the participation of non-fertilizing sperms in the sexual process. Folia biol., 2, 239-248.

Zrbina E. V., r953. Etude cytologique de la fécondation et des premiers stades de développement de l'œuf de Lapine. En russe) Dokl. Akad. Nauk SSSR, 88, 917-92 I.

Regu en janvier 1961.

\section{SUMMARY}

\section{POLYSPERMY IN ANIMALS}

\section{General Conclusions}

Our present concept of the nature of fertilization stems from the epoch-making investigations of $O$. Hertwig (1875), made on the egg of the sea urchin, and those of Van Beneden on the egg of the rabbit (1875) and of Ascaris (I883).

Normal fertilization is achieved through two mechanisms. In one, only one spermatozoon gains entry into the cytoplasm of the egg : fertilization is purely monospermic. Occasional polyspermy, i.e. the entrance of two or more spermatozoa into the egg cytoplasm, leads almost invariably to abnormal development ; hence the name "pathological polyspermy. " This type of fertilization occurs in most groups of the animal kingdom.

In the other type, several and sometimes numerous spermatozoa regularly enter the egg and transform into pronuclei; however, only one of these fuses with the egg nucleus, while the " supernu* merary " sperm nuclei are eliminated during later development. This " physiological polyspermy " is observed in insects, elasmobranch fishes, urodeles, reptiles and birds.

In this article a general review has been presented of the two types of polyspermy, especially from the point of view of cytology and development. Most of our knowledge of the morphology of polyspermic fertilization, and of its impact on further development, comes from the extremely intensive investigations undertaken at the end of the last and the beginning of the present century. Some recent results, such as the discovery of a new type of " pathological polyspermy " in mammals, intriguing genetical observations on the possible rôle of " supernumerary spermatozoa " in insects and birds, have made it necessary to supplement and, in part, to revise the picture held previously. In the following some general conclusions are given and the significance of recent observations briefly discussed. 


\section{a) Physiological Polyspermy}

Physiological polyspermy occurs in eggs rich. n yolk (insects, urodeles), or very rich in yolk (elasmobranchs, reptiles, birds). There exists, however, in these eggs a mechanism which tends to inhibit the penetration of an excessive number of sperm as indicated by the following facts : I. The number of spermatozoa entering the egg is normally limited although there are marked species and individual variations. It may be only a few in insects and arachnids; up to a dozen in urodeles; between 10 and 30 in elasmobranchs, reptiles and birds ; but very many in Bryozoa. 2. A large number of spermatozoa remain frequently attached to the outer surface of the vitelline membrane without being able to cross it (e.g. in elasmobranchs, birds).

The cytological events generally take the following course: All spermatozoa entering the egg transform into pronuclei and develop spermasters (in species where it occurs) which are mutually repulsed. The development of the pronuclei is more rapid in the animal (cytoplasm rich) zone of the egg. Only one of the sperm nuclei (apparently whichever happens to be the nearest) unites with the egg nucleus. The formation of the zygote nucleus marks a critical point in the development of the "supernumerary" nuclei. The latter are usually repulsed towards the vegetative zone of the egg and degenerate either without dividing at all (insects, urodeles) or after making a few divisions. In eggs with partial cleavage (elasmobranchs, reptiles, birds) the mitotic activity of male nuclei shows up in a characteristic " accessory cleavage " at the periphery of the blastodisc. But only in the elasmobranchs is there good evidence that the supernumerary sperm nuclei may divide continuously and may even contribute to the formation of the so called "vitelline syncytium." An exception to the above scheme is furnished by the Bryozoa where the numerous supernumerary sperm heads seem to degenerate directly without transforming into pronuclei.

The direct causes of the inhibition and degeneration of the supernumerary male nuclei are little known and are probably manifold. The following factors seem to be involved : I. Repulsion of the nuclei towards the yolk rich vegetative segments of the egg where conditions for their division are unfavorable; 2. Their haploid state which alone would be responsible for their degeneration in the silk worm, as shown by the detailed studies of Bataillon and Tschou-Su; 3. Special inhibition by the zygote nucleus, persuasively demonstrated by the investigations of Fankhauser in the triton. The mechanism of this inhibitory effect, however, remains unknown.

A much discussed question has been the biological role and utility of physiological polyspermy. Boveri (I98I) postulated that in the large eggs, heavily laden with yolk, polyspermy may increase the chances of pronuclear syngamy. In the solaciens where physiological polyspermy was first described by Rückert ( $189 \mathrm{r}$ ), a developmental rôle seems probable in the formation of the "vitelline syncytium " (organ of yolk digestion) but in no other groups has such a role been substantiated.

Several early authors held the opinion that occasional supernumerary male nuclei may undergo independent development and be eventually incorporated into the body of the embryo. This view, based mainly on cytological observations, found convincing evidence recently in the morphological and genetical study of gynandromorphs and other mosaics in the parasitic wasp Habrobracon (Whiting, I943), the honeybee (Rothenbuhler et al., 1952) and the pigeon (Hollander, 1949). The capacity for the production of gynandromorph honeybees is apparently dependent on a factor in the egg cytoplasm and can be increased considerably by selection. Although it is doubtful whether the mosaic state confers any biological advantage to the individual, these chimeras offer obvious possibilities to study the consequences of the coexistence of genetically different tissues (f. i. autonomy of various characters; somatic and genetic transformations; immunological behaviour). It is interesting to note, that the descendants of a mosaic hen showed some deviation in plumage color and other characters, presumably due to a change in the maternal milieu (Blyth 1954).

The question of degenerating sperm nuclei deserves special attention. The products of these nuclei remain in the egg cytoplasm and are eventually absorbed. Some early investigators expressed the view that this " somatic chromatin " may be useful for the embryo in one way or another, and even indispensable in Bryozoa where it would reestablish the normal "nucleoplasmic ratio." However, the general opinion has prevailed that supernumerary sperm nuclei are not necessary for normal development of the embryo and, when present, have no effect on it.

The problem can now be reconsidered in the light of our present knowledge of cellular metabolism and gene action. The degenerative nuclei (in some cases up to several hundred) represent a large amount of deoxyribonucleic acid within the egg which may well have a physiological and genetical significance. It is known that genes may exert their effects very early in embryonic development (Waddington 1956, p. 134). The almost immediate dependence of the action of a specific gene upon sperm penetration has been observed in Drosophila (Glass and Plaine I950). The detailed investigations of Counce (1956) into "female sterility " in Drosophila indicate that the supernumerary nuclei may advantageously affect development by supplying a factor missing in the zygote nucleus. Similar effects may be invoked, in certain instances, to explain some perplexing genetical problems such as penetrance and expressivity. Physiological and morphogenetic action of supernumerary sperm 
nuclei is suggested in several experiments on " heterospermic " fertilization (insemination with mixed sperm from several unrelated males) : an increased rate of development, greater vitality, and in some cases morphological changes of the offspring were reported in the silk worm (Tchou-Su I953) and the hen (f.i. Kushner I954; Galpern I958).

Possible mechanisms of supernumerary sperm action may tentatively be summarized as follows; I. specific interaction between gene and egg cytoplasm soon after sperm penetration (cf. Glass I957) : 2. participation in the metabolism, especially protein synthesis, of embryonic cells ; 3. replacement of genetic material on the pattern of "bacterial transformation ".

Still more research is necessary, however, before the biological significance of physiological polyspermy can be definitely judged. It would seem that, at least in certain cases, the penetration of several spermatozoa may confer physiological and developmental advantages to the embryo. The genetical diversity of sperm elements, as in " heterospermic» inseminations, may enhance this effect. Drosophila appears to be an excellent subject for further study of this problem of fundamental biological interest.

\section{b) Pathological Polyspermy}

The common feature of normally monospermic eggs is the existence of a defense mechanism which protects the egg against the penetration of more than one sperm. This so called « block to polyspermy " has been intensively investigated in several lower animals, especially in the sea urchin, and its morphological features thoroughly described. The nature and the functioning of the underlying mechanism, however, is still not clearly understood (cf. Rothschild 1956).

In mammals, besides the egg's own reaction, an important factor in preventing polyspermy is the drastic reduction in the number of spermatozoa getting into the vicinity of the egg. Only about one out of a million ejaculated spermatozoa has a chance to reach the segment of the oviduct where fertilization takes place. The mechanism of this restrictive function, which seems to operate especially in certain segment of the female genital tract, is very little known.

Polyspermy (dispermy) may occur under normal conditions of fertilization in a very low proportion of eggs (in mammals the incidence of this "natural " polyspermy is usually around one per cent). But its frequency can be increased considerably (up to too per cent polyspermy) by a variety of factors which may be I., physiological (overinsemination, aging or immaturity of eggs) ; 2 ., chemical, such as the classical "Hertwig reagents» (nicotine, narcotics, etc.) ; 3., physical (e.g., heat, cold). The percentage of induced polyspermy shows great variations according to species and individual. Among the mammals, in the rat delayed matings (i. e. mating after the time of ovulation and heating of the egg (hyperthermia) appear to be the most effective agents (up to 34 per cent polys. permy in an extreme group ; Austin I956 b).

A particular case of polyspermy is the " refertilization " of already fertilized eggs as demonstrated in the echiuroid worm (Tyler and Schultz 1932) and the sea urchin; refertilization can be achieved even in the segmented egg. In mammals, in spite of some claims, there is no good evidence that such "refertilization" can take place.

The so called "supplementary spermatozoa " which remain frequently blocked in the perivitelline space or within the zona pellucida of fertilized mammalian eggs, show very little morphological change during early segmentation. Upon dissolution of the zona, they are probably liberated into the uterine lumen where they disintegrate. There is no proof so far as to their possible develop. mental effect. This possibility, although it appears remote, cannot entirely be ruled out and would merit further investigation.

According to the development and fate of polyspermic eggs we can differentiate three distinct types which can be called, after the species most thoroughly investigated, the sea urchin, frog and rat types of polyspermy.

I. Sea urchin. In the typical case both sperm nuclei unite with the egg nucleus and a tripolar or tetrapolar first cleavage spindle is formed. The chromosomes are distributed at random in the arising blastomeres and this nuclear heterogeneity is reproduced at every successive division. The majority of embryos does not develop beyond the blastula stage. It is of historic interest that the classic studies of Boveri (1902, 19०7) into the fate of dispermic sea urchin eggs led to the discovery of qualitative distinctness of chromosomes. In most groups of animals polyspermy follows the above course.

2. In the frog, where the character of polyspermic development was established by Brachet (I9I0) and Herlant (IgII), the distinctive feature is that only one sperm nucleus participates in syngamy while the others undergo independent division. A mosaic embryo arises which is composed of diploid tissue of zygogenetic origin and of haploid tissue deriving from sperm nuclei. In large scale experiments, only about 10 per cent of di- or trispermic embryos reached the tadpole stage and none of these survived until maturity.

3. In the rat, the possibility of polyspermic fertilization and the character of cleavage of dispermic eggs were demonstrated by Austin and Braden (1953 a, b). In dispermic eggs, both male 
pronuclei undergo a parallel development and both fuse with the female pronucleus, giving rise to a triploid first division metaphase. Unlike the sea urchin egg, however, the dispermic rat egg divides by a bipolar spindle and goes through a normal early cleavage. In a recent study ( $P i k \dot{o}$ and $B o m s e l$ Helmreich 1960 ) triploid rat embryos, deriving apparently from dispermic fertilization, were found up to I 2 days' gestation. Most of the triploid embryos were highly delayed and abortive but some of them looked normal at that stage. The chances of polyploid (triploid) mammalian embryos to go to term are, in general, faint (cf. Beatty 1957). The possibility, however, that some exceptional triploid individual may survive until birth is shown by the recent recording of a triploid human (Böök and Santesson 1960). Although the origin of triploidy in this case is unknown, dispermy may be one of its possible causes.

To conclude, it would seem that, whatever be the type of pathological polyspermy, this condition is most likely to be a fatal, or unhappy, event for the individual involved. The term " pathological " is thus fully justified. The indications are that in mammalian development, including possibly the human, the effects of polyspermy may show up in an embryonic mortality especially at the period of mid-pregnancy. Besides its implications in mammalian pathology, an experimental study of pathological polyspermy appears to be a valuable means to investigate further the mechanism of fertilization and cleavage, and some cytogenetical problems. 